\title{
Activity in Social Media related to Business Events: The Case of Merger Announcements
}

\author{
Dissertation \\ zur Erlangung des wirtschaftswissenschaftlichen Doktorgrades \\ der Wirtschaftswissenschaftlichen Fakultät der Georg-August-Universität Göttingen
}

vorgelegt von

Dipl.-Kfm. Mirko Jan Zülch

aus Frankfurt am Main

Göttingen, 2016 


\section{Betreuungsausschuss}

Erstbetreuer: $\quad$ Prof. Dr. Jan Muntermann

Zweitbetreuer: Prof. Dr. Matthias Schumann

Drittbetreuer: Prof. Dr. Lutz M. Kolbe

Tag der mündlichen Prüfung: $\quad$ 20.12.2016 


\section{Table of Contents}

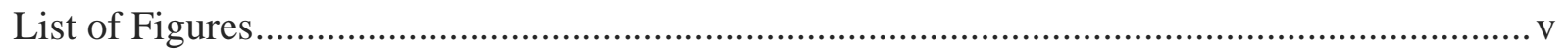

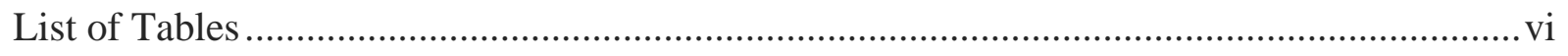

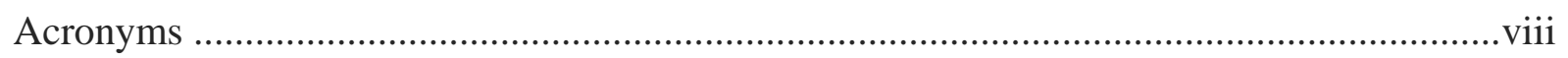

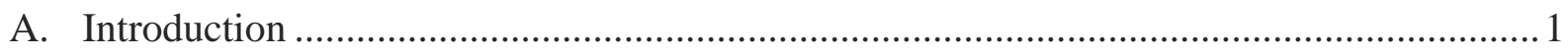

I. Motivation and Research Question ................................................................ 1

II. Research Model and Structure of the Thesis ......................................................... 4

a. Research Model ............................................................................................ 4

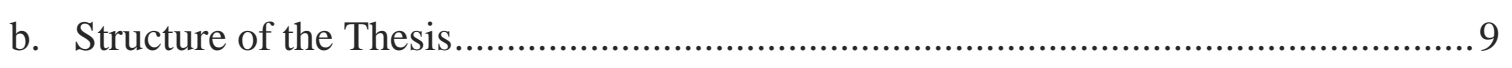

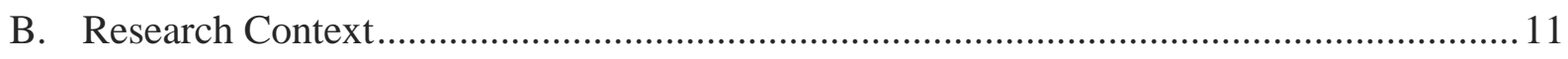

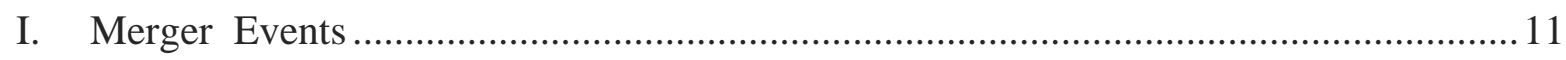

II. Social Media and User-Generated Content........................................................... 14

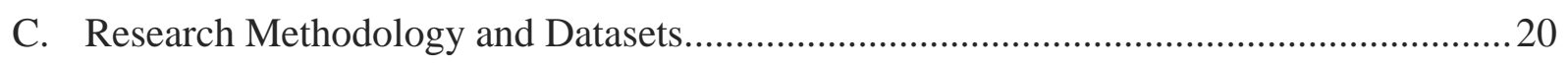

I. Statistical Analysis and Content Analysis ......................................................... 20

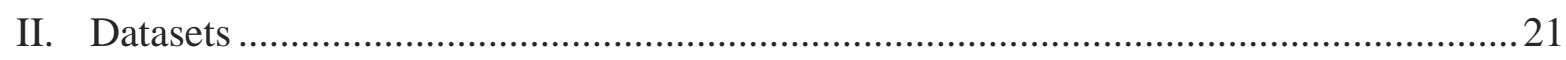

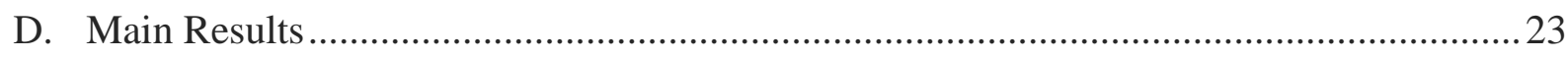

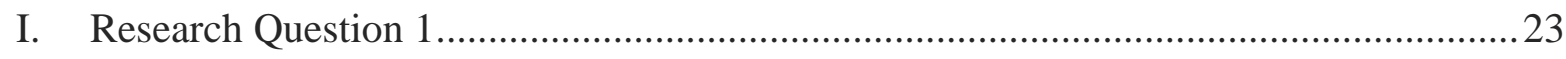

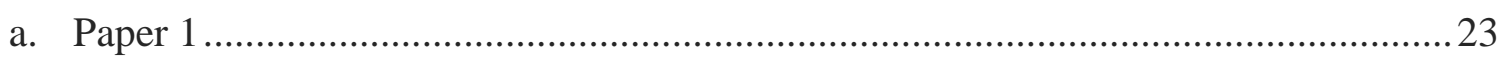

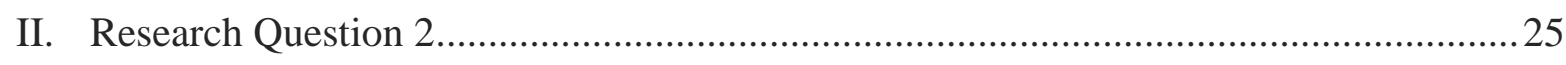

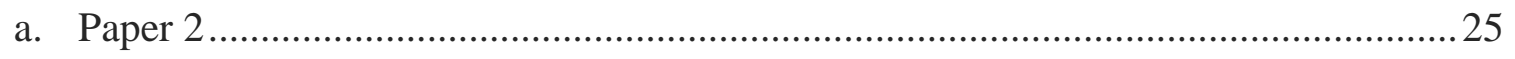

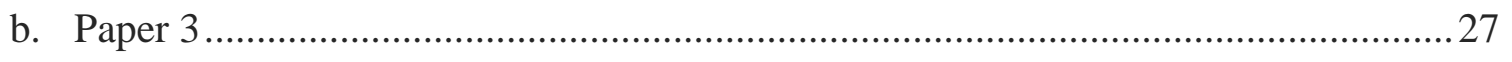

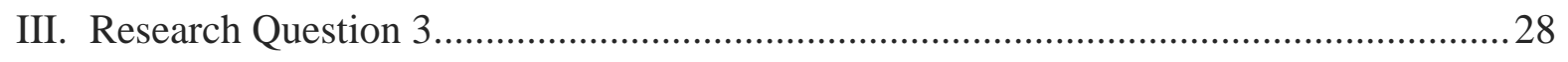

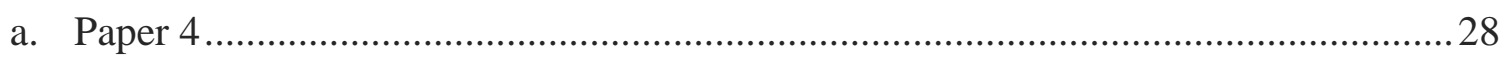

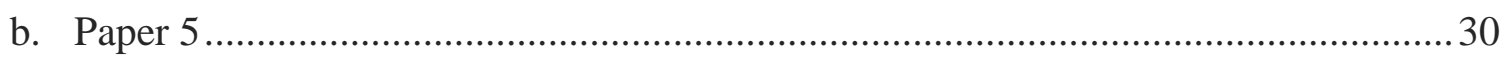




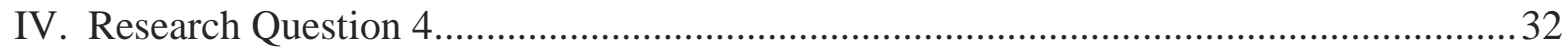

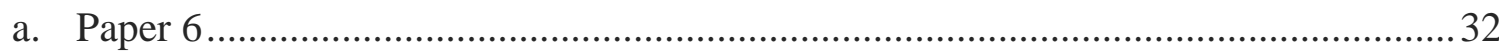

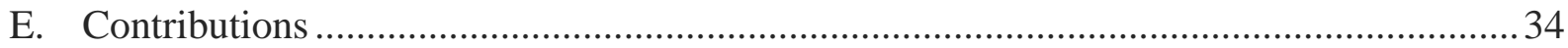

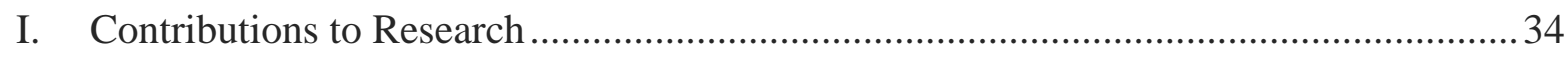

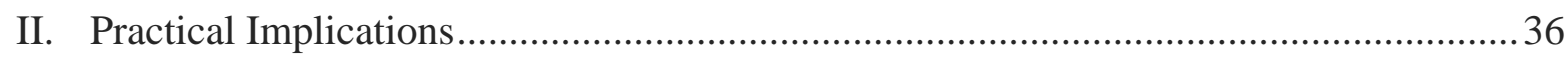

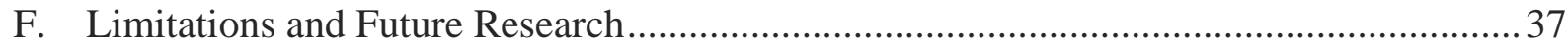

G. Published Research Papers ................................................................................. 40

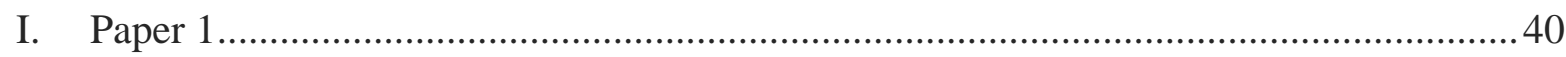

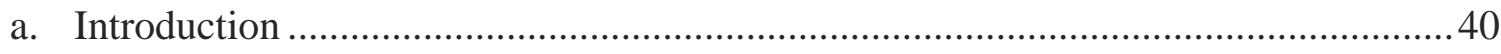

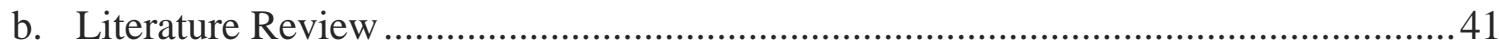

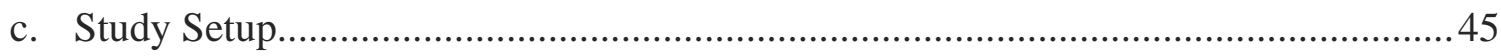

d. Research Hypotheses and Empirical Results .................................................... 47

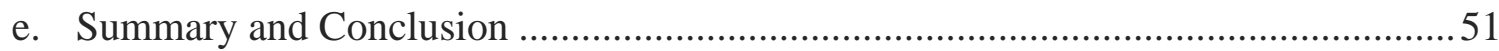

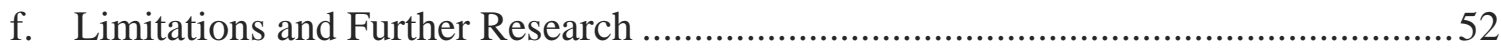

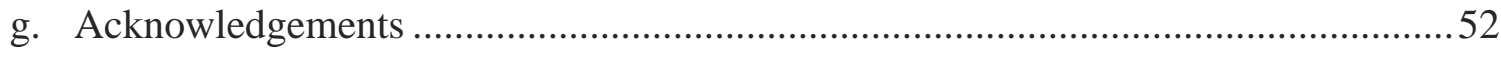

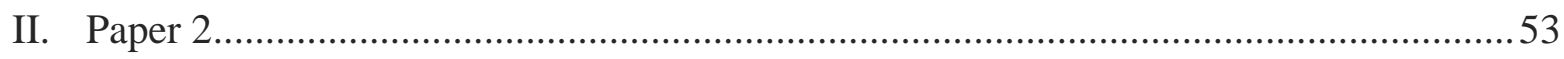

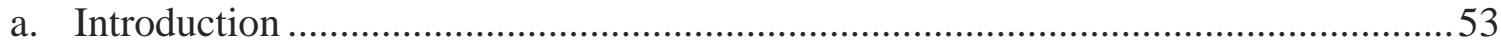

b. Literature Review and Hypotheses Development ............................................54

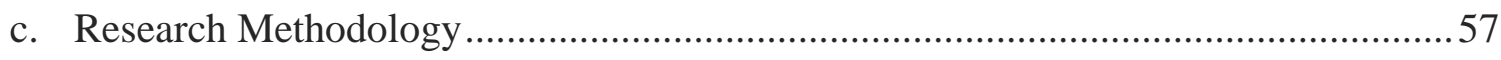

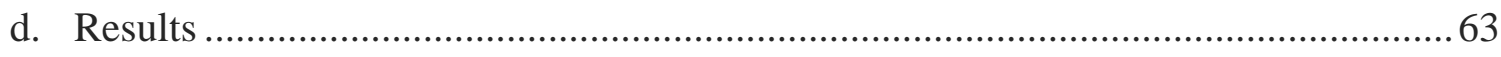

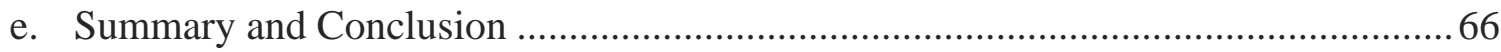

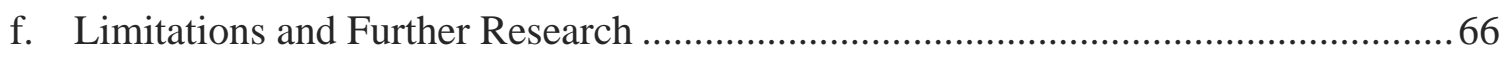

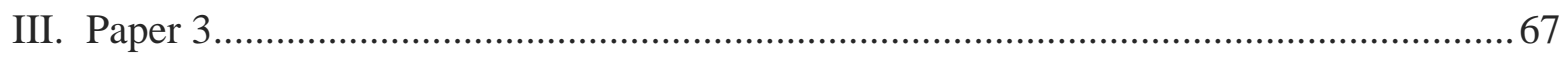

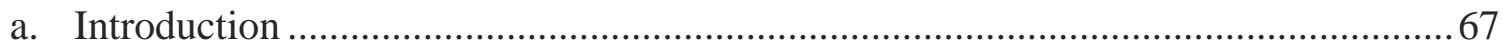

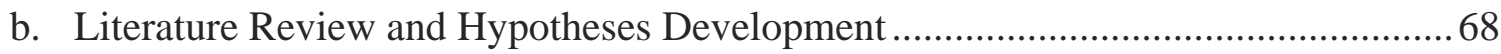




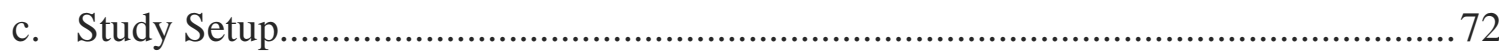

d. Research Hypotheses and Empirical Results ............................................................. 75

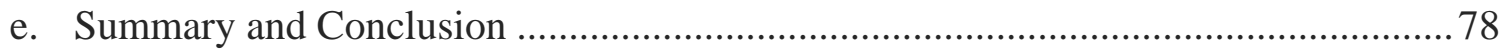

f. Limitations and Further Research ………………….............................................. 79

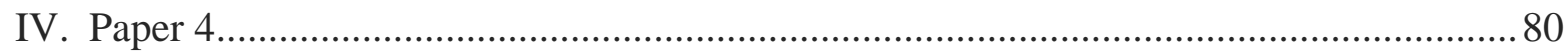

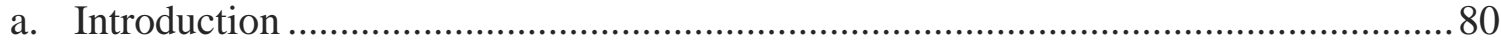

b. Literature Review and Hypotheses Development ....................................................... 81

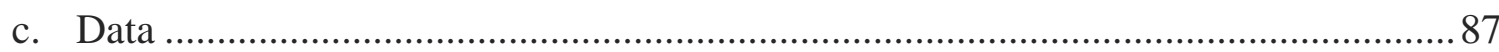

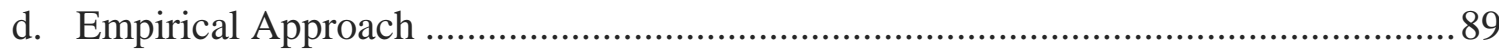

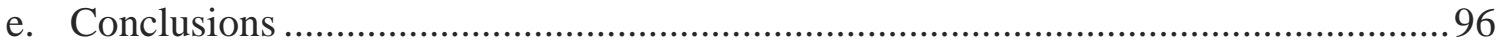

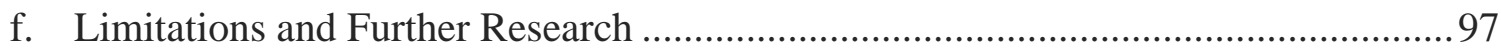

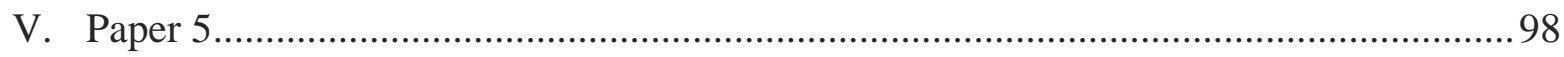

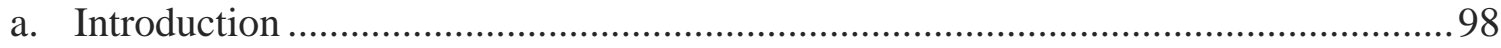

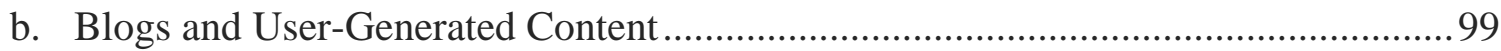

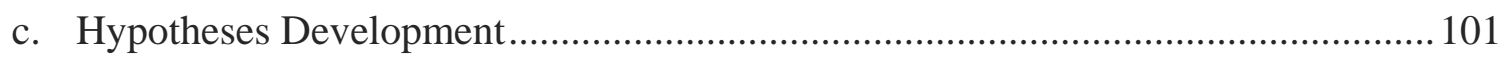

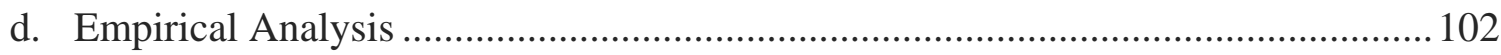

e. Discussion and Conclusions ..................................................................................... 110

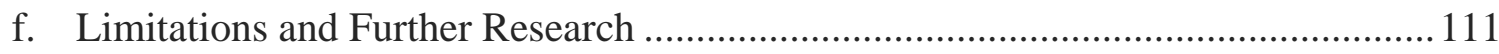

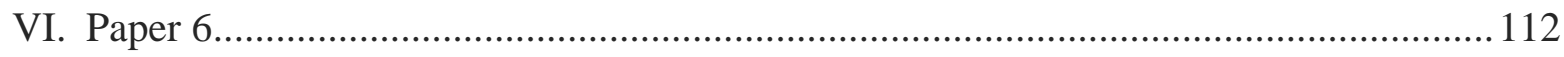

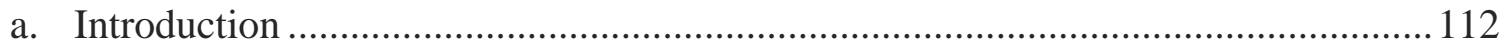

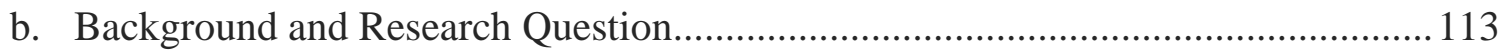

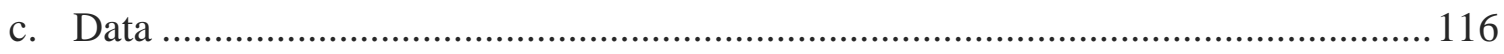

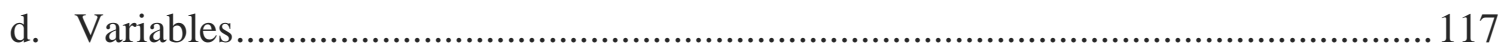

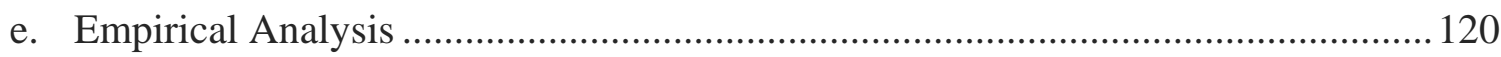

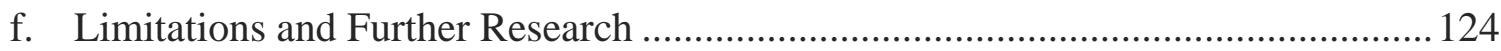


References 


\section{List of Figures}

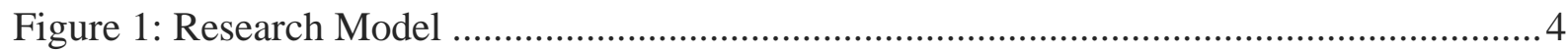

Figure 2: Research Model and Sub Research Questions......................................................... 10

Figure 3: Section of Research Model addressed by Paper 1 ...................................................2 23

Figure 4: Section of Research Model addressed by Paper 2 and Paper 3 ................................25

Figure 5: Section of Research Model addressed by Paper 4 and Paper 5 ................................2 28

Figure 6: Section of Research Model addressed by Paper 6 ........................................................ 33

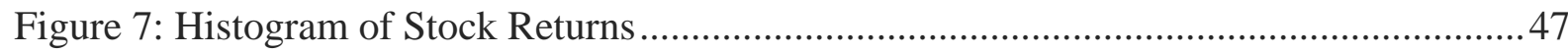

Figure 8: Frequency Distribution of the Dependent Variable - Posting Lag of UGC (measured

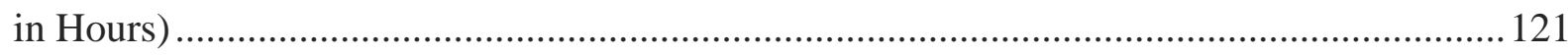




\section{List of Tables}

Table 1: List of Papers and Sub Research Questions ...................................................... 9

Table 2: Fact Sheet of Paper 1 (Zülch et al. 2011) ........................................................... 23

Table 3: Fact Sheet of Paper 2 (Zülch 2013) ................................................................. 25

Table 4: Fact Sheet of Paper 3 (Zülch 2013a) ..................................................................27

Table 5: Fact Sheet of Paper 4 (Zülch et al. 2014a) ......................................................... 28

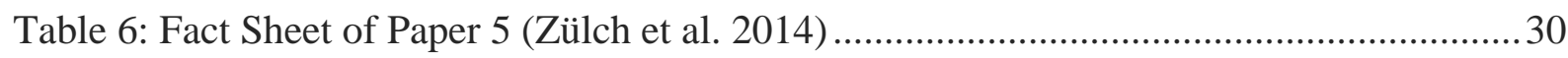

Table 7: Fact Sheet of Paper 6 (Zülch et al. 2014b) .......................................................... 32

Table 8: Fact Sheet of Paper 1a (Zülch et al. 2011) ............................................................. 40

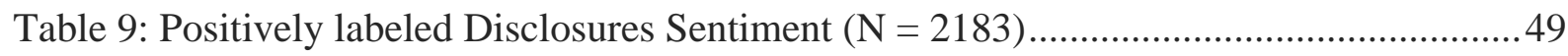

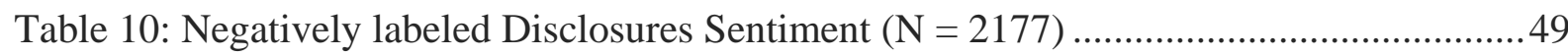

Table 11: Sentiment Comparison of negatively and positively labeled Disclosures ..............50

Table 12: Fact Sheet of Paper 2a (Zülch 2013) ….......................................................53

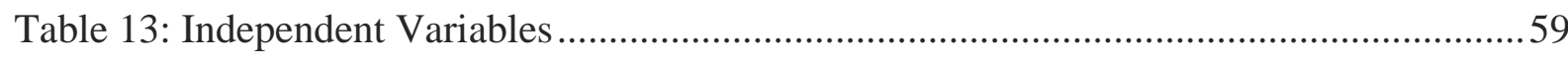

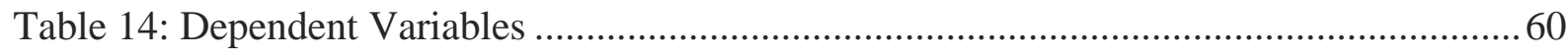

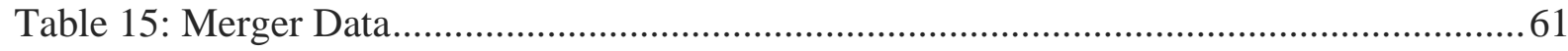

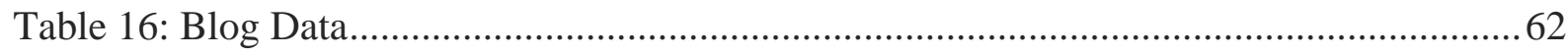

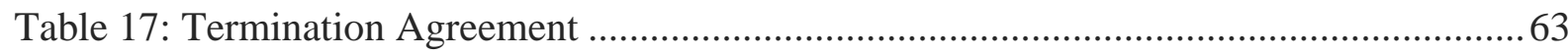

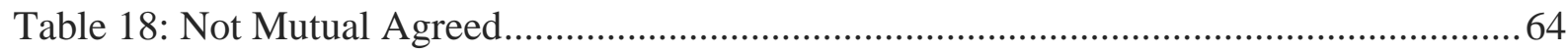

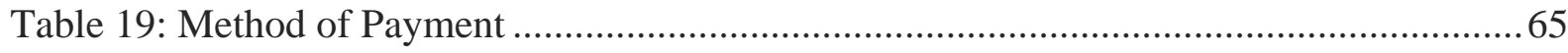

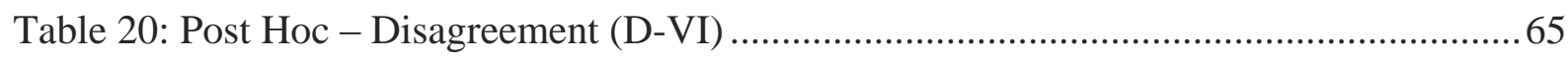

Table 21: Fact Sheet of Paper 3a (Zülch 2013a) ............................................................67

Table 22: Sample Description of Merger Data........................................................... 73

Table 23: Sample Description of Blog Data.................................................................. 74 


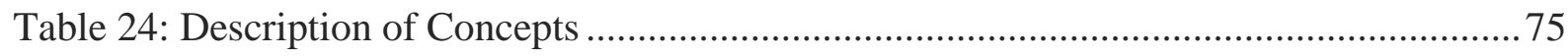

Table 25: Certainty - Comparison of successful and failed Merger Attempts ...................... 76

Table 26: Success - Comparison of successful and failed Merger Attempts.........................77

Table 27: Sentiment - Comparison of successful and failed Merger Attempts ......................78

Table 28: Fact Sheet of Paper 4a (Zülch et al. 2014a) .................................................... 80

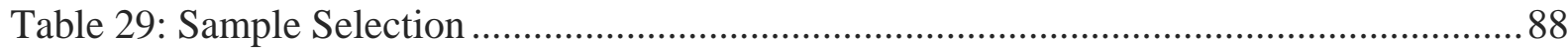

Table 30: SDL-SM2 - Data Fields ........................................................................... 89

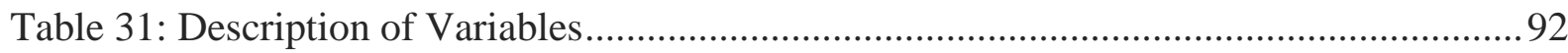

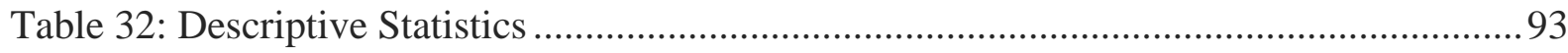

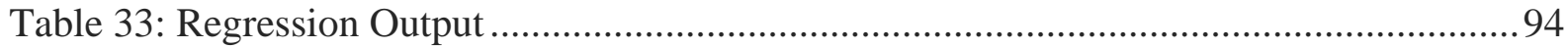

Table 34: Fact Sheet of Paper 5a (Zülch et al. 2014) ........................................................ 98

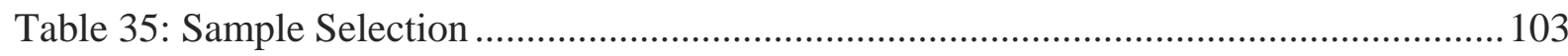

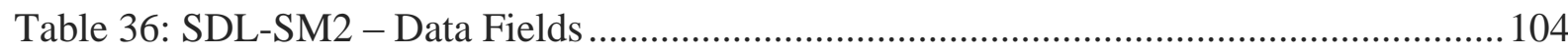

Table 37: Dimensions of Information Quality based on Wang \& Strong (1996) .................. 104

Table 38: Overview of Constructs and Variables......................................................... 108

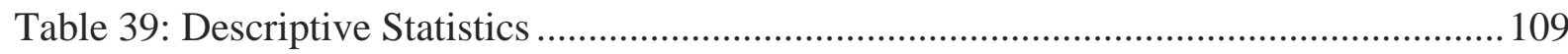

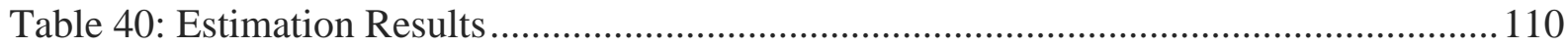

Table 41: Fact Sheet of Paper 6a (Zülch et al. 2014b) ................................................. 112

Table 42: Data Description - SDL-SM2 …............................................................ 117

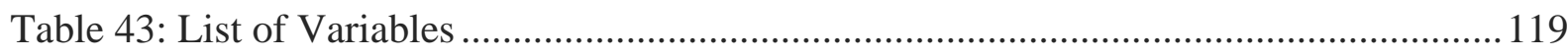

Table 44: Extract of Regression Results for Posting Lag of UGC .................................... 122 


\section{Acronyms}

$\begin{array}{ll}\text { AMCIS } & \text { Americas Conference on Information Systems } \\ \text { BLED } & \text { Bled eConference } \\ \text { CRQ } & \text { Central Research Question } \\ \text { eWoM } & \text { Electronic Word-of-Mouth } \\ \text { FTSE-100 } & \text { Financial Times Stock Exchange 100 Index } \\ \text { IS } & \text { Information Systems } \\ \text { M\&A } & \text { Mergers and Acquisitions } \\ \text { PACIS } & \text { Pacific Asia Conference on Information Systems } \\ \text { RM } & \text { Research Model } \\ \text { RQ } & \text { Research Question } \\ \text { SMA } & \text { Social Media Activity } \\ \text { UGC } & \text { User-Generate Content }\end{array}$




\section{A. Introduction}

\section{Motivation and Research Question}

Be it blogs, social network sites (e.g. Facebook), microblogs (e.g. Twitter) or message boards, social media exist in many types and have dramatically changed the way people communicate and interact with each other on the internet (Kaplan \& Haenlein 2010; Burnett 2000; Boyd \& Ellison 2007; Schmidt 2007; Kaplan \& Haenlein 2011). Central to social media is their ability to create online social networks and to facilitate the exchange of information in form of usergenerated content (i.e. social media posts) on an unprecedented scale (Kaplan \& Haenlein 2010; Burnett 2000). In general, people use social media to exchange information and opinions related to all kinds of topics and aspects of life (Boyd \& Ellison 2007; Nardi et al. 2004). In particular and as discussed herein, economy-related topics and events in the business domain (henceforth referred to as business events) are discussed by social media users (Gu et al. 2007; Herrmann 2007). Especially investors use social media to gather and exchange information as well as opinions regarding recent events in the business domain (e.g. product and strategic measures announcements, mergers \& acquisitions, earnings announcements, debt and equity measures or changes to the board of directors) in order to evaluate the influence of these events on their investment strategies (Hersberger et al. 2007; Herrmann 2007; Gu et al. 2007; Tirunillai \& Tellis 2012; Wysocki 1998). In this regard, social media support investors in their decision-making and sense-making processes (Herrmann 2007).

Publicly traded companies can benefit from the aforementioned social media exposure regarding their disclosed business events. Social media exposure is responsible for a higher availability of company-related information and thus, reduces information asymmetries between companies and investors (Healy \& Palepu 2001; Tirunillai \& Tellis 2012; Saxton \& Anker 2013). In addition, social media exposure creates visibility in the capital market which attracts investors to a company's securities and increases shareholder base (Baker et al. 1999; Bushee \& Miller 2012; Grullon at el. 2004). The resulting increase in transparency and liquidity reduces the cost of capital as well as improves the ability and efficiency of raising funds (Diamond \& Verrecchia 1991; Pagano \& Röell 1996; Luo et al. 2013; Aggarwal et al. 
2012; Chang et al. 2012). Businesses also value information exchange of social media users with respect to business intelligence purposes (social media intelligence) (Chau \& Xu 2012; Zeng et al. 2010). Businesses are able to monitor and analyze reactions of investors in response to business events in order to obtain valuable feedback regarding their decisions and actions (Kau et al. 2008; Aggarwal \& Singh 2013; Zeng et al. 2010).

Information systems (IS), marketing and finance research provide evidence of the impact and predictive power of online information exchange via social media with respect to economic outcomes such as sales and stock market reactions (Antweiler \& Frank 2004; Wysocki 1998; Bollen et al. 2011; Liu 2006; Goh et al. 2013). In order to explain what influences online information exchange among social media users, studies in IS research investigate factors that influence information contribution in terms of quantity and quality of information ( $\mathrm{Lu} \mathrm{\&}$ Yang 2011). Prior research draws on theories in the sociology literature in order to address the question why individuals exchange information in social media (Wasko \& Faraj 2005; Lu \& Yang 2011; Cheung \& Lee 2012; Chiu et al. 2006; Hsu et al. 2007). Firstly, studies derive motives that affect information contribution behavior of individuals from social cognitive theory (Chiu et al. 2006; Bandura 1986; Hsu et al. 2007) and social exchange theory (Blau 1964; Wasko \& Faraj 2005; Cheung \& Lee 2012). Secondly, prior research draws on social capital theory in order to investigate how the relationships among social media users affect information contribution behavior (Nahapiet \& Ghoshal 1998; Coleman 1988; Wasko \& Faraj 2005; Lu \& Yang 2011; Chiu et al. 2006; Chai et al. 2011; Tsai \& Bagozzi 2014). In this regard, studies investigate information exchange of social media users in different contexts such as commerce (Cheung \& Lee 2012; Hennig-Thurau et al. 2004) or events like natural disasters (Lu \& Yang 2011). For example, Lu \& Yang (2011) draw on social capital theory in order to investigate what influences information contribution, in terms of quantity and quality of information, in the context of a natural disaster where people exchanged information on a message board in order to satisfy their information needs related to the event. Nevertheless, the influence of contextual factors on information exchange in social media with regard to the characteristics of the respective context, for example an event, is not explored. In particular, to the best of my knowledge, no other study investigates the influence of contextual factors on information exchange in social media with regard to the characteristics of business events. 
Because of the previously stated benefits of social media exposure for companies as well as the stated impact of social media content in the business domain, it is of high relevance for businesses to know what influences activities in social media in the context of business events and why a business event draws more or less activity in social media. In addition, investors can chose different types of social media in order to exchange information (Kaplan \& Haenlein 2010; Aggarwal \& Singh 2013; Wysocki 1998). Therefore, in order to efficiently monitor activities in social media, it is important for companies to identify what types of social media investors choose to exchange information related to business events. To address these issues and the described gap in the literature with regard to the influence of contextual factors on information exchange in social media, this dissertation thesis deals with the following central research question:

Central research question (CRQ): How does the announcement of business events affect the activity in social media and the choice of social media?

This dissertation thesis addresses this research question in context of merger announcements. A merger announcement represent an excellent opportunity to investigate the event-related activity in social media because of the event's high relevance to all stakeholders and due to the existence of uncertainties on many levels that give investors reason to exchange information regarding the implications of the announcement. In addition, there is a defined time period between the announcement of a merger and its official date of completion or failure where the activity in social media can be observed.

The description of the research model, the detailed structure of this cumulative dissertation as well as specific sub research questions addressed by each paper are presented in the following section. 


\section{Research Model and Structure of the Thesis}

\section{a. Research Model}

With regard to the $\mathbf{C R Q}$, the research of this dissertation thesis is guided by the following theoretical model (RM) (see Figure 1).

Figure 1: Research Model

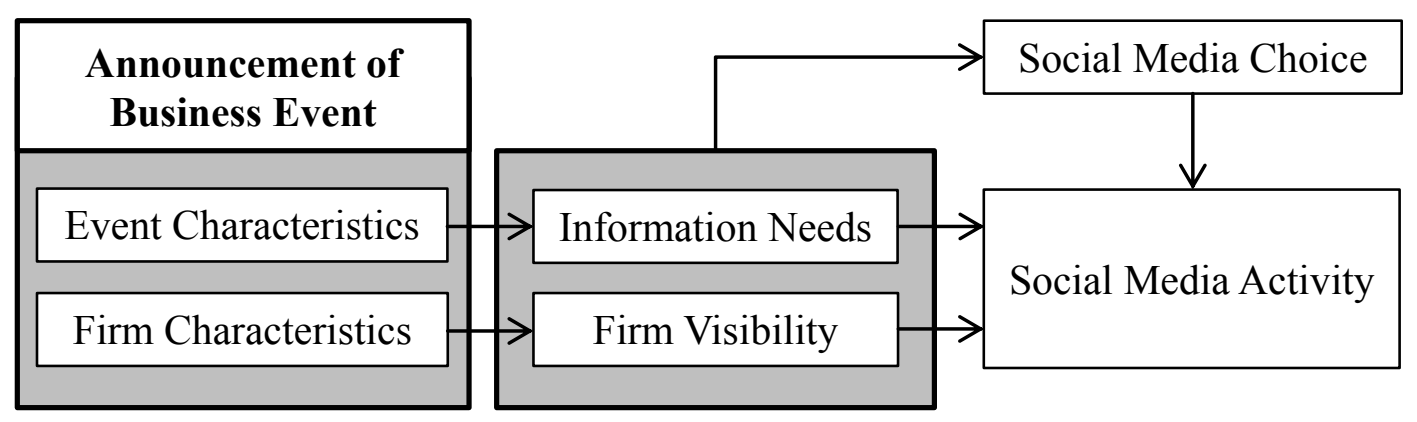

As depicted in the above research model, the aim of this dissertation thesis is to investigate the influence of disclosed business events on the event-related social media activity (SMA). Within the scope of this thesis social media activity is defined as the extent of information exchange via social media and in particular, social media activity refers to the quantity of information (e.g. the amount of social media posts) and the quality of content of information exchanged in social media (e.g. length of social media posts) (Lu \& Yang 2011; Wang \& Strong 1996) as well as the subjective information (e.g. the sentiment of social media posts) (Xia et al. 2011; Pang \& Lee 2008) and the mode of emergence of generated social media content (e.g. the type of social media used to create content).

In various research streams (e.g. finance, accounting, and marketing) "an event study measures the impact of a specific event on the value of a firm" (MacKinlay 1997, p. 13). Studies include firm- and event-specific factors in their analysis in order to evaluate the impact of an event (Tetlock 2010; Cotei \& Joseph 2013; Tipton et al. 2009; Godfrey et al. 2009). Likewise, in order to analyze the influence of a business event on the event-related social media activity, the research model distinguishes between two categories of contextual influencing factors: event-specific factors that are directly related to the characteristics of an event (event characteristics) and firm-specific factors that are directly related to the characteristics of firms that are associated with the event (firm characteristics). 
In general, information asymmetries do exist between companies and investors (Healy \& Palepu 2001; Akerlof 1970; Greenwald \& Stiglitz 1986; Spence 1973). When companies disclose an event, the magnitude of the difference in the level of information between companies and market participants is dependent on the complexity of the event with regard to its type-specific characteristics (Healy \& Palepu 2001). For example, the complexity of a change to the board of directors is not comparable with the complexity of a merger of two companies. The availability of reliable information is an important premise of a sustainable free-market economy (Akerlof 1970). In order to minimize information asymmetries between companies and market participants, mechanism to maximize transparency have to be established. In this regard, regulatory authorities have established a set of rules and obligations for companies that require them to publish material information concerning events that are relevant to shareholders (disclosable event) in a timely fashion (Healy \& Palepu 2001; Carter \& Soo 1999).

When a company discloses an event that is relevant to shareholders, investors are faced with uncertainty (Miller 1977), for example regarding the impact and the consequences of the event and its evaluation. The concept of uncertainty is rooted in the information theory, organizational theory as well as in the communication theory literature (Weick 1979; Simon 1972; Shannon \& Weaver 1949; Daft \& Macintosh 1981; Galbraith 1973; Wilson 1981). Within an organizational context uncertainty is associated with imperfect knowledge or lack of control regarding the external environment, as well as internal processes referred to as task uncertainty (Barnard 1938; Van de Ven et al. 1976; Lawrence \& Lorsch 1967; Pfeffer \& Salancik 1978; Thompson 1967; Duncan 1972; Milliken 1987; Downey \& Slocum 1975). The connection between uncertainty and its counterpart information was established by Shannon \& Weaver (1949); accordingly uncertainty and information have a reciprocal relationship with each other (Daft \& Macintosh 1981; Daft et al. 1987). Uncertainty is broadly described as the state of not knowing, a lack of knowledge and information, associated with the inability to predict future events and outcomes (Leifer \& Mills 1996; Lipshitz \& Strauss 1997; Galbraith 1977; Milliken 1987).

In the context of decision making and task-related information processing, uncertainty is commonly referred to as the "difference between the [required] amount of information to perform a task and the amount of information already possessed" by a decision maker or an 
organization (Galbraith 1973, p. 5). Here "the amount of information required to perform a task is a function of the nature of the task itself and the level of performance" (Galbraith 1977, p. 37). Uncertainty also arises when existing information about an event or the state of the world is ambiguous, leading to multiple meanings or conflicting interpretations of the situation a decision maker has to face, also referred to as equivocality (Weick 1979; Leifer \& Mills 1996; Daft \& Macintosh 1981; Daft \& Lengel 1984). The former refers to situations of incomplete information, whereas the latter is based on the inadequate understanding of the available information by a decision maker and the decision maker's inability to differentiate between alternatives (Lipshitz \& Strauss 1997). Accordingly, uncertainty is reduced by gathering objective information, whereas ambiguity as a component of uncertainty is resolved by exchanging opinions and interpretations about a situation among decision makers, preferably by processing 'rich information' (Daft \& Lengel 1986; Daft \& Lengel 1984). Milliken (1987) describes three types of uncertainty that are experienced by decision makers: state uncertainty referring to the unpredictability and likelihood of an event or outcome, effect uncertainty referring to a lack of understanding of cause-effect relationships regarding the impact of an event, and response uncertainty referring to a lack of knowledge of available response options to an event and their respective consequences. With respect to information processing theory uncertainty is not solely an obstacle decision makers have to overcome but, along with complexity, uncertainty also represents a limit on rationality of decision makers with constrained information-processing capacities (Simon 1957; Simon 1972).

According to the research model (Figure 1), certain event characteristics of an announcement business event are associated with information needs of investors. Taylor (1962) defines four forms of information needs: "the actual, but unexpressed, need for information (the visceral need); the conscious within-brain description of the need (the conscious need); the formal statement of the question (the formalized need); the question as presented to the information system (the compromised need)" (Taylor 1962, p. 392); here the definition of the visceral need fits best within the scope of the presented research model. According to Belking (1980) the source of information needs is an individual's anomalous state of knowledge, meaning a perceived lack of knowledge, uncertainty, or an inadequate understanding of a situation or problem. Similarly, in Kuhlthau's (1993) model of the information search process, the process of information seeking is initiated by information needs of individuals due to uncertainty or by experiencing a gap in meaning. A gap in meaning is also central to the concept of 
sensemaking, a process of constructing meaning and "a search for contexts within which small details fit together and make sense" (Weick 1995, p. 133). The gap is representative for information needs of individuals who want to reduce equivocality and make sense of a situation (Dervin 1983; Dervin 1998; Weick 1995; Weick 1979). In accordance with the previously stated definitions of uncertainty and the described sources of uncertainty, each of these theoretical explanations regarding information seeking behavior specify that uncertainty is responsible for information needs of individuals. Therefore, uncertainty due to a business event with respect to its type-specific event characteristics is hypothesized to be responsible for increased information needs of investors.

In addition, information seeking behavior of individuals is defined as "the purposive seeking for information as a consequence of a need to satisfy some goal. In the course of seeking, the individual may interact with manual information systems (such as a newspaper or a library), or with computer-based systems (such as the World Wide Web)" (Wilson 2000, p. 49). Furthermore, information needs can be satisfied via means of communication (Daft \& Lengel 1986; Daft \& Lengel 1984). In this regard, social media provide communication channels for investors to seek and exchange information in order to satisfy their information needs and reduce uncertainty (Kaplan \& Haenlein 2010; Lu \& Yang 2011; Weiss et al. 2008; Luo et al. 2013; Aggarwal \& Singh 2013; Antweiler \& Frank 2004; Das \& Chen 2007). Wilson's (1981; 1999) model of information behavior indicates that information seeking behavior due to information needs includes the exchange of information with other individuals in order to satisfy these needs as well as the provisioning of information that an information seeker perceives as useful to others. Hence, as depicted in the research model, information needs of investors are hypothesized to be responsible for increased event-related activities in social media (social media activity).

It is reasonable to expect that not only investors will engage into online chatter regarding an event. Members of the general public, for example customers of a company, are likely to discuss actions and events of companies via social media. Some companies may be more likely to attract higher levels of social media activity from both investors and individuals. The research model addresses this issue by including firm characteristics that are associated with the visibility of companies involved in a business event. Firm visibility is representative of how visible a company is to the general public (e.g. due to media exposure) and to the capital 
market (e.g. in the case of liquid stocks) as well as to its stakeholders (Pfarrer et al. 2010; Bushee \& Miller 2012; Grullon at el. 2004; Wang \& Qian 2011). The term firm visibility is also referred to as firm celebrity, organizational visibility and public visibility, and is considered an intangible asset of a company (Pfarrer et al. 2010; Capriotti 2009; Wang \& Qian 2011). Firm visibility creates awareness of the existence and the actions of a company (Pfarrer et al. 2010; Bushee \& Miller 2012; Grullon at el. 2004; Baker et al. 1999; Wang \& Qian 2011). Higher awareness towards a company and its products leads to increased online information exchange among its customers and other consumers (Duan et al. 2008). With respect to capital markets, visibility of a company increases the awareness of investors regarding the existence and the actions of the company and thus, increases the shareholder base of the company (Baker et al. 1999; Bushee \& Miller 2012; Grullon at el. 2004). According to Huberman (2001), "a person is more likely to invest with a company he knows (or thinks he knows)" (Huberman 2001, p. 678). In this regard, firm visibility creates familiarity with a company and attracts investors to the company's stock (Baker et al. 1999). This leads to increased scrutiny of companies' actions and events from investors, analysts and the media (Baker et al. 1999; Dewenter et al. 2001). Therefore, more visible companies are expected to receive higher levels of social media activity from both investors and individuals (e.g. customers) regarding their actions and business events. In conclusion, not only information needs of investors due to uncertainty concerning a business event but also firm visibility of companies involved in a business event are hypothesized to be responsible for increased event-related social media activity.

As depicted in the research model (Figure 1), information needs of investors and the visibility of firms involved in a business event affect media choice with respect to different social media types (social media choice) that determine the mode of emergence of event-related content in social media. Understanding media choice during task-related communication processes has been a major topic of inquiry in IS research with regard to organizational and communication theory (Daft \& Lengel 1984; Daft et al. 1987; Daft \& Lengel 1986; Dennis et al. 2008; Rice 1992; Lee 1994; Trevino et al. 1987; Markus 1994; George et al. 2013; Kahai \& Cooper 2003; Straub \& Karahanna 1998; Webster \& Trevino 1995; Sheer \& Chen 2004; Carlson \& Davis 1998). With respect to social media choice, individuals can choose from various social media platforms in order to exchange information. Each of these platforms belongs to a certain type of social media featuring a set of media capabilities (Kaplan \& 
Haenlein 2010). Capabilities of media determine if a medium fits the communication process of a task (Daft \& Lengel 1984; Dennis et al. 2008). If task communication requirements change, the medium of choice may change as well (Daft \& Lengel 1984; Dennis et al. 2008). In many cases a mix of media in succession or simultaneously is recommended for taskrelated communication processes in order to improve overall communication performance (Dennis et al. 2008). Therefore, with respect to information needs and firm visibility, communication processes regarding uncertainty reduction related to a business event are hypothesized to determine social media choice of investors.

\section{b. Structure of the Thesis}

As shown in Table 1, this cumulative dissertation thesis encompasses six papers (see section $\mathbf{G}$ for the complete versions of these papers). To uncover in more detail how the announcements of business events affect social media activity and social media choice, these papers are assigned to four sub research questions $(\mathbf{R Q})$.

Table 1: List of Papers and Sub Research Questions

\begin{tabular}{|c|c|c|}
\hline RQ 1: & $\begin{array}{l}\text { Does the content of corporal disclosures give market par } \\
\text { seek additional information elsewhere? }\end{array}$ & to \\
\hline No. & Title & Reference \\
\hline 1 & $\begin{array}{l}\text { How "good" is bad News? Exploring Sentiments of Corporate } \\
\text { Disclosures }\end{array}$ & Zülch et al. 2011 \\
\hline RQ 2: & \multicolumn{2}{|l|}{ How do merger announcements affect activity in social media? } \\
\hline No. & Title & Reference \\
\hline 2 & $\begin{array}{l}\text { "Will They Merge?" - Financial Event-Related Information } \\
\text { Processing in Social Media }\end{array}$ & Zülch 2013 \\
\hline 3 & An Empirical Analysis of Merger-Related Blog Posts & Zülch 2013a \\
\hline RQ 3: & \multicolumn{2}{|c|}{$\begin{array}{l}\text { What are the influencing factors that drive activity in social media related to } \\
\text { merger announcements? }\end{array}$} \\
\hline No. & Title & \\
\hline 4 & $\begin{array}{l}\text { Drivers of Information Quantity: The Case of Merger- } \\
\text { Acquisition Events }\end{array}$ & Zülch et al. 2014a \\
\hline 5 & $\begin{array}{l}\text { Drivers of Information Quality on Blogs: The Case of Business } \\
\text { Events }\end{array}$ & Zülch et al. 2014 \\
\hline RQ 4: & \multicolumn{2}{|l|}{ How do merger announcements affect the choice of social media? } \\
\hline No. & Title & Reference \\
\hline 6 & $\begin{array}{l}\text { Social Media Choice: An Explorative Study on Inf } \\
\text { Transmission via Social Media }\end{array}$ & Zülch et al. 2014b \\
\hline
\end{tabular}


The numbers depicted in Figure 2 refer to the aforementioned sub research questions and illustrate which part of the research model, i.e. which causal relationship between theoretical constructs, is addressed by each sub research question (Shmueli 2010).

Figure 2: Research Model and Sub Research Questions

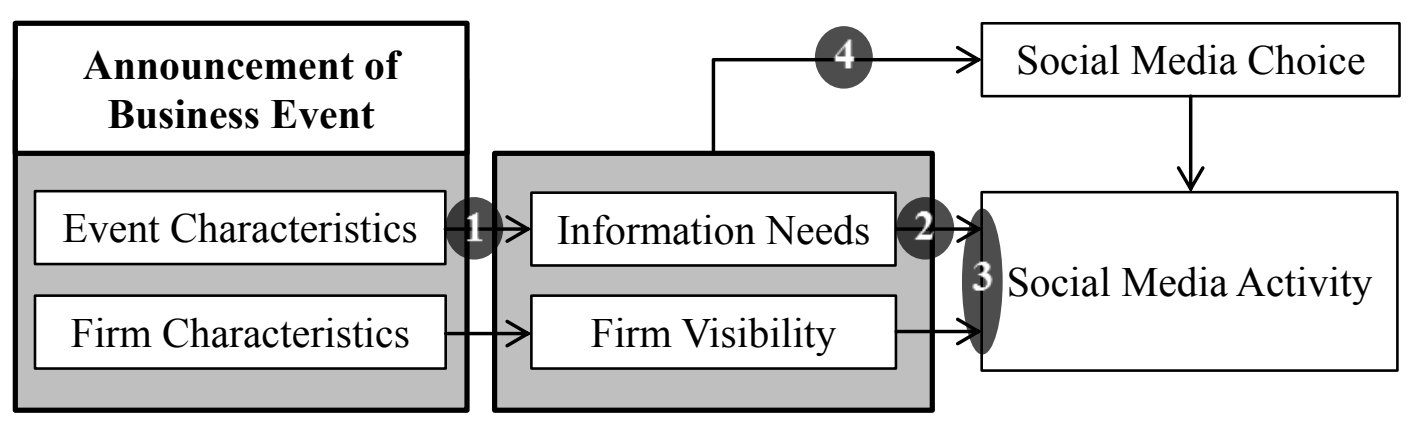

With respect to the central research question and given the explanatory character of the theoretical model (RM), explanatory modeling, which is defined as "the application of statistical models to data for testing causal hypotheses about theoretical constructs" (Shmueli 2010, p. 291), is used in all six studies presented in this thesis (i.e. Papers 1-6) (Gregor 2006; Shmueli \& Koppius 2011).

Paper 1 focuses on the announcement of events in the business domain with respect to corporate disclosures and Papers 2-6 utilize the context of merger announcements in order to investigate information exchange in social media related to the announcement of a major business event. Paper $\mathbf{1}$ addresses the question (RQ 1), "Does the content of corporal disclosures give market participants reason to seek additional information elsewhere?". The study analyzes the content of corporate disclosures with respect to the sentiment provided by the diction in order to investigate if these external reports provide reliable objective information to market participants in order to satisfy their information needs. Papers 2 and $\mathbf{3}$ address the question (RQ 2), "How do merger announcements affect activity in social media?". Both studies use a data set of merger-related blog posts that were posted in the course of merger attempts. Paper 2 investigates if certain event characteristics that serve as proxies for investors' uncertainty about merger completion are related to an increased eventrelated social media activity. Paper 3 investigates whether the uncertainty about merger completion is reflected in the textual content of these blog posts. Papers 4-5 address the question (RQ 3), "What are the influencing factors that drive activity in social media related to merger announcements?". Paper 4 investigates if event characteristics related to 
information needs of investors and firm characteristics related to firm visibility drive social media activity in terms of quantity of information exchanged with respect various social media types. Paper 5 introduces a novel approach to quantitatively measure certain dimensions of information quality of social media posts within a financial context. The study investigates whether the influencing factors mentioned above drive social media activity in terms of information quality of merger-related blog posts. Paper 6 addresses the question (RQ 4), "How do merger announcements affect the choice of social media?". The study explores the occurrence of content (social media posts) among social media types subsequent to merger announcements while accounting for event- and firm-related factors.

This introductory paper proceeds as follows. Section B provides an overview of the research background of this dissertation regarding merger events as well as social media and usergenerated content. Section $\mathbf{C}$ provides an overview on the applied research methods and data sources with respect to each paper. Section $\mathbf{D}$ introduces each paper and discusses their main results with respect to each sub research question. Section $\mathbf{E}$ summarizes the contributions to research and the practical implications of this dissertation thesis. Section $\mathbf{F}$ discusses limitations of the presented research and proposes potential future research directions. Finally, section $\mathbf{G}$ contains the complete research papers of this cumulative dissertation thesis.

\section{B. Research Context}

\section{Merger Events}

In this dissertation thesis the influence of business events on activities in social media is investigated in the context of merger events because they usually draw a lot of attention by investors from the moment when companies announce the intent to merge (merger announcement). Mergers "are business combination transactions involving the combination of two or more companies into a single entity" (SEC 2013). In reality mergers are rather acquisitions where a company (i.e. the acquirer or bidder) buys out a majority stake or 100 percent of the shares in a target company (i.e. the target) (Faulkner et al. 2012).

In general, there are three types of mergers: horizontal mergers (merging companies share the same kind of business activity), vertical mergers (merging companies are at different stages of production operations) and conglomerate mergers (the business activity of merging 
companies is unrelated) (Copeland et al. 1988). In addition there is a distinction between national or cross-border mergers (Wirtz 2003). In general, the motives for mergers are: synergistic gains such as economies of scale and scope, diversification, increasing market power, access to resources and assets as well as markets, managerial and personal motives (e.g. empire building) (Wirtz 2003; Chakravorty 2012).

For investors mergers represent an often unanticipated and complex business event (Louis \& Sun 2010). In general, investors have to evaluate if the expected synergistic value is worth the financial risk resulting from the merger (Bradley et al. 1988). With regard to the post-merger performance, a lot of mergers do not meet their expectations and are not successful with respect to the difference between the expected and actual post-merger performance, e.g. due to a lack of organizational or strategic fit (Chakravorty 2012; Healy et al. 1992).

It can take several months between the announcement of a merger and its official completion. In this time period the merger attempt passes through several stages where the shareholders and regulatory authorities have to give their approval to the merger (SEC 2013; Faulkner et al. 2012). The deal will be terminated when shareholders or regulatory authorities do not approve to the merger or when the management of one party abandons the merger attempt. After the official completion both parties begin the process of integration (post-merger phase) (Wirtz 2003).

The acquisition can either be hostile or friendly. In a hostile takeover the board of directors of the target company does not agree to the deal and can initiate several counter measures in order to prevent the completion of the takeover (e.g. white knight defense) (Copeland et al. 1988). Hostile takeover are usually initiated with a tender offer where the acquiring company makes an offer to directly purchase all shares, including a premium, from the shareholders of the target company (Copeland et al. 1988). In the case of a friendly merger the acquirer and the target company can also enter in a mutual termination agreement, in the case one party terminates the deal it is obliged to pay a fee to the other party (Bates \& Lemmon 2003). This increases the burden for the termination of the transaction and increases the likelihood of the completion of the merger (Bates \& Lemmon 2003).

In general, for mergers there are three forms of payments for the deal: cash, stocks, or mixture of both (Faulkner et al. 2012). In cash transactions the acquirer directly purchases all equity shares of the target company. Here the shareholders of the acquirer bear all the risk from the 
transaction with regard to the post-merger performance, while the overall financial risk for the acquirer is associated with the total transaction value and is dependent on the value of the acquirer relative to the value of to the target company (Martin 1996; Madura \& Ngo 2012; Faulkner et al. 2012). In stock-for-stock mergers the acquirer offers its own shares for the shares of the target's shareholders according to a predetermined exchange ratio (Houston \& Ryngaert 1997). Consequently, the risk will be shared between the shareholders of the acquirer and the target company (Martin 1996). In this case investors have to assess the value of the target and the acquiring company as well as the potential synergistic gains of the mergers (Louis \& Sun 2010). Bidders tend to use cash when their shares are undervalued and stocks when their shares are overvalued (Myers \& Majluf 1984; Agrawal \& Jaffe 2000). Cash acquisitions signal acquirer's confidence in the post-merger performance and are associated with a higher probability of merger completion (Muehlfeld et al. 2007; Goergen \& Renneboog 2004; Yook 2003).

The announcement of a merger of public traded companies is directly followed by severe price reactions with regard to the stocks of both the acquiring and the target (Goergen \& Renneboog 2004; Asquith 1983; Dodd 1980). These price reactions vary depending on the characteristics of merger events, for example with regard to the chosen method of payment or in the case of hostile takeovers (Travlos 1987; Goergen \& Renneboog 2004). Till the official completion or termination of a merger, the prices constantly adjust to merger-related news and reflect the uncertainty about merger completion (Asquith 1983; Dodd 1980; Kau et al. 2008). Managers of merging companies extract feedback from the market reaction and take it into consideration whether they want to proceed or terminate the deal (Kau et al. 2008; Luo 2005).

In conclusion, besides information asymmetries between the merging companies and investors (Healy \& Palepu 2001), for investors (including shareholders of merging companies) mergers represent complex business events with uncertainties on many levels. There is uncertainty about whether the announced merger will actually be completed, if proclaimed value gains are feasible, and about the implications of the announcement on current investments in the merging companies. Investors have to consider several characteristics (i.e. event characteristics) of the merger such as the financial structure of the 
deal as well as the strategic fit of both companies in order to evaluate if the expected value gain is worth the financial risk resulting from the merger.

\section{Social Media and User-Generated Content}

Social media are "a group of Internet-based applications that build on the ideological and technological foundations of Web 2.0, and that allow the creation and exchange of User Generated Content” (Kaplan \& Haenlein 2010, p. 61). Social media represent online platforms "via which individuals and communities share, co-create, discuss, and modify usergenerated content" (Kietzmann et al. 2011, p. 241). User-generate content (UGC) represents “i) content made publicly available over the Internet, ii) which reflects a certain amount of creative effort, and iii) which is created outside of professional routines and practices" (OECD 2007, p. 4). Social media enable an engaging communication between the authors of UGC and its readers by offering ways of many-to-many communication, thus social media users are both consumers and contributors of UGC (Xu \& Zhang 2014; Aggarwal et al. 2012; Burnett 2000). Therefore, one central aspect of social media is the exchange of information in the form of UGC among social media users.

Along with the advances of the internet in recent history many types of social media emerged (Kaplan \& Haenlein 2010; Boyd \& Ellison 2007; Kietzmann et al. 2011; Schmidt 2007). Kaplan \& Haenlein (2010) offer one of the first classification schemes of social media types. They classified social media types like blogs, social network sites, collaborative projects, content communities, virtual social worlds, and virtual gaming worlds according to media richness and social presence theory as well as with respect to self-presentation and selfdisclosure. Nevertheless, their classification scheme does not include microblogs and message boards (online discussion forums) as social media types despite its recognition by the literature (Java et al. 2007; Jiang et al. 2014; Shi et al. 2014; Kaplan \& Haenlein 2011). Based on the vast possibilities that internet based technologies offer, social media applications and platforms overlap in their functionalities and feature sets that make it difficult to clearly assign social media platforms to distinctive types of social media. In this regard, Kietzmann et al. (2011) chose the approach to identify functionalities of social media in order to classify social media platforms according to their functionalities instead of predefined social media types. They present seven functional building blocks within their framework by which social 
media platforms can be defined: presence, relationships, reputation, groups, conversations, sharing, and identity.

Social media enable the creation of social networks on the internet. The interactions between social media users (e.g. by posting, commenting, citing or following) create relationships between users (Kaplan \& Haenlein 2010; Burnett 2000). If these created social networks revolve around a common interest or goal, social media enable the formation of online communities (also known as virtual communities) (Chiu et al. 2006; Hersberger et al. 2007; Kaplan \& Haenlein 2010; Ren et al. 2012; Butler 2001; Lu \& Yang 2011). Gu et al. (2007) suggest that the value of online communities for social media users is dependent on the trade of between the quantity and the quality of UGC. Burnett (2000) provides a typology of information behavior that can be identified in online communities. The characteristics of these social structures and the diffusion of UGC can be analyzed by means of social network analysis (Chau \& Xu 2012; Kane et al. 2014; Sundararajan et al. 2013). In this regard, network analysis uncovers the information flow within the social network in order to identify implicit communities, opinion leaders (i.e. influential members of the community) as well as the interactions between online community members (Chau \& Xu 2012).

Prior research investigates the influencers of UGC creation. Related studies are mainly concerned with motives that affect information contribution behavior of social media users and how the relationships among social media users affect information contribution behavior (Lu \& Yang 2011; Chiu et al. 2006; Cheung \& Lee 2012). In general, social media users participate in information exchange activities in online communities with the intention to seek advice and answers as well as to access useful information that satisfy their information needs (Wasko \& Faraj 2000). Social capital theory (Nahapiet \& Ghoshal 1998; Coleman 1988; Lu $\&$ Yang 2011), social cognitive theory (Bandura 1986; Chiu et al. 2006; Hsu et al. 2007) and social exchange theory (Blau 1964; Wasko \& Faraj 2005; Cheung \& Lee 2012) serve as a theoretical base to investigate factors that affect UGC contribution of social media users with respect to social media types such as blogs and message boards (Chai et al. 2011; Lu \& Yang 2011).

Social capital is "the sum of the actual and potential resources embedded within, available through, and derived from the network of relationships possessed by an individual or social unit" (Nahapiet \& Ghoshal 1998, p. 243). Studies find that the number of social interaction 
ties of a user with other users, the trust in other users, reciprocity relationships with other users, a sense of belonging to the online community, a shared language among users and a shared goal that the online community wants to achieve positively influence information contribution behavior of online community members in terms of quality and quantity of UGC (Wasko \& Faraj 2005; Lu \& Yang 2011; Chiu et al. 2006; Chai et al. 2011; Tsai \& Bagozzi 2014).

According to social cognitive theory individuals more likely choose behavior that they belief is associated with a positive expected outcome (Chiu et al. 2006; Bandura 1986; Hsu et al. 2007). Chiu et al. (2006) find that community related outcome expectations such as successful functioning and growth of the online community positively influence information contribution behavior of online community members in terms of quality and quantity of UGC. Hsu et al. (2007) find that personal outcome expectations such as beneficial and better relationships with other online community members, recognition from other users, trust and respect from other users positively influence information contribution behavior of online community members. Social exchange theory states that individuals pursue social interactions when the rewards of the social exchange outweigh the cost (Blau 1964). Studies find that enjoyment (of helping others) as well as gains in reputation and status are positively associated with information contribution behavior (Cheung \& Lee 2012; Wasko \& Faraj 2005).

Another research stream is concerned with the influence of UGC and how to exploit UGC for predictions on various economic outcomes. The related studies make use of extensive unstructured and semi-structured social media datasets in order to make predictions in the areas of finance and commerce (Antweiler \& Frank 2004; Zhang et al. 2012).

In finance research the efficient market hypotheses states that market prices follow a random walk, reflect all public available information and quickly adjust to new information (semistrong form) (Fama 1965; Fama 1970; Fama et al. 1969). Behavioral finance research has introduced behavioral aspects to finance research by incorporating cognitive psychology to the decision making of investors and suggests that prices are influenced by what investors think, indicating that prices can be predicted to some degree and thus, contradicts the notion that prices follow a random walk (De Long et al. 1990; Hirshleifer 2001; Hirshleifer \& Teoh 2003). In addition, market imperfections stem from asymmetric information between investors and firms (Healy \& Palepu 2001). Research suggests that investors engage into 
information exchange activities via social media in order to satisfy their information needs and reduce informational asymmetries (Luo et al. 2013; Tirunillai \& Tellis 2012; Wysocki 1998). Thus, social media provide the opportunity to observe decision making and sense making of investors which can be used to reveal what investors think about economic developments and business events (Herrmann 2007). In this regard research in the area of finance investigates the predictive relationship between UGC and various capital market outcomes.

Several studies show that the quantity of UGC exchanged on message boards (Wysocki 1998; Antweiler \& Frank 2004; Das et al. 2005; Sabherwal et al. 2011; Tumarkin \& Whitelaw 2001), on blogs (Fotak 2007; Luo et al. 2013), and via online reviews (Tirunillai \& Tellis 2012) has predictive power regarding stock prices and trading volumes (Fotak 2007; Antweiler \& Frank 2004; Wysocki 1998; Luo et al. 2013; Tirunillai \& Tellis 2012) as well as volatility (Antweiler \& Frank 2004). Studies indicate that the information exchange of investors gravitates around companies with a higher firm visibility (Antweiler \& Frank 2004; Wysocki 1998; Fotak 2007), whereas the impact of UGC is higher on stocks of companies with a lower firm visibility (Sabherwal et al. 2011). Similar to stock prices, the quantity of UGC reacts quickly to news and business events (e.g. earnings announcements) (Tetlock 2007; Wysocki 1998; Fotak 2007; Antweiler \& Frank 2004). Overall, studies that explore the impact of the quantity of UGC on financial outcomes focus primarily on message boards and blogs, whereas the impact of information quality of exchanged content is underexplored (Antweiler \& Frank 2004: Fotak 2007).

Furthermore, many studies make use of the linguistic aspect of UGC and extract the sentiment expressed by the textual content in order to capture mood states of investors as well as the general public which tend to drive capital market movements (Nofsinger 2005; Pang \& Lee 2008). In order to extract the sentiment of UGC means of content analysis such as dictionarybased and machine learning approaches are applied (Pang \& Lee 2008). Studies show that the sentiment of UGC from microblogs (Bollen et al. 2011; Zhang \& Skiena 2010; Yu et al. 2013), social network sites (Siganos et al. 2014; Danbolt et al. 2015), blogs (Zhang \& Skiena 2010; Yu et al. 2013), message boards (Antweiler \& Frank 2004; Das \& Chen 2007; Sabherwal et al. 2011; Jiang et al. 2014; Li et al. 2014; Yu et al. 2013) as well as online reviews (Tirunillai \& Tellis 2012) can be used in order to make predictions with regard to 
capital market outcomes like trading volume (Jiang et al. 2014; Zhang \& Skiena 2010; Siganos et al. 2014; Sabherwal et al. 2011; Das \& Chen 2007; Tirunillai \& Tellis 2012), stock prices (Danbolt et al. 2015; Yu et al. 2013; Li et al. 2014; Jiang et al. 2014; Das \& Chen 2007; Das et al. 2005; Sabherwal et al. 2011; Zhang \& Skiena 2010; Bollen et al. 2011, Siganos et al. 2014; Tirunillai \& Tellis 2012), and volatility (Jiang et al. 2014; Das \& Chen 2007; Sabherwal et al. 2011; Siganos et al. 2014). Especially the variety in opinions and more subjective opinions are associated with higher trading volumes (Zhang \& Skiena 2010; Antweiler \& Frank 2004). With respect to merger events, Danbolt et al. 2015 find that the sentiment index from Facebook (i.e. a social network site) has a significant relationship with bidder abnormal returns at the announcement of a merger.

In the area of commerce online review systems and online consumer communities facilitated by social media have a great influence on decision making of consumers (Adjei et al. 2010; Brown et al. 2007; De Valck et al. 2009; Dewan \& Ramaprasad 2012; Dellarocas 2003; Bickart \& Schindler 2001). Users exchange information and opinions about products and are able to observe the purchasing decisions of others which reduce the uncertainty about product quality (Chen et al. 2011; Murray 1991; Dewan \& Ramaprasad 2012). Consumers especially value these shared opinions because they are considered unbiased, more credible and trustworthy compared to opinions from other sources (e.g. advertisement) (Murray 1991; Liu 2006).

In marketing related research this product related UGC from consumers is referred to as electronic word-of-mouth (eWoM) (Zhang et al. 2012; Luo et al. 2013; Goh et al. 2013). Electronic word-of-mouth can be defined as "any positive or negative statement made by potential, actual, or former customers about a product or company, which is made available to a multitude of people and institutions via the Internet" (Hennig-Thurau et al. 2004, p. 39). The motives for consumers to engage in eWoM activities are social interaction, the concern for other consumers, economic incentives and enhancing self-worthiness (Hennig-Thurau et al. 2004). The volume of word-of-mouth is hypothesized to raise consumer awareness of products while the valence (i.e. a positive or negative value assigned to a product or a company) of word-of-mouth is hypothesized to change the consumer attitude towards products (Liu 2006). 
Empirical research provides evidence that product-related UGC in social media and online review systems positively influences sales (e.g. book, music and box-office sales) (Forman et al. 2008; Dellarocas et al. 2007; Chevalier \& Mayzlin 2006; Liu 2006; Goh et al. 2013; Duan et al. 2008; Chintagunta et al. 2010; Zhang et al. 2012; Godes \& Mayzlin 2004). Studies show that the volume of eWoM (i.e. quantity of UGC) (Liu 2006; Duan et al. 2008; Dellarocas et al. 2007; Chevalier \& Mayzlin 2006; Chintagunta et al. 2010) and the valence of eWoM (e.g. positive or negative product reviews) (Zhang et al. 2012; Dellarocas et al. 2007; Chevalier \& Mayzlin 2006; Goh et al. 2013; Chintagunta et al. 2010) have a predictive relationship with sales. Overall the results are mixed whether the volume or the valence of eWoM has greater impact on sales (Aggarwal et al. 2012), while the impact of negative eWoM on sales is greater compared to positive eWoM (Chevalier \& Mayzlin 2006). In addition, the dispersion of eWoM has a positive influence on product ratings (Godes \& Mayzlin 2004), while the valence of eWoM influences the volume of eWoM (Duan et al. 2008).

Other studies investigate the influence of eWoM provided by blogs that are concerned with ventures (Aggarwal et al. 2012; Aggarwal \& Singh 2013). Previous studies related to sales treated the decision making process of consumers as a single-stage process (Aggarwal \& Singh 2013). In contrast to these studies, Aggarwal \& Singh (2013) investigate the signaling effect of UGC provided by blogs on multiple stages of decision making of venture capitalists. They show that the volume of eWoM has a significant positive influence at the screening stage where venture capitalists evaluate which venture they should consider for financing. In addition, Aggarwal et al. (2012) show that the volume of popular blogs has a positive impact on venture financing at early development stages of ventures when the uncertainty associated with ventures is high. Both studies highlight that social media and especially blogs can be considered a valid information source for investors because they provide in depth and additional information as well as cover topics that are not covered by the traditional media. 


\section{Research Methodology and Datasets}

\section{Statistical Analysis and Content Analysis}

The quantitative research presented in this dissertation is conducted by applying methods of statistical analysis and content analysis. In Papers $\mathbf{1}$ and $\mathbf{3}$ research hypotheses are tested by examining mean difference between two samples. Given the numerical character of variables in each sample, in the analyses of Paper $\mathbf{1}$ and Paper $\mathbf{3}$ unequal-variances $t$-tests are applied (Weiers 2005). The unequal-variances $t$-tests can be used to compare the means of two independent samples and can be applied if the $F$-tests on the equality of the two sample variances have been rejected (Weiers 2005). In the analyses of Paper 2 hypotheses are tested by examining the difference between two samples as well as between three samples. Given the categorical character of variables, in the analyses of Paper 2 Mann-Whitney $U$-tests are applied (Weiers 2005). Mann-Whitney $U$-test represents a nonparametric test and can be used to examine the difference between two samples and is similar to the $t$-test on independent samples but can be performed on ranked or ordinal data (Weiers 2005). In addition, in the analyses of Paper 2 Kruskal-Wallis $H$-tests are applied. Kruskal-Wallis $H$-test also represents a nonparametric test that can be performed on categorical data (Weiers 2005). Kruskal-Wallis $H$-Test can be used in order to examine the difference between more than two samples and represents a between-groups analysis (Weiers 2005).

Papers 4-5 apply multiple linear regression analysis in order to investigate the relationship between a dependent variable and multiple independent variables (predictors) (Weiers 2005). In the regression analysis the nature of this relationship will be determined and how much of the variance in the independent variable can be explained by the resulting multiple regression equation (Weiers 2005). For each analysis in Papers 4-5 no evidence of multicollinearity between independent variables was detected (Weiers 2005). In addition, the assumptions of normally distributed errors and homoscedasticity are met for each analysis (Weiers 2005). In the analyses of Paper 6 a hazard function model regression is applied (Greene 1997). This type of regression is used in survival analysis and is used to estimate how long an entity will stay in a certain state (e.g. until death) (Greene 1997). In the analysis the hazard rate $\lambda$ is the likelihood at which an entity does not change its state within a given time period (Greene 
1997). In contrast to a linear regression this type of analysis considers the positive characteristics and the non-linear behavior of the dependent variable (Greene 1997).

Content analysis is defined as "any technique for making inferences by objectively and systematically identifying specified characteristics of messages" (Holsti 1969, p. 14). In the analyses of Papers 1-3 and Paper 5 computer-assisted dictionary-based approaches are applied (Rosenberg et al. 1990). In this regard, a dictionary provides a list of terms that are categorized according their psychological or contextual meaning (Weber 1984). This is often applied in sentiment analysis where the tone (e.g. positive or negative) in source materials such as UGC or news is determined (Pang \& Lee 2008; Pang et al. 2002; Das \& Chen 2007). Firstly, Papers 1-3 and Paper 5 apply a dictionary provided by the General Inquirer which consists of word lists that can be used to categorize words according to their psychosocial meaning (Stone \& Hunt 1963; Stone et al. 1966). Secondly, Paper 1 applies a dictionary that categorizes words according to their meaning in a financial context (Loughran \& McDonald 2011). Thirdly, Paper 5 applies the Thomson Reuters Financial Glossary (2013) which contains key terms that are used in the financial industry. These aforementioned word lists are used in order to obtain the frequency of terms with respect to certain categories of meaning (e.g. positive words and negative words) contained in textual data such as UGC (Papers 2-3 and Paper 5) and corporate disclosures (Paper 1). Furthermore, in the analyses of Paper 5 the Gunning-Fog Index is applied in order measure the readability of writing in text (i.e. UGC) (Gunning 1952; Loughran \& McDonald 2014). Readability is defined as "the ease of understanding or comprehension due to the style of writing" (Klare 1963, p. 1). In this regard, the Gunning-Fog Index assesses the average sentence length in a text in combination with the proportion of complex words in a text (Gunning 1952).

\section{Datasets}

In the following the archival data sources that were used in the papers of this dissertation are described. Overall, the used datasets consist of structured as well as semi-structured data. With regard to Paper 1, a sample of 4,360 FTSE-100 corporate disclosures was collected that were published during trading hours of the London Stock Exchange via Regulatory News Services between November 2007 and November 2009. With respect to the collected 
corporate disclosures, Thomson Reuters Tick History was used to collect intraday price series of the corresponding stocks.

Thomson Reuters SDC Platinum was used in order to identify merger events and to collect merger-specific data. In total 28,933 US mergers \& acquisitions transactions have been identified that have been announced between January $1^{\text {st }} 2008$ and December $31^{\text {st }} 2011$. This provided the base for the sample selection processes of merger events in Papers 2-6. For each sample of merger events, Thomson Reuters SDC Platinum and Thomson Reuters Datastream were used to collect company-specific data of companies that are involved in a merger attempt. With regard to the selected samples of merger events, LexisNexis was used in order to collect news articles that have been published in The Wall Street Journal and in The New York Times (Papers 4-6). Only news article were collected that were citing the name of a company involved in a merger attempt and that were published during the year prior to the announcement of the respective merger attempt.

In the sample selection processes of merger events in Papers 2-6 only merger events were selected that were officially either completed or withdrawn as of July 2012. In this regard, only merger-related social media posts (i.e. UGC) were collected that were posted in the course of a merger attempt, i.e. between the merger announcement and the date when the final outcome of the merger attempt is known (either completed or withdrawn). In Papers 2-3 Newstex Blogs on Demand was used to collect merger-related blog posts that contain the company name of the acquirer, the company name of the target and the word "merger". In Papers 4-6 SDL's SM2 Social Media Monitoring was used to collect merger-related social media posts that contain the company name of the acquirer and the company name of the target. SDL-SM2 is a database for historical social media content and provides the advantage to access social media data with respect to various social media types. All social media posts in the database are assigned to a specific social media type (e.g. blog, message board, microblog and social networking site) and to a specific social media platform (e.g. Facebook or Twitter). Both aforementioned social media data sources provide the full content (written text), the author, the source and the time of publication for all collected social media posts. 


\section{Main Results}

\section{Research Question 1}

Does the content of corporal disclosures give market participants reason to seek additional information elsewhere?

\section{a. Paper 1}

Table 2: Fact Sheet of Paper 1 (Zülch et al. 2011)

\begin{tabular}{|c|c|}
\hline Title & How "good" is bad News? Exploring Sentiments of Corporate Disclosures \\
\hline Authors & $\begin{array}{l}\text { Mirko Jan Zülch, mirko.zuelch@ wiwi.uni-goettingen.de* } \\
\text { Irina Alic, irina.alic@ wiwi.uni-goettingen.de* } \\
\text { Jan Muntermann, muntermann@ @iwi.uni-goettingen.de* } \\
\text { *University of Göttingen }\end{array}$ \\
\hline Outlet & $\begin{array}{l}\text { Proceedings of the 17th Americas Conference on Information Systems (AMCIS } \\
\text { 2011) }\end{array}$ \\
\hline
\end{tabular}

According to the research model (see section A.II.a), uncertainty due to a disclosed business event with respect to its event characteristics is hypothesized to be responsible for increased information needs of investors (see Figure 3).

Figure 3: Section of Research Model addressed by Paper 1

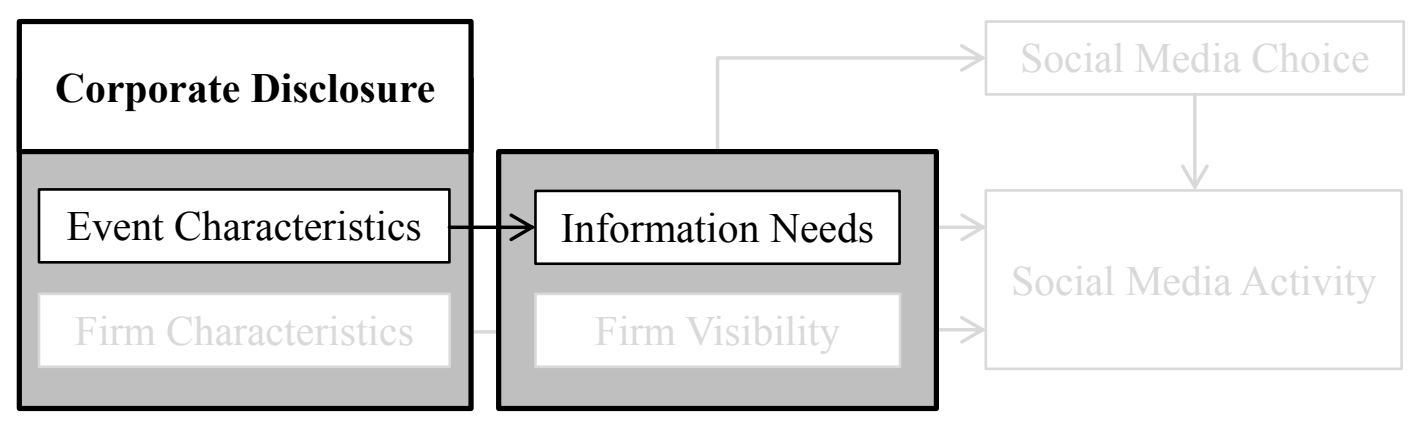

In this regard, corporate disclosures are part of the mechanisms that regulatory authorities have established in order to meet information needs of investors, and increase transparency between publicly listed companies and market participants regarding these disclosable events. In the case of the UK, companies are required to disclose any information that affect security prices and that is relevant to market participants regarding their investment decisions (EU Directive 2003; Financial Services Authority 2011). However, even with the existence of these mechanisms, companies have the incentive to favorably alter the content of the 
disclosed information (Verrecchia 1983). In this regard, Paper 1 represents an empirical study of corporate disclosures (FTSE-100 corporate disclosures); the study analyzes the content of these external reports with respect to the sentiment provided by the diction in order to investigate the former supposition. Two different word lists are used in order to determine the sentiment (positive or negative) of each document in the sample (see section C.I). The first word list categorizes words according to their general meaning and the second word list particularly categorizes words in a financial context (Stone et al. 1966; Loughran \& McDonald 2011). Finally, samples of corporate disclosures with either a corresponding positive or negative market reaction are being compared.

The study shows that corporate disclosures with a corresponding positive or negative market reaction express a positive sentiment. Surprisingly, the analysis did not reveal any evidence that the sentiment of each group is worse than the other. Additionally, all results remain the same when applying either of the previously mentioned word lists to determine the sentiment of documents in the sample. This indicates that disclosable events are reported too positively in general and, in particular, the content of negatively labeled corporate disclosures may have been altered in order to leave a more positive mark. Accordingly, this would undermine the regulatory claim to create transparency by providing reliable objective information to market participants.

With respect to $\mathbf{R Q} \mathbf{1}$, market participants cannot fully rely on the information that companies disclose to the public. This increases the need for additional information that is not provided by the respective company. Therefore, investors have to make an increased effort to reduce information asymmetries between companies and themselves in order to reduce uncertainty about the consequences and the evaluation of a disclosed business event. In consideration of the fact that financial information disseminated to the public itself is difficult to comprehend (Loughran \& McDonald 2014) and in conjunction with the results of Paper 1, market participants are well advised to make use of additional information sources to gather relevant and reliable information to satisfy their information needs in order to adequately respond to emerging events in the business domain. 


\section{Research Question 2}

How do merger announcements affect activity in social media?

\section{a. Paper 2}

Table 3: Fact Sheet of Paper 2 (Zülch 2013)

\begin{tabular}{|l|l|}
\hline Title & $\begin{array}{l}\text { "Will They Merge?” - Financial Event-Related Information Processing in Social } \\
\text { Media }\end{array}$ \\
\hline Authors & $\begin{array}{l}\text { Mirko Jan Zülch, mirko.zuelch@ wiwi.uni-goettingen.de* } \\
\text { *University of Göttingen }\end{array}$ \\
\hline Outlet & $\begin{array}{l}\text { Proceedings of the 19th Americas Conference on Information Systems (AMCIS } \\
\text { 2013) }\end{array}$ \\
\hline
\end{tabular}

The results of Paper 1 suggest that investors are well advised to seek information from additional information sources in order to reduce uncertainty regarding disclosed events. According to the research model (see section A.II.a) information needs of investors are hypothesized to be responsible for increased event-related activities in social media (social media activity). As stated previously stated, this phenomenon is investigated in the context of merger announcements for the remainder of this thesis. In the course of a merger attempt certain characteristics of the merger (e.g. whether it is a friendly or hostile takeover) are responsible for increased information needs of investors (see section B.I) which give them reason to engage in online information exchange via social media in order to reduce uncertainty (see Figure 4).

Figure 4: Section of Research Model addressed by Paper 2 and Paper 3

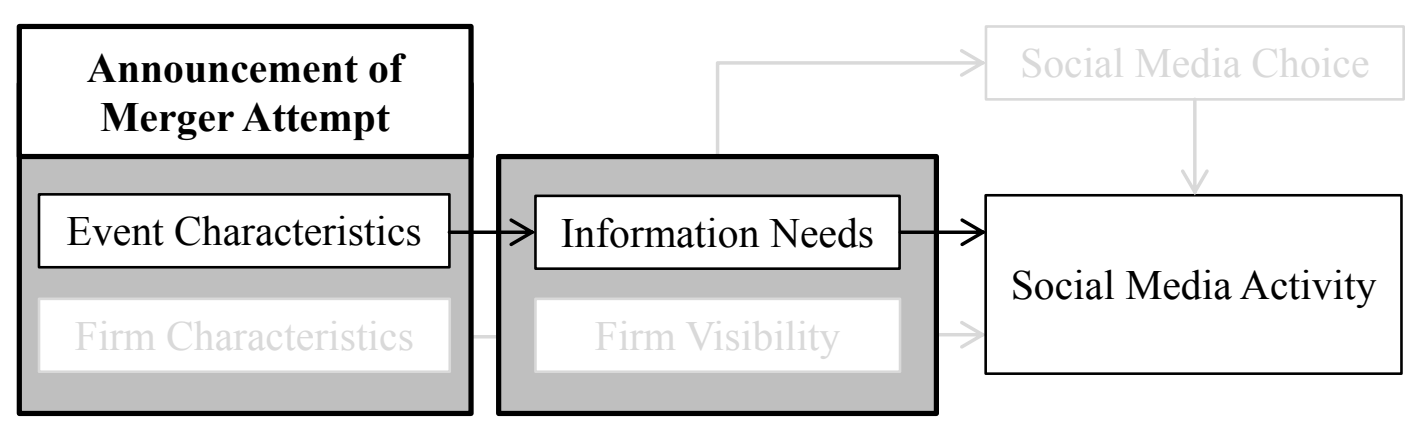

In general, it is uncertain if an announced merger attempt will be completed in the end (see section B.I). The probability of completion of merger attempts is related to the concept of state uncertainty (Milliken 1987; see section A.II.a) and represents one type of uncertainty 
experienced by investors in the context of merger announcements. In this regard, Paper 2 represents an empirical study that aims to explore the activity in social media driven by information needs of investors related to merger attempts' probability of completion. Using a data set of merger-related blog posts that were posted in the course of merger attempts, the study investigates if certain event characteristics that serve as proxies for mergers' likelihood of completion are related to an increased event-related social media activity. The results show that when merger attempts are not mutually agreed (hostile takeover), representing a proxy for a higher uncertainty about merger completion, social media activity on blogs is increased in terms of the amount of blog posts (i.e. the quantity of information exchanged), the length of blog posts (i.e. the quality of information exchanged with respect to the depth of information) and variety of content that is shared via blogs.

Related to RQ 2 and $\mathbf{C R Q}$, the results show that a higher uncertainty about the completion of a merger can be linked to an increased activity on blogs. Blogs meet information needs of investors by providing additional and more comprehensive information as well as multiple interpretations and opinions due to the ambiguity of the situation. This implies that information needs of investors are driving the event-related activity in social media in terms of variety, quantity and quality of UGC. In reference to Paper 1, these results underline that social media can serve as an additional information source for investors. In addition, these findings indicate that social media can play an important role in the sense-making process of investors. In this regard, social media support users in their information processing activities and facilitates the creation of a shared understanding concerning events in the business domain. 


\section{b. $\quad$ Paper 3}

Table 4: Fact Sheet of Paper 3 (Zülch 2013a)

\begin{tabular}{|l|l|}
\hline Title & An Empirical Analysis of Merger-Related Blog Posts \\
\hline Authors & $\begin{array}{l}\text { Mirko Jan Zülch, mirko.zuelch@ wiwi.uni-goettingen.de* } \\
\text { *University of Göttingen }\end{array}$ \\
\hline Outlet & Proceedings of the 26th Bled eConference (BLED 2013) \\
\hline
\end{tabular}

Paper 2 shows that the activity on blogs subsequent to merger announcements is driven by uncertainty about the final outcome of the events. Paper 3 represents an empirical study that provides an extension of these findings by analyzing if the uncertainty about merger completion is reflected in the textual content of blog posts. Accordingly, the study investigates if the previously hypothesized uncertainty (see section D.II.a ) is reflected in the sentiment of blog posts (see Figure 4).

Similar to Paper1, a computer-assisted approach for content analyses of textual data (Stone et al. 1966; see section C.I) is used in order to categorize words according to their meaning. In order to investigate if blog posts reflect the probability of merger completion, three measures are created in order to determine different types of sentiment of the content of blog posts that are either related to a failed or a successful merger attempt. The first measure reflects the sentiment of uncertainty or certainty; the second measure reflects the sentiment of success or failure; the third measure reflects the sentiment of optimism or pessimism. The analysis reveals that blog posts related to merger attempts that failed in the end reflect more uncertainty, less optimism and a lower sentiment of success compared to blog posts related to merger attempts that were completed in the end. With regard to RQ 2 and $\mathbf{C R Q}$, these findings complement the results of Paper 2 and show that the announcement of a merger not only affects the activity on blogs in terms of the variety of content, the quality and the quantity of information but in addition, uncertainty and other sentiments regarding the outcome of a business event are reflected by the UGC itself. 


\section{Research Question 3}

What are the influencing factors that drive activity in social media related to merger announcements?

\section{a. $\quad$ Paper 4}

Table 5: Fact Sheet of Paper 4 (Zülch et al. 2014a)

\begin{tabular}{|l|l|}
\hline Title & Drivers of Information Quantity: The Case of Merger-Acquisition Events \\
\hline Authors & $\begin{array}{l}\text { Mirko Jan Zülch, mirko.zuelch@wiwi.uni-goettingen.de* } \\
\text { Balaji Rajagopalan, bur14@psu.edu** } \\
\text { Jan Muntermann, muntermann@wiwi.uni-goettingen.de* }\end{array}$ \\
\hline Outlet & $\begin{array}{l}\text { *University of Göttingen } \\
\text { **Pennsylvania State University } \\
\text { (PACIS 2014) }\end{array}$ \\
\hline
\end{tabular}

Paper 2 introduces event characteristics that are related to the probability of merger completion as driving factors for merger-related social media activity. With regard to eventrelated social media activity, the research model (see section A.II.a) distinguishes between two categories of influencing factors: event characteristics related to information needs of investors and firm characteristics related to firm visibility. In this regard, Paper 4 represents an empirical study that investigates if these influencing factors drive the merger-related activity in social media (see Figure 5).

Figure 5: Section of Research Model addressed by Paper 4 and Paper 5

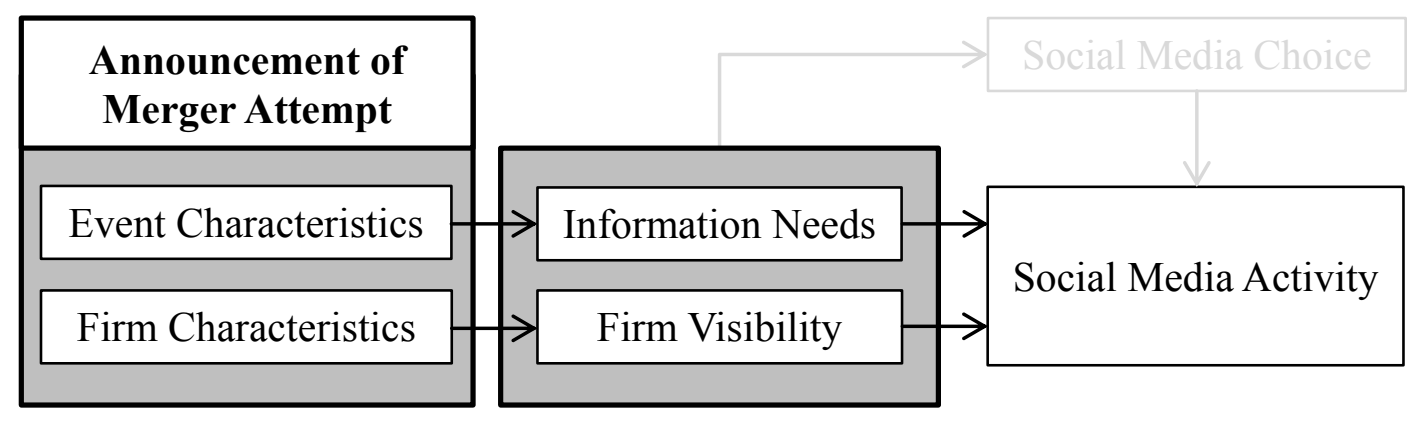

In contrast to previous papers above (see section D.II), Paper 4 examines event characteristics that are hypothesized to be responsible for information needs of investors with respect to several types of uncertainty regarding a merger attempt. For example, uncertainties 
related to expected synergistic gains of a merger or the financial risk of the transaction are hypothesized to incentivize investors to seek and exchange information via social media. In addition, Paper $\mathbf{4}$ proposes that firm characteristics related to the visibility of firms involved in a merger attempt are driving the event-related activity in social media as well. For example, mergers of companies that are bigger in size or that received a lot of media exposure prior to the announcement are hypothesized to create more awareness of the event among investors and other social media users (e.g. customers of involved companies). The study investigates the relationship between the two influencing factors above and the merger-related quantity of UGC (i.e. quantity of information exchanged) generated among various social media types in the transaction process. In contrast to previous studies above, Paper 4 uses an extensive dataset that includes a wide range of social media types and platforms: message boards, microblogs, blogs, social network sites, and video/photo sharing sites.

As for the event characteristics, the results show that the deal value of a merger attempt is driving the merger-related quantity of information exchanged via social media. In reference to section B.I, the transaction value is associated with the financial risk of a merger and investors have to evaluate if the expected synergistic value is worth the financial risk resulting from the merger. Therefore, from an uncertainty perspective, the deal value in the case of a merger announcement serves as a proxy for information needs of investors. Hence, investors exchange information via social media in order to reduce uncertainty about the financial risk of the deal. However, event characteristics related to the financial structure of a deal and future synergistic gains do not significantly drive social media activity in terms of information quantity.

As for firm characteristics, the results show that the media coverage that the acquiring firm received prior to the merger announcement is also driving the merger-related quantity of information exchanged via social media. For a company, receiving a lot of media attention in general will result in an increased firm visibility in the capital market as well as in the general public regarding their actions and business events. Therefore, an announced merger is more likely to catch the attention of social media users, resulting in an increased merger-related information exchange. In reference to results above, larger deal values of announced mergers are expected to draw more attention from the media, increasing the visibility of merger events which also translates into an increased UGC generation regarding the event. However, firm 
characteristics like firm size, the portion of shares that are in the hands of public investors and a firm's production focus on consumer goods do not significantly drive social media activity in terms of the quantity of information exchanged.

Related to RQ 3 and CRQ, Paper 4 shows that contextual factors of merger announcements are responsible for an increased quantity of information exchanged via social media with respect to various social media types. Furthermore, the previously defined constructs information needs of investors and firm visibility explain a significant percentage of the variation in the quantity of merger-related UGC. Both of the proposed influencing factors are significantly driving event-related social media activity in terms of information quantity. Event-specific factors of a business event (i.e. event characteristics) and firm-specific factors directly related to involved firms (i.e. firm characteristics) significantly affect the eventrelated activity in social media.

\section{b. Paper 5}

Table 6: Fact Sheet of Paper 5 (Zülch et al. 2014)

\begin{tabular}{|l|l|}
\hline Title & Drivers of Information Quality on Blogs: The Case of Business Events \\
\hline Authors & $\begin{array}{l}\text { Mirko Jan Zülch, mirko.zuelch@wiwi.uni-goettingen.de* } \\
\text { Jan Muntermann, muntermann@ @iwi.uni-goettingen.de* } \\
\text { Balaji Rajagopalan, bur14@psu.edu** }\end{array}$ \\
& $\begin{array}{l}* \text { University of Göttingen } \\
* * \text { Pennsylvania State University }\end{array}$ \\
Outlet & $\begin{array}{l}\text { Proceedings of the 20th Americas Conference on Information Systems (AMCIS } \\
\text { 2014) }\end{array}$ \\
\hline
\end{tabular}

Paper 4 establishes a link between previously proposed influencing factors and an increased amount of UGC (i.e. the quantity of information) exchanged via social media with regard to merger announcements. Nevertheless, not every social media post that is related to an event in the business domain is expected to be valuable or relevant for investors. Paper $\mathbf{2}$ and Paper $\mathbf{3}$ already establish a link between the content of merger-related blog posts and the uncertainty about the final outcome of merger attempts. The judgment whether social media serve as an adequate mean to reduce uncertainty of investors is dependent on the quality of content of information exchanged (i.e. information quality of UGC) (Lu \& Yang 2011); whereat information quality of UGC is related to the usefulness of UGC (Wang \& Strong 1996). 
Higher information quality of UGC reduces search costs of social media users and increases their task-related information processing efficiency ( $\mathrm{Gu}$ et al. 2007). While information quality is a well-established concept in the information science and information systems literature (Knight \& Burn 2005; Wang \& Strong 1996), little attention has been given to the assessment and influencing factors of information quality of social media posts. In contrast to other social media studies that adopted dimensions of information quality to assess information quality of UGC ( $\mathrm{Lu} \&$ Yang 2011), Paper 5 introduces a novel approach to quantitatively measure certain dimensions of information quality of social media posts within a financial context.

Paper 5 represents an empirical study that aims to explore how previous proposed influencing factors (i.e. event characteristics and firm characteristics) drive social media activity in terms of information quality of merger-related blog posts (see Figure 5). With regard to other social media types, blogs are not limited by length which helps to better uncover variations in the quality of UGC. Similar to Paper 4, in the operationalization process of Paper 5 several proxies are created for information needs of investors and a firm's visibility. Accordingly, the study investigates if these measures are related to dimensions of information quality of blog posts.

As a result, Paper 5 provides insights regarding RQ 3 and the central research questions of this thesis: Both of the proposed influencing factors (i.e. event and firm characteristics) affect certain dimensions of information quality of merger-related blog posts. Higher information needs of investors based on the financial structure of a transaction drive the information quality of blog posts. This indicates that more comprehensive information and opinions are shared due to ambiguity of the merger situation. Nevertheless, with regard to factors directly related to involved firms, the analysis provides only mixed results concerning the information quality of UGC. No clear relationship between firm visibility and included dimensions of information quality is detected. Paper 4 shows that factors regarding information needs of investors and firm visibility of the acquirer affect the quantity of merger-related UGC. However, the results of Paper 5 imply that the quality of content of information exchanged via social media related to events in the business domain is merely driven by information needs of investors. 


\section{Research Question 4}

How do merger announcements affect the choice of social media?

\section{a. Paper 6}

Table 7: Fact Sheet of Paper 6 (Zülch et al. 2014b)

\begin{tabular}{|l|l|}
\hline Title & $\begin{array}{l}\text { Social Media Choice: An Explorative Study on Information Transmission via } \\
\text { Social Media }\end{array}$ \\
\hline Authors & $\begin{array}{l}\text { Mirko Jan Zülch, mirko.zuelch@ wiwi.uni-goettingen.de* } \\
\text { Moritz Christian Weber, moweber@wiwi.uni-frankfurt.de** } \\
\text { Jan Muntermann, muntermann@wiwi.uni-goettingen.de* }\end{array}$ \\
$\begin{array}{l}* \text { University of Göttingen } \\
* * \text { Goethe University Frankfurt }\end{array}$ \\
\hline Outlet & Proceedings of the 27th Bled eConference (BLED 2014) \\
\hline
\end{tabular}

In the event of a merger announcement, investors face uncertainty about the consequences of the merger, they are confronted with the task to evaluate the transaction and the post-merger performance of the acquiring firm. Hence, task-related information needs give investors reason to exchange information online in order to reduce uncertainty. The analysis of Paper 4 reveals that investors/individuals choose various social media platforms to exchange information related to a merger. According to the research model (see section A.II.a), taskrelated communication processes regarding uncertainty reduction related to a business event are hypothesized to determine social media choice of investors. In this regard, Paper 6 represents an exploratory empirical study that aims to shed light on social media choice regarding the activity in social media subsequent to merger announcements. The study analyses the occurrence of UGC among several social media types (i.e. blogs, microblogs, social network sites, and message boards) in the course of merger attempts while accounting for event- and firm-related factors introduced in sections A.II.a and D.III (see Figure 6). 
Figure 6: Section of Research Model addressed by Paper 6

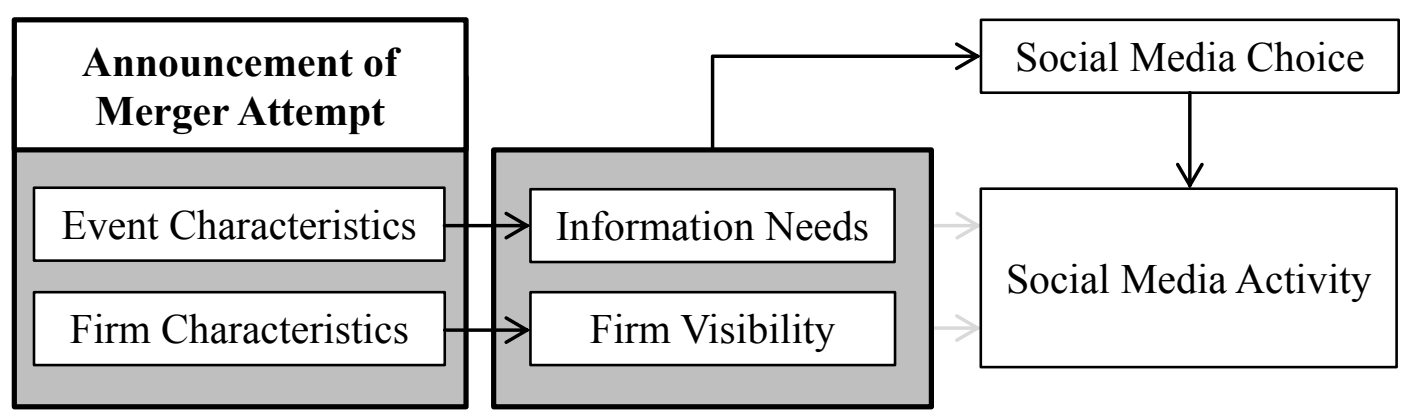

Paper 6 investigates the time of occurrence of social media posts in relation to the time of announcement of a merger, further referred to as posting lag of UGC. The analysis reveals that the probability of shorter posting lags of UGC is highest for microblogs, followed by social network sites, message boards, and finally blogs. This indicates that microblogs are more likely to be faster in providing merger-related content compared to the other social media types. In addition, all influencing factors that are accounted for significantly influence the posting lag of UGC. Overall, the results are mixed regarding the directions of the effect of information needs of investors and firms' visibility on posting lag of UGC.

With regard to RQ 4 and $\mathbf{C R Q}$, these results provide insights regarding social media choice following the announcement of business events and in particular in the course of merger attempts. In line with the expected length of UGC provided by each social media type; media capabilities of microblogs are responsible for a quicker reaction to merger announcements by social media users compared to social network sites. In general, message boards facilitate indepth discussions among investors ( $\mathrm{Gu}$ et al. 2007), whereas the content of blogs is associated with some kind of expertise by providing comprehensive information (Aggarwal \& Singh 2013). These characteristic correspond to the result that message boards and blogs are more likely to be slower in providing UGC compared microblogs and social network sites. This indicates that social media types are more likely to be used in succession than simultaneously and that different social media types are used at different task-related communication processes in the course of a merger attempt (Dennis et al. 2008). Therefore, successive choices of social media types shape the information exchange via social media following the announcement of a business event. Related to previous papers above, Paper $\mathbf{6}$ shows that both of the proposed influencing factors (i.e. event and firm characteristics) affect social media choice subsequent to the announcement of major business events. 


\section{E. Contributions}

\section{Contributions to Research}

This dissertation provides several contributions to social media research. With regard to the central research question, this dissertation improves the understanding of how an announced business event affects the event-related activity in social media and the choice of social media. A theoretical model is presented that provides guidance and explanations regarding the influencing factors that affect the activity in social media related to a business event. In this regard, this dissertation extends previous research that is concerned with activities in social media with regard to the influencers of UGC generation. As stated in section B.II, prior research is mainly concerned with motives that affect information contribution behavior of social media users and how the relationships among social media users affect information contribution behavior. In contrast to these studies, this dissertation sheds light on the influence of contextual factors (i.e. event characteristics and firm characteristics), introduced by Paper 4, on the activity in social media in the context of business events and provides evidence that these factors are associated with the event-related activity in social media. The research presented in this dissertation provides evidence that both event characteristics related to information needs of investors as well as firm characteristics related to firm visibility are able to explain several aspects of the event-related activity in social media. Another contribution is that Papers 2-6 investigate the influencers of event-related UGC in a context (i.e. merger announcements) that is significantly different from research contexts investigated in previous research.

With regard to information asymmetry between companies and investors, Paper 1 makes another case on why investors can not only rely on information companies release in order to assess the implications of disclosed events. The other research presented shows that eventrelated uncertainties explain event-related online information processing and sense-making activities of investors. In this regard, Paper 2 and Papers 4-5 introduce contextual proxies for information needs of investors based on event characteristics with respect to different types of uncertainty related to the event (i.e. merger announcements). Papers 2 and Papers 4-5 provide evidence that information needs of investors due to uncertainties related to characteristics of a business event drive social media activity in terms of quantity and quality 
of UGC. In addition, Paper 2 shows that even a specific type of uncertainty (i.e. state uncertainty) can be linked to activities in social media. The results of Paper $\mathbf{4}$ show that the visibility of a company that is associated with a business event drives event-related online chatter (i.e. quantity of UGC exchanged), however Paper 2 and Paper 5 show that a meaningful information exchange (i.e. the exchange of quality content) among social media users is driven by investors' need for useful information to reduce uncertainty about the implications of a disclosed event.

Paper 5 contributes to the IS research stream concerned with information quality by introducing a novel approach to assess information quality of UGC. While previous research addressed the question of what influences quality information contribution by means of survey research (Lu \& Yang 2011), Paper 5 introduces a new approach to quantitatively measure established dimensions of information quality of UGC. This approach considers the financial context with regard to the contextual relevance of the content of information exchanged, which can also be adopted and applied to other contexts. This enables the analysis of the quality of UGC on larger samples in a shorter time frame.

An extensive literature stream in the area of finance is concerned with the influence and predictive power of UGC in the business domain (Luo et al. 2013). The explanatory model presented in this dissertation provides explanations why UGC possesses predictive power in certain scenarios with respect to business events (Shmueli 2010). Furthermore, Paper 4 and Paper 6 provide evidence that all dominant text-based social media types are extensively used by investors as a mean to discuss events in the business domain and to exchange eventrelated information. Therefore, predictions based on UGC can be enhanced by including multiple social media types. This provides support for the approach of Yu et al. (2013) to include several social media types in order to make predictions with regard to capital market outcomes.

With regard to IS and finance research that is considered with the impact of the sentiment of UGC on the capital market reaction, Paper 3 provides a novel approach to create dictionarybased polarity measures with regard to different types of sentiment of UGC (i.e. uncertainty or certainty, and success or failure). Furthermore, the results of Paper 3 provide indications that these kinds of measures can be applied to research that aims to exploit the predictive power of UGC with respect to the outcome of events and phenomena in the business domain. 
Finally, Paper 6 contributes to IS research concerned with media choice (Dennis et al. 2008) by providing evidence that the choice of social media types by social media users determine the task-related communication processes. Different social media types are used at different times following the announcement of business events. Paper 6 indicates that certain media capabilities of social media types are responsible for the successive use of different social media types with respect to information-processing activities of social media users.

\section{Practical Implications}

The research presented in this dissertation thesis bears some important practical implications with regard to social media strategies of businesses. As stated in section A.I, business benefit from social media exposure related to business events. In addition, social media exposure creates unidirectional dissemination of information in the form of eWoM, brand awareness and reputation, knowledge about customers and their demands, feedback and new insights, and has a direct impact on sales (Chau \& Xu 2012; Luo et al. 2013; Hu \& Schlagwein 2013). Therefore, for businesses that aim at leveraging the benefits of social media exposure with regard to their actions and business events, it is important to acknowledge that higher levels of event-related online chatter is not merely dependent on the characteristics of these events but firms' visibility plays an equally important role in achieving the desired social media exposure (Paper 4). For example, a constant news media exposure that increases a firm's visibility is nothing that can be achieved in the short term. Therefore, companies have to design long-term strategies to increase their firm's visibility in the capital market as well as in the general public in order to maximize social media exposure with regard to their actions and business events.

Furthermore, this dissertation thesis bears some important practical implications with regard to social media intelligence which "aims to derive actionable information from social media in context-rich application settings, develop corresponding decision-making or decisionaiding frameworks, and provide architectural designs and solution frameworks for existing and new applications that can benefit from the "wisdom of crowds" through the Web" (Zeng et al. 2010, p. 15). Social media intelligence includes the gathering and analysis of UGC (social media analytics) as well as constant monitoring of social media activities (social media monitoring) (Zeng et al. 2010; Luo et al. 2013; Chau \& Xu 2012). Companies that want to 
monitor activities in social media for business intelligence purposes and want to design effective social media strategies have to consider that the early social media "buzz" with respect to business events is more likely to occur on microblogs and social networking sites. A more in-depth discussion regarding these events is more likely to occur on message boards and blogs at later times (Paper 6). In addition, managers should closely monitor the activities in social media. Increased levels of social media activity in terms of quantity and quality of UGC and the expression of uncertainty of social media users can serve as an indicator that stakeholders are uncertain about the expected benefits and the motives of managers' decisions (Papers 2-5). This can provide valuable feedback for managers to rethink their decisions or to improve their way of communicating the reasons behind their decisions and actions, for example by providing additional information. In the case of political involvement in merger transactions this could be crucial for companies to shape the public opinion in their favor. In addition, searching for increased activities in social media can support companies to identify and monitor significant events and actions of their competitors.

Finally, the research presented provides evidence that investors and traders should look closely at increased activities in social media related to companies (Paper 2 and Paper 4). This can provide indications for investors and traders that an important event has occurred they have not noticed before or that investment opportunities they aim to capitalize on are also being discussed by other investors.

\section{F. Limitations and Future Research}

The research presented in this dissertation thesis contains several limitations and provides avenues for future research. Firstly, the influence of business events on the event-related activity in social media was investigated in the context of merger announcements; future research should aim to confirm the results and the applicability of the presented research model to other events in the business domain (e.g. product and strategic measures announcements or earnings announcements).

Secondly, with regard to Papers 4-5, not all variables were significant in explaining social media activity. There is room for improvements with regard to the operationalization of information needs based on event characteristics of mergers and firm visibility based on firm 
characteristics of involved companies. For example, the amount of media coverage that mergers receive during the transaction process could provide indications if UGC merely repeats or responds to what was already known from news reports (Antweiler \& Frank 2004), as well as if information needs of investors are already met by the traditional news media. In addition, the analyst following of companies could be used in order to better grasp the visibility of companies in the capital market (Baker et al. 1999). With regard to Paper 2, reports (e.g. news reports) on the expected decision of antitrust authorities concerning the regulatory approval of a merger could be used to operationalize uncertainty related to merger attempts' probability of completion. Finally, the operationalization processes of Paper $\mathbf{2}$ and Papers 4-6 include several binary variables related to information needs and firm visibility. The binary coding may not uncover in detail all dynamics between independent variables and the respective social media activity.

Thirdly, the analysis of Papers 3 regarding the sentiment of UGC and the analysis of Paper 5 regarding the information quality of UGC are limited to UGC exchanged on blogs. Future research should take other text-based social media types (e.g. message boards, social networking sites and microblogs) into account in order to verify the findings of these papers. In addition, Papers 2-3, and Paper 5 applied a dictionary-based approach in order to categorize words according to their meaning. Given the economic and financial context of these studies, the analyses could be improved by creating or applying dictionaries that are more appropriate for the context in order to avoid misclassification errors of words in mergerrelated UGC (Loughran \& McDonald 2011).

Fourthly, Papers 2-6 investigated the post-merger announcement social media activity. By means of event study analysis future research should investigate how much social media activity related to a company increases compared to times where no significant event is announced by the company. In addition, Papers 2-6 do not take different stages of the merger process (e.g. the shareholder voting or the regulatory approval) into account. Investors' uncertainty about the merger may vary depending on the anticipated and actual outcome of these stages. Following Aggarwal \& Singh (2013), future research should treat merger attempts as a multi-stage process in order to improve our understanding of influencers of merger-related social media activity. 
Fifthly, similar to Wysocki (1998) and Antweiler \& Frank (2004), future research should investigate if the event-related information exchange via social media has an influence on the decision-making of investors by analyzing if the event-related social media activity can predict capital market outcomes (e.g. stock prices or trading volume) following the merger announcement with respect to the stocks of merging companies.

Finally, Paper 6 indicates that certain media capabilities of social media are responsible for the successive use of different social media types following the announcement of a business event. Prior studies concerned with the classifications of social media types are limited in providing an understanding about the different information processing capabilities of social media types because they do not develop a classification at the construct level (Kaplan \& Haenlein 2010; Kietzmann et al. 2011). Future research should aim at developing a taxonomy of social media types in order to investigate more deeply the choice and use of social media by taking into account their distinct information processing capabilities (Nickerson et al. 2013). 


\section{G. Published Research Papers}

\section{Paper 1}

Table 8: Fact Sheet of Paper 1a (Zülch et al. 2011)

\begin{tabular}{|l|l|}
\hline Title & How “good" is bad News? Exploring Sentiments of Corporate Disclosures \\
\hline Authors & $\begin{array}{l}\text { Mirko Jan Zülch, mirko.zuelch@ @iwi.uni-goettingen.de* } \\
\text { Irina Alic, irina.alic @ wiwi.uni-goettingen.de* } \\
\text { Jan Muntermann, muntermann @ wiwi.uni-goettingen.de* }\end{array}$ \\
\hline Outlet & $\begin{array}{l}\text { Proceedings of the 17th Americas Conference on Information Systems (AMCIS } \\
\text { 2011) }\end{array}$ \\
\hline Abstract & $\begin{array}{l}\text { To satisfy legal requirements, listed companies are required to continuously } \\
\text { publish a wide range of disclosures and reports. Regulatory authorities such as } \\
\text { the SEC in the US or the FSA in the UK have developed a complex set of rules } \\
\text { and regulations that aim at expanding transparency of capital markets. } \\
\text { Therefore, corporations hire professional editorial teams, often being supported } \\
\text { by financial service communication consultancies. While the regulatory } \\
\text { objective is to increase transparency, the management has an inherent } \\
\text { motivation to give the reports a positive spin. We aim to explore this conflict by } \\
\text { analyzing the sentiment of corporate disclosures and to compare this tone with } \\
\text { the price reactions following the disclosures' publication. On the basis of an } \\
\text { empirical analysis of intraday stock price reactions and word lists which } \\
\text { provide means to assess the tone of documents, our results provide evidence } \\
\text { that corporates follow a strategy to positively adjust their external reporting. }\end{array}$ \\
\hline Keywords & $\begin{array}{l}\text { Transparency Legislation, Financial Reporting, Corporate Disclosures, } \\
\text { Sentiment }\end{array}$ \\
\hline
\end{tabular}

\section{a. Introduction}

Since the national regulators such as the SEC in the US or the FSA in the UK have the objective to maintain confidence in the financial systems, one central objective is market transparency. To comply with the corresponding regulatory legislation of the financial service industry, listed corporations have to report a wide range of financial transactions and reports or other relevant business events such as changes in the management board that have the potential to affect a firm's value. This paper explores such regulatory driven corporate disclosures with an analysis of sentiment, a field that has attracted much attention in the field 
of information systems research in recent years. The motivation of our research is based on the duality of motivation behind such disclosures: On the one hand side, the management needs to comply with regulations and therefore has to assure the report of all relevant cases. On the other hand, the management's major objective is to increase a firm' value, and therefore it will mitigate any effects that could negatively affect this value. Further, there exist a number of consultancy firms providing advice regarding financial service communication in this field. As the corporate disclosures have to cover both positive and negative facts, we assume that there exists a motivation to choose wordings that will make readers feel positive about the statements at first sight. We aim to explore these two facets of external reporting on business events in the following.

The remainder of our paper is as follows. In the next section, we provide a review on relevant literature regarding financial reporting, accounting information systems and the regulatory background. Further, we provide insights into the relevant literature on sentiment and its analysis. Then, we present our study setup, which comprises a description of our dataset and our research approach. In the subsequent section, we formulate our research hypotheses and present our empirical results. We finally conclude with a summary of our findings, the limitations of our research and potential future research directions.

\section{b. Literature Review}

\section{b.1 Financial Reporting and Accounting Information Systems}

The avoidance of information asymmetries represents an important issue in the financial sector. Especially capital markets are dependent on reliable information in order to be efficient. Key elements for information provision to the financial domain are corporate disclosures. With respect to corporate disclosures, which represent information that is publicly available, capital markets are tending to be semi-strong form efficient (Fama 1970), meaning all public information is reflected in securities prices. Financial reporting in general and especially corporate disclosures enable companies' management to reduce information asymmetries between themselves and investors.

Healy \& Palepu (2001) describe the role of disclosures in capital markets with respect to two issues which market participants have to deal with. Information disclosure helps to avoid breakdown of markets, as described by Akerlof (1970), because it can resolve adverse selection problems between investors and entrepreneurs. The existence of "information 
problems" does explain the important role of information and financial intermediaries, like rating agencies, financial analysts and banks, in order to overcome managers' information advantage. They also argue that information disclosure is important for monitoring managers in a moral hazard setup, as described by Jensen \& Meckling (1976), between investors and managers. Thus, the requirement for continuous revealing relevant information by managers to their investors is a solution to the "agency problem".

Besides the need for information available to investors in order to achieve the above stated avoidance of information asymmetries, the relation between financial reporting and financial market reactions is addressed by capital market research. It is examined if the published information is relevant for investors. A variety of studies show that regulated financial reports provide pertinent information for market participants in order to predict future investor cash flows. An overall substantial review of the corresponding research topics is given by Kothari (2001).

Further, our study is associated with accounting information systems (AIS) research. AIS, as specialized subsystems of information systems (IS), emerged from the application of information and communication technology in the accounting domain (Sutton 1996). Therefore, the connection of the IS domain and accounting is established by AIS research (Poston \& Grabski 2000). Samuels \& Steinbart (2002) identified eight major research themes addressed by AIS research: organization and management of an IS; internal control and auditing; judgment and decision making; databases; expert systems, artificial intelligence, and decision aids; general AIS frameworks; the accounting and consulting profession; educational issues. These topics have been expanded by topics like the effects of decision aids on users, analysts' forecasts and investments in information technology in recent years (Ferguson \& Seow 2011). In general, the purpose of AIS is to process and report information with regard to the financial aspect of business events (Gelinas \& Dull 2008). Since our study is associated with the reporting of such business events and the analyses of sentiments of related reporting (in our case corporate disclosures), we believe our study contributes to the understanding regarding the utilization of such reported information.

\section{b.2 Regulatory Background}

In almost all economies there exist financial regulating authority institutions with various jurisdictions. In the USA this is the Securities and Exchange Commission (SEC). SEC was 
established in 1934 and was given enforcement authority. In the UK, the Financial Service Authority (FSA) is an independent non-governmental financial supervisory authority. It has very broad statutory powers and sanctioning options (Busch 2002).

The FSA is responsible for maintaining market confidence in the UK financial system, the supervision of financial institutions and enforcement of regulatory rules. One of the main goals of the FSA is to identify market abuse and counteract financial crime (Busch 2002). A survey of Monteiro et al. (2007) shows a significant reduction of insider trading from $19.6 \%$ to $2 \%$ for the FTSE 350 listed companies. From a perspective, the FSA is a non-profit society and is independent of the government supervisory body. It is empowered to make regulations and to set legally binding arrangements and sanctions.

The FSA regulated companies are required to meet the standards set out by the FSA in order to monitor and regulate their business. Companies are required to publish all inside information relevant to the market in a timely manner (EU directive 2003/6/EC). Inside information is any information which can be used by investors for investment decisions, and which would have an effect on security prices (Financial Services Authority 2011).

\section{b.3 Sentiment Analysis}

Sentiments in general represent opinions, ideas or beliefs based on emotions. They can also describe a shared belief or opinion among a group of individuals.

In the financial context, sentiment refers to general beliefs among investors or financial analysts on the behavior of capital markets with respect to external factors. In this sense, sentiments are also known as market sentiments. Market sentiment represents a general consensus of a group of investors whether markets are either bullish or bearish. This prevailing attitude can give an indication to the anticipated price movements in financial markets.

In this paper, we follow a definition of Pang \& Lee (2008) and Pang et al. (2002), who state that sentiment analysis aims to determine the tone and the underlying information in source materials. Extracting sentiment from textual documents is a severe semantic problem. Recent studies tried to measure the mood of certain groups of individuals or investors in the financial domain with a variety of technical and statistical methods. 
A relatively new subject to this topic is the extraction of sentiments from Web sources, like message boards, blogs and all kinds of user generated contents, in order to grasp the opinion of communities about a certain subject. Antweiler \& Frank (2004) investigated the influence of financial message boards (in this case Yahoo! Finance and Raging Bull) on the movement of stock markets (concerning companies in the Dow Jones Industrial Average and Dow Jones Internet Index). They were able to provide evidence that internet message boards can give an indication for predicting market volatility and overall stock market movements. Further Studies were also able to analyze sentiments expressed on the internet and link them to stock market reactions. Bollen et al. (2011) investigated if collective mood states of the public are linked to development of the economy. In fact, they were able to find a correlation between the public mood, derived from a collection of tweets posted on twitter.com, and the following Dow Jones Industrial Average index values three to four days later. Besides analyzing sentiment of text documents or messages of virtual communities, the community network themselves are also in the focus of recent studies, evaluating the quality of investor communities (Gu et al. 2007). Another study also examined the automated extraction of sentiment from stock message boards and compared the performance of several classifiers for the classification task (Das \& Chen 2007). The classification task is to identify the sentiment (buy, hold, sell) of the messages posted by the authors or investors to the respective stock. From a methodological perspective, they applied additional databases for improving classification algorithms. An English dictionary and a hand-picked collection of words of the finance domain were applied. Because messages on internet stock message boards are highly ambiguous, meaning the classification cannot be easily conducted, the authors aimed at reducing the noise of their sample. They used the General Inquirer, a computer-assisted word categorization from Harvard University (categorized word lists are also available in the Harvard Psychosociological Dictionary), in order count the optimistic and pessimistic words in their sample of messages. By determining an optimism score for each message, they filtered messages by ambiguity which drastically improved classifiers' performance. In addition, using their developed methodology they generated a sentiment index by accumulating sentiment from board messages of tech-sector stocks and examined its relationship to the Morgan Stanley High-Tech Index. Their findings provide evidence that the stock index is related to the lagged sentiment value, but only a weak relationship was detected. 


\section{c. Study Setup}

\section{c.1 Dataset Description}

In the following, we make use of three different kinds of data sources. First, we have collected a sample of corporate disclosures that have been published in the UK. Second, in order to positively or negatively label these disclosures, we collected stock price series that provide a basis to assess capital market reactions following their publication. Third, we make use of two word lists that provide guidance with regard to assessing the tone of the disclosures.

\section{c.1.1 Corporate disclosures}

In this study, we focus on FTSE-100 corporate disclosures, which were published via Regulatory News Services (RNS). RNS is a financial communication channel for regulatory news announcements in the UK. Our collected sample of corporate disclosures was published between November 2007 and November 2009 during trading hours of the London Stock Exchange.

In total, our dataset comprises 4360 disclosures. Company disclosures published via RNS have the following data structure: company name, TIDM (company ID), headline, publication date and the text of the concrete disclosures.

\section{c.1.2 Stock Price Series}

In order to label corporate disclosures according to their price effect, required intraday price series of the corresponding stocks have been collected. The dataset shows the following formal setup relevant for our experiments: Instrument identifier, time stamps and stock prices exact to the second.

\section{c.1.3 Word Lists}

Besides corporate disclosures and the corresponding stock returns we make use of two word lists. All lists contain words which are considered as negative and positive in different terms. These lists provide word classifications for gauging tone or sentiments in textual documents. The first word list consists of the TAGNeg list (see http://www.webuse.umd.edu:9090/tags/TAGNeg.html), containing words with a general negative meaning, and the TAGPos list 
(see http://www.webuse.umd.edu:9090/tags/TAGPos.html), containing words with a general positive meaning. These two lists are part of the Harvard Psychosociological Dictionary (H44), representing sentiments of words and goes back to Stone \& Hunt (1963). The Harvard Psychosociological Dictionary consists of several word lists classified in categories of meaning in a more general psychosociological manner. The TAGNeg list used in our analysis contains 2006 words and the TAGPos list contains 1636 words.

Our second word list (FIN) was derived from Loughran \& McDonald (2011). They created a dictionary of words in order to create alternative word lists which reflect more accurately the tone in the financial context compared to the Harvard word lists. Loughran and McDonald's derived word lists through textual analysis on a sample of Form 10-Ks (annual reports) published between 1994 and 2008. They used a word categorization method ("bag of words") in order to create the respective vectors of words and word counts. Along their analysis they created six word lists for different word classifications in financial text: negative, positive, uncertainty, litigious, strong modal and weak modal. For our analysis we consider the negative and positive word lists only (FIN-Neg and FIN-Pos). The FIN-Neg word list (words which have a negative meaning in the financial domain) contains 2337 words and the FIN-Pos word list (words which have a positive meaning in the financial domain) contains 353 words. Both lists are considered to better reflect tone in financial text. The authors were able to provide evidence that the FIN-Neg is more related to excess returns following the Form 10-K filing date compared to the Harvard word lists.

\section{c.2 Research Approach}

Most responses to published corporate disclosure usually take place within the first 15 minutes subsequent to its release (Patell \& Wolfson 1981). Furthermore, Gosnell et al. (1996) determined a rapid change of stock prices within 15 minutes after the release of positive disclosures. In addition Muntermann \& Güttler (2007) detected significant abnormal price effects within 15 to 30 minutes following the publication dates. Further, they found that the market adjusts more quickly to positive disclosures than to negative disclosures.

To assess the impact of corporate disclosures, we first labeled the disclosures positive or negative according to the price effect of the stock price 15 minutes subsequent to the publication date. Therefore, we used the stock price $p_{0}$ at the publication date of the disclosure and price $p_{1}$, which has been observed 15 minutes later. 
The publication date of disclosures was given in a format exact to the minute (hh:mm) and price data was given in a form exact to the second (hh:mm:ss). For each disclosure we then calculated discrete returns as:

$r=\frac{p_{0}-p_{1}}{p_{0}}$

Given the return measure, a company disclosure is labeled as

- positive if $r>0$

or

- negative if $r<0$

Figure 7 shows the return distribution of the calculated stock returns and the labeling of our dataset.

Figure 7: Histogram of Stock Returns

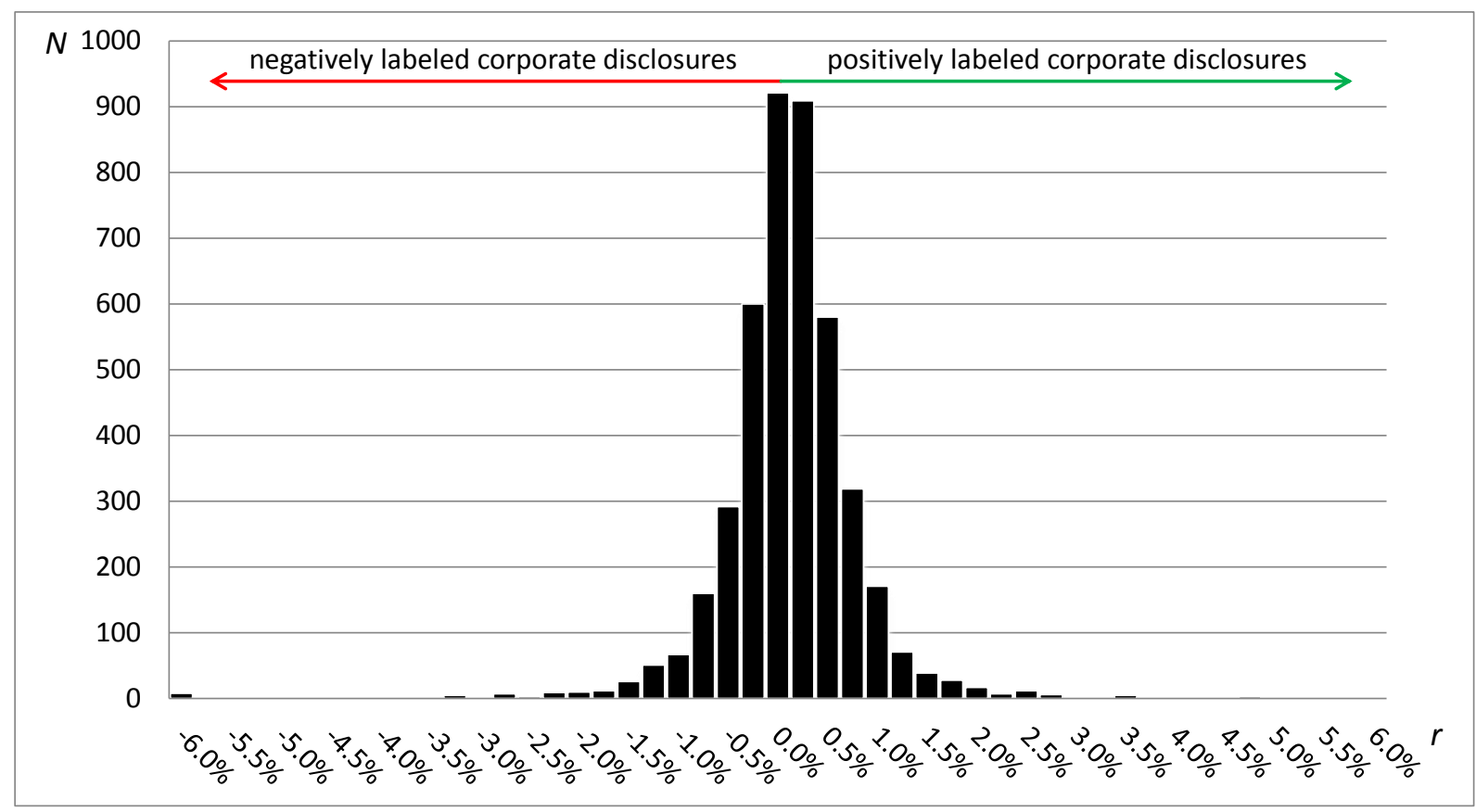

Our labeling approach provides 2183 positive labeled corporate disclosures and 2177 negative labeled disclosures.

\section{d. Research Hypotheses and Empirical Results}

In our research, we explore sentiments of corporate disclosures given the reaction of the capital market to their provided information content. Given the positive or negative price 
reaction of the corresponding stocks, we aim to analyze the role of subjective information that can be observed in regulatory-driven disclosures that should objectively report on business events in order to comply with market transparency legislation and the corresponding regulatory obligations. Since the analyzed RNS disclosures report on market-relevant events such as operational updates, financial statements and corporate actions that all can result in positive or negative market reactions, we hypothesize that positive (negative) price effects are driven by positive (negative) sentiment of the corporate disclosure. We derive this hypothesis from the word lists used in our study that for example list words such as "achievement", "gain" and "improvement" in the positive category, while words such as "bankruptcy", "losses" and "penalty" are listed in the negative category. If a disclosure contains more (less) such positive words (\#pos) than negative words (\#neg), we refer to a positive (negative) sentiment in the following.

Given the labeling of corporate disclosures being based on the price reaction of the capital markets, we first explore positively labeled disclosures, i.e. those for which we observed a positive price reaction on the capital market. We consequently formulate our first research hypothesis that aims at exploring the sentiment of disclosures that resulted in positive price reactions.

\section{H1: Positively labeled corporate disclosures show a positive sentiment.}

Statistically, $\mathrm{H} 1$ is explored by the following null hypotheses $\mathrm{H} 1_{0}$, using the Harvard (H4-4) and Financial (FIN) word lists, which we aim to reject in the following. Since the word lists have a different ratio of positive and negative words (H4-4: 1:1.23; FIN 1:6.62), this test is rather ambitious. We therefore further adjusted our observation numbers by these factors (see negative (adj.)).

$\mathrm{H} 1_{0} \mu(\#$ neg; poslabeled $) \geq \mu(\#$ pos; poslabeled $)$ vs. $\mathrm{H}_{\mathrm{A}} \mu(\#$ neg; poslabeled $)<\mu(\#$ pos; poslabeled) 
Sample characteristics and test results are given in the following Table 9:

Table 9: Positively labeled Disclosures Sentiment $(N=2183)$

\begin{tabular}{|c|c|c|c|c|c|c|}
\hline \multirow[b]{2}{*}{ Words } & \multicolumn{3}{|c|}{ Number of words from H4-4 list } & \multicolumn{3}{|c|}{ Number of words from FIN list } \\
\hline & Mean & Median & Std. dev. & Mean & Median & Std. dev. \\
\hline \#neg (adj.) & $7.74(6.31)$ & 6 & $10.73(8.75)$ & $2.90(0.44)$ & 2 & $9.86(1.49)$ \\
\hline \#pos & 20.47 & 18 & 26.23 & 1.38 & 0 & 7.02 \\
\hline$t$-Value ( $F$-Value) & & $23.93 * * *$ & $(8.97 * * *)$ & & $6.13 * * *$ & $(22.20 * * *)$ \\
\hline
\end{tabular}

For the hypotheses test, we applied an unequal variances $t$-test for comparing the means of two independent samples since the corresponding $F$-tests on the equality of the two sample variances have been rejected (Weiers 2005). The results presented above corroborate hypothesis $\mathrm{H} 1$, since the test statistics provide strong evidence to infer that positively labeled disclosures contain more positive tone words than negative words, i.e. the show a positive sentiment. We also detected statistical significance for the non-adjusted sample on a $1 \%$ level of significance.

After exploring the sentiment of positively labeled disclosures, we explore the sample of negatively labeled disclosures. Given the argument that negatively labeled disclosures should have a negative tone, we formulate the corresponding hypothesis $\mathrm{H} 2$ :

\section{H2: Negatively labeled corporate disclosures show a negative sentiment.}

Statistically, $\mathrm{H} 2$ is explored by the following null hypotheses, which we again aim to reject in the following.

$\mathrm{H} 2_{0} \mu(\#$ neg; neglabeled $) \leq \mu(\#$ pos; neglabeled $)$ vs. $\mathrm{H} 2_{\mathrm{A}} \mu(\#$ neg; neglabeled $)>\mu(\#$ pos; neglabeled)

The following Table 10 shows descriptive sample characteristics and the statistical test result.

Table 10: Negatively labeled Disclosures Sentiment $(N=2177)$

\begin{tabular}{|c|c|c|c|c|c|c|}
\hline \multirow[b]{2}{*}{ Words } & \multicolumn{3}{|c|}{ Number of words from H4-4 list } & \multicolumn{3}{|c|}{ Number of words from FIN list } \\
\hline & Mean & Median & Std. dev. & Mean & Median & Std. dev. \\
\hline \#neg (adj.) & \multicolumn{2}{|c|}{$7.98(6.50) 6$} & $12.64(10.31)$ & $2.83(0.42)$ & 2 & $7.21(1.09)$ \\
\hline \#pos & 20.52 & 18 & 25.66 & 1.27 & 0 & 6.44 \\
\hline$t$-Value $(F$-Value $)$ & & $23.63 * * *$ & $(6.19 * * *)$ & & $6.06 * * *$ & $(34.95 * * *)$ \\
\hline
\end{tabular}

*** indicates $1 \%$ level of significance 
As the analysis is biased by the ratio of positive and positive word within the word lists (Harvard H4: 1:1.23; FIN list 1:6.62), we also adjusted the observations by these factors (negative (adj.)). High statistical significance has been found by an unequal variances $t$-test, but in contrast to $\mathrm{H} 2$, we detect strong evidence that also negatively labeled disclosures show a positive sentiment. This is remarkable as disclosures resulting in a negative market reaction come with a positive tone authored by the corporates of the disclosures.

Finally, we aim to compare the sentiment of negatively and positively labeled disclosures. To do so, we first calculated the ratio of negative / positive words (using the H4-4 and FIN lists) for each disclosure. Ratios have also been adjusted by the ratios of positive and negative words in the word list and calculated only if \#pos and \#neg were unequal zero.

Given the argument that negatively labeled disclosures should have a negative tone, we formulate the corresponding hypothesis $\mathrm{H} 2$ :

H3: The sentiment of negatively labeled disclosures is worse than the sentiment of positively labeled disclosures.

$\mathrm{H} 3$ is addressed by the following null hypotheses:

$\mathrm{H} 3_{0} \mu($ neg/pos ratio; neglabeled $) \leq \mu($ neg/pos ratio;poslabeled $)$ vs.

$\mathrm{H} 3_{\mathrm{A}} \mu($ neg/pos ratio; neglabeled $)>\mu($ neg/pos ratio;poslabeled $)$

The following Table 11 shows sample characteristics and our statistical test results.

Table 11: Sentiment Comparison of negatively and positively labeled Disclosures

\begin{tabular}{|c|c|c|c|c|c|c|c|c|}
\hline \multirow[b]{2}{*}{ Labeling } & \multicolumn{4}{|c|}{ \#neg/\#pos ratio from H4-4 list } & \multicolumn{4}{|c|}{ \#neg/\#pos ratio from FIN list } \\
\hline & Mean & Median & Std. dev. & $\mathrm{N}$ & Mean & Median & Std. dev. & $\mathrm{N}$ \\
\hline Negative & 0.34 & 0,27 & 0.25 & 2175 & 0.36 & 0.18 & 0.42 & 255 \\
\hline Positive & 0.33 & 0.27 & 0.23 & 2181 & 0.37 & 0.16 & 0.48 & 292 \\
\hline$t$-Value ( $F$-Value) & & 0.82 & $(1.14 * * *)$ & & & 0.41 & $(1.36 * *)$ & \\
\hline
\end{tabular}

The number of observations $(\mathrm{N})$ differs from the total number of disclosures since not all texts contained one positive and one negative word from the two H4-4 and FIN word lists. This becomes especially relevant for the FIN list ratio, because it's total word count is much smaller compared to the H4-4 list. 
While the observed means and medians are much smaller than 1 (which would indicate a balance of positive and negative words), the actual number provide some evidence that all samples contain more positive than negative words of the word lists. One first surprising finding is that for both samples (i.e. for both the H4-4 and the FIN word lists), we observed quite similar sample characteristics. Given these findings and the test statistics we calculated test statistics for comparing the means of the two samples. We do not find any evidence that sentiment of negatively labeled disclosures is worse than the sentiment of positively labeled disclosures.

\section{e. Summary and Conclusion}

In this paper we have explored the sentiment of corporate disclosures that have been published by listed companies due to regulatory legislation. Our analysis covers a period of more than two years between November 2007 and November 2009 and is based on a unique dataset that contains 4360 corporate disclosures published via the Regulatory News Service (RNS) in the UK. In order to label these disclosures regarding their impact on the capital market, we have collected intraday price series of the corresponding stocks. Since financial research has shown that significant price effects can be expected for a period of 15 minutes following the publication of corporate disclosures, we calculated return measures for this period and labeled the documents according to these returns (i.e. positive and negative). As we are interested in the sentiment of the corporate disclosures, we then compared the disclosures' contents with word lists that provide insights into the tone of a given document. We applied the well-known Harvard Psychosociological Dictionary H4-4 and a word list that has recently been developed for the financial domain (derived from Form 10-K reports) and applied a word count approach in order to explore the tone of the documents. Given the labeling of the disclosures based on their market impact, we hypothesized that positively (negatively) labeled disclosures are expected to show a positive (negative) sentiment. We were able to reject the statistical hypotheses that the mean word counts differ, but not as we have expected: According to our measures, all disclosures show a significant positive sentiment and there is no significant difference between positively and negatively labeled disclosures. We interpret this finding given the area of conflict the management faces. On the one hand side, given the regulatory legislation, corporates need to report all kinds of relevant business events that have the potential to (positively or negatively) affect the firm's value, i.e. the value of the corporate shares. On the other hand, the management has a general motivation 
to increase the firm's value and so, to mitigate the effects of negative facts being reported. Our results provide strong evidence that the management of publicly listed corporations put significant effort into the disclosures contents with the objective to give the reports a positive spin.

\section{f. Limitations and Further Research}

Our analysis is based on a statistical analysis of the tone of corporate disclosures. While the results provide first empirical insights into their sentiment, our research provides diverse motivation for future research directions in this field.

Our results are based on simple word count measures and statistical test procedures that we aim to refine in future research. First, we aim to refine our approach to compare the similarity of the given corporate disclosures and the wordlists and aim to apply document similarity measures that can be calculated by utilizing text mining techniques (Cios et al. 2007). Another second stream of future research is domain-specific word lists. While our analysis is based on one generic psychosociological dictionary (H4-4) and one word list that has been developed for the financial domain (FIN), creating and evaluating own word lists could be subject of future research. Such word lists could be developed by applying a Support Vector Machine (SVM) approach to our sample of RNS disclosures by analyzing the vectors obtained from such an analysis (Witten \& Frank 2005). Third, and after developing such specific word lists, text mining techniques could also provide means to develop forecasting models that could contribute to the explanation of price effects that have been observed by a wide range of empirical analyses that have explored intraday price effects following the publication of regulatory-driven corporate disclosures (Carter \& Soo 1999; Muntermann \& Güttler 2007; Patell \& Wolfson 1984).

\section{g. Acknowledgements}

The research leading to these results has received funding from the European Community's Seventh Framework Programme (FP7/2007-2013) within the context of the Project FIRST, Large scale information extraction and integration infrastructure for supporting financial decision making, under grant agreement n. 257928. 


\section{Paper 2}

Table 12: Fact Sheet of Paper $2 a$ (Zülch 2013)

\begin{tabular}{|l|l|}
\hline Title & $\begin{array}{l}\text { "Will They Merge?" - Financial Event-Related Information Processing in } \\
\text { Social Media }\end{array}$ \\
\hline Authors & $\begin{array}{l}\text { Mirko Jan Zülch, mirko.zuelch @ wiwi.uni-goettingen.de* } \\
\text { *University of Göttingen }\end{array}$ \\
\hline Outlet & $\begin{array}{l}\text { Proceedings of the 19th Americas Conference on Information Systems (AMCIS } \\
\text { 2013) }\end{array}$ \\
\hline Abstract \\
$\begin{array}{l}\text { Ancerger is a complex process and for investors it represents a situation of } \\
\text { exchange in order to reduce informational uncertainty. Social media can } \\
\text { facilitate effective information exchange among investors. Drawing on the } \\
\text { concepts of information processing and sense-making, I investigate information } \\
\text { processing activities on blogs related to merger-related uncertainty. } \\
\text { Furthermore, I investigate information generation, information depth, and the } \\
\text { variety of information provided by blogs related to the completion likelihood of } \\
\text { a merger. The analysis shows that financial event-related uncertainty can be } \\
\text { related to information processing activities in social media. }\end{array}$ \\
\hline Keywords & $\begin{array}{l}\text { Social media, Information Processing, Sense-Making, Merger, Uncertainty, } \\
\text { Financial Event }\end{array}$ \\
\hline
\end{tabular}

\section{a. Introduction}

Mergers are "business combination transactions involving the combination of two or more companies into a single entity" (SEC 2013) and are highly relevant events for investors who are invested in one of the involved companies, likewise for potential future investors (Dodd 1980). In the financial domain social media are heavily used, for example for the discussion of investment decisions and financial events such as merger announcements which forces investors to reassess their investment decisions (Das \& Chen 2007). Nowadays social media play a key role in the overwhelming exchange of information among users. Kaplan \& Haenlein (2010) define social media as: "a group of Internet-based applications that build on the ideological and technological foundations of Web 2.0, and that allow the creation and exchange of User Generated Content" (p. 61). This emphasizes two of the key reasons for the use of social media, namely the generation and exchange of information. In this sense, social 
media supports information processing activities of users by facilitating active discussions and information exchange among users.

Blogs, as one of the most prominent types of social media, can be described as "frequently updated websites where content (text, pictures, sound files, etc.) is posted on a regular basis and displayed in reverse chronological order" (Schmidt 2007, p. 1409). In particular, in the financial domain blogs are frequently used as an information source and for information exchange, e.g. in the context of investment recommendations and further insights on markets events (Fotak 2007). Previous literature on blogs was mainly concerned with the incentives to blog (Nardi et al. 2004), and with the impact of blog posts (Fotak 2007).

Lu \& Yang (2011) examined information exchange in online discussion forums after a natural disaster, whereby disaster-related uncertainties increase the need for information. I adopt this setting to the financial domain, where merger announcements cause uncertainties for investors concerning the evaluation of the announced merger and concerning the final execution of the deal (Muehlfeld et al. 2007). In my hypotheses development process I draw on the literature on information processing and sense-making. In order to obtain new insights concerning information processing in social media, this research captures data from financial blogs and empirically investigates the relationship between merger-related uncertainty and information processing activities on blogs, and is in this sense, to the best of my knowledge, the first if its kind.

The remainder of the paper is organized as follows. First, I describe the theoretical foundation and hypotheses development process. The following section is concerned with the empirical analyses, addressing the operationalization of variables, the data selection process, and the description of the applied methodology. Then I present the results and implications of the analysis, and the concluding section summarizes the findings and provides an outlook for further research.

\section{b. Literature Review and Hypotheses Development}

A merger represents a growth opportunity and a possibility for realizing synergistic gains, such as economies of scale and scope (Chakravorty 2012). Because of the significant price effect subsequent to the announcement of a merger attempt, investors who are invested in at least of one of the involved parties have to analyze the event and its implications to their investment portfolio. Mergers are complex transactions, investors have to evaluate the target 
and acquiring company as well as the synergistic gains (Louis \& Sun 2010). In addition, a lot of mergers do not meet their proclaimed expectations and many are withdrawn before their completion or end in divestures (Muehlfeld et al. 2007). Therefore, a merger announcement represents a situation of uncertainty on many levels. In the event of a merger, the information provided by the involved companies is generally less standard and more difficult to process for investors compared to other financial events (Louis \& Sun 2010). Consequently, investors have to process more information compared to other financial events and experience higher information needs. Investors may engage in online information exchange and online communication in order to reduce informational uncertainty (Herrmann 2007).

Uncertainty can be defined by the difference between information currently possessed by the individual and the information needed (Galbraith 1973). From an information uncertainty perspective, the primary source of uncertainty is the lack of information about situational, social and environmental factors (Lawrence \& Lorsch 1967). In addition, uncertainty represents "the inability to predict future outcomes or states of the world" (Galbraith 1977, p. 36). Therefore, in a merger transaction investors experience uncertainty concerning the final execution of a merger deal, because it is not certain that the merger will either get approved by shareholders or regulatory authorities. It is also possible that the management of one of the involved parties cancels the deal or that the management of the target company employs one of many defense tactics in the case of a hostile takeover. The remainder of this paper will be concerned with uncertainty concerning the completion likelihood of a merger.

On the individual level, information processing theory, which takes the perspective that people process received information, can serve as a mean to investigate human decision making (Slovic et al. 1977). The higher the uncertainty during the process of decision making the more information needs to be processed in order to achieve certain goals (Galbraith 1973). In this sense, information behavior includes the identification of information needs, the search for the required information, as well as the provision and utilization of such information (Wilson 1999). The described behavior includes also the provision or generation of information considered as being of value for other individuals (Wilson 1999). Hence, mergerrelated uncertainty triggers information needs on the part of investors, meaning more amounts of information is required, therefore, I hypothesize: 
1. Hypothesis (H1): The higher the uncertainty related to a financial event the more information is generated in social media.

Organization science as well as information science is familiar with the concept of sensemaking (Dervin 1983; Weick 1995). Sense-making involves the above mentioned activities of information behavior in order to make sense out of a certain situation (Dervin 1999). The term sense-making has been used in several scientific disciplines (Weick 1995; Dervin 1983; Russel et al. 1993). Sense-making addresses the process of understanding and the construction of meaning (Dervin 1983). According to Dervin's (1983) sense-making approach, individuals face information needs (e.g. because of uncertainty), called a 'gap', representing the difference between a given 'situation' and the desired situation, whereby a 'bridge' is considered as some mean of closing the 'gap'. From Weick's (1995) perspective sensemaking can be viewed as the reduction of equivocality, the problem of too many meanings. Sense-making represents a cognitive activity, mostly investigated at the individual level (Russel et al. 1993). Nevertheless, people tend to share and communicate constructed meanings and their understanding to one another, creating a shared understanding. This is referred to as collective sense-making (Poltrock et al. 2003). In this context, social media can play a crucial role in the sense-making process on the individual and the collective level (Herrmann 2007). Social media can facilitate effective information generation and exchange among individuals who are dealing with ambiguous situations and informational uncertainties.

The concept of sense-making can also be applied to the event of a merger, when investors try to understand or make sense of huge amounts of complex information from several sources (Herrmann 2007). To create a shared understanding in the presence of uncertainty, the shared information has to be more comprehensive in order to reduce equivocality. In this perspective, information generation in social media can be viewed as a part of the collective sense-making process and one can expect a higher need for in-depth information by investors in the event of a merger:

2. Hypothesis (H2): The higher the uncertainty related to a financial event the more information depth is generated in social media.

The rationality of actors (individuals) can be bounded by incomplete information about alternatives (Simon, 1972). Furthermore, individuals face limitations in their information 
processing capabilities, leading to incomplete and simplified representations of the world (Simon 1972). Because uncertainty represents inability to predict future outcomes, one can expect that the higher the uncertainty the more interpretations of a given situation are possible by individuals who are limited by bounded rationality. Therefore, a larger variety of interpretations by investors concerning the outcome of an announced merger attempt is expected, which leads to my third hypothesis:

3. Hypothesis (H3): The higher the uncertainty related to a financial event the higher the variety of information that is generated in social media.

In the following these hypotheses will be tested with respect to the occurrence of blog postings in the event of a merger.

\section{c. Research Methodology}

\section{c.1 Variables}

In the following I describe the operationalization of the previously hypothesized constructs. Firstly, I describe three kinds of measures of uncertainty that are concerned with the completion likelihood of a merger and the reasoning behind those. Secondly, I describe the operationalized information processing variables (dependent variables).

\section{c.1.1 Independent Variables - Uncertainty Measures}

'Method of Payment' - Two major forms of financing a merger do exist. The acquirer can either choose cash or stock, where the payment is made with the acquiring company's stock, as a form of payment. Payment made in cash has a positive signaling effect and is associated with post-merger performance (Yook 2003). Cash payment is associated with raising debt and according to the free cash flow theory, cash financed deals are associated with a disciplining effect and larger benefits compared to mergers paid through the exchange of stock (Jensen 1986). Stock financing is preferred by the management of the acquiring company if the acquiring firm is considered as being overvalued (Myers \& Majluf 1984). Empirical studies concerned with the post-announcement market reaction have shown that more negative abnormal returns are associated with transactions paid through the exchange of stock (e.g. Asquith 1983). In addition, studies show an empirical association between positive abnormal returns, as a post announcement performance measure, and cash acquisitions. This can be translated in into a higher completion likelihood of cash-financed bids (Muehlfeld et al. 
2007). Hence, deals that are paid in 'cash' can be considered as possessing less uncertainty concerning the completion of the deal compared to stock-financed deals. I consider a mixture of cash and stock financing as a 'hybrid' form of payment, representing a lower uncertainty with regard to the completion of a merger attempt than those that are paid through the exchange of stock, and representing a higher uncertainty compared to cash-financed deals.

'Termination Agreement' - “Termination fee clauses in merger agreements entail a contingent payment by one party to a counter party and are triggered when the former dissolves the agreement" (Bates \& Lemmon 2003, p. 470). The existence of a termination agreement is significantly positively associated with the likelihood of the deal being completed (Bates \& Lemmon 2003). In my analysis I consider mergers where at least one party was bound to pay a termination fee as being less likely to be withdrawn by one of the involved companies.

'Not Mutual Agreed' - Bids in merger transaction can be defined as being friendly or hostile. In hostile deals the management of the target company does not approve the takeover. Usually tender offers are hostile, where the acquirer purchases the necessary shares directly from the shareholders of the target (Chakravorty 2012). In hostile deals the management can employ a variety defensive tactics to countervail a takeover attempt (e.g. poison pills, lock-ups, white knights, to name a few). Hence, friendly mergers attempts are expected to be more likely to be completed. I consider merger attempts that are considered as being hostile or where the target employed a defensive tactic as being 'not mutual agreed', and consequently less certain to be completed.

Table 13 provides an overview on the selected independent variables, their categories, and their conceptual level of uncertainty with respect to the completion likelihood of a merger attempt. 
Table 13: Independent Variables

\begin{tabular}{|l|l|l|}
\hline \multicolumn{1}{|c|}{ Name } & \multicolumn{1}{|c|}{ Categories } & \multicolumn{1}{c|}{ Level of Uncertainty } \\
\hline \multirow{3}{*}{ Method of Payment $(M P)$} & Cash & Low \\
\cline { 2 - 4 } & Hybrid & Medium \\
\cline { 2 - 4 } & Stock & High \\
\hline \multirow{2}{*}{ Termination Agreement (TA) } & Yes & Low \\
\cline { 2 - 4 } & No & High \\
\hline \multirow{2}{*}{ Not Mutual Agreed (NMA) } & Yes & High \\
\cline { 2 - 4 } & No & Low \\
\hline
\end{tabular}

\section{c.1.2 Dependent Variables}

'Information Generation' (H1): The amount of information that is generated can be measured by information quantity (Wasko \& Faraj 2005). Therefore, I measure the quantity of information by the number of occurring blog posts concerned with a merger between the date of announcement and the date of completion/abandonment of a merger attempt.

'Information Depth' (H2): As suggest by Mudambi \& Schuff (2010), review depth of a provided messages in the context of online product reviews can be measured by the number of words of a message, representing a proxy for information diagnosticity. I adopt this approach to measure the depth of the provided information of blog postings that are concerned with a merger attempt by using the average word count of overall blog postings between the date of announcement and the date of completion/abandonment of the merger attempt.

'Variety of Information' (H3): My first approach to measure the variety of information is by looking at the number of unique blog sources that are concerned with a merger, which I will refer to as 'Media Variety' in the following. My second approach, in order to assess the different opinions and interpretations concerned with a merger, is to look at the overall 'disagreement' among blogs that cover a specific merger. I use the standard deviation of the sentiment polarity of blog posts that cover a merger as a proxy for disagreement among blogs (Antweiler \& Frank 2004). In so doing, I obtain sentiment scores (positive and negative) of individual words in each blog post by using a computer-assisted approach for content analyses of textual data (General Inquirer) (Stone et al. 1966). Then I calculate the polarity of each blog post according to the following formula (Zhang \& Skiena 2010): 
Polarity $=($ Number of positive words - Number of negative words) $/$ (Sum of positive and negative words)

Table 14 provides an overview on the selected dependent variables.

Table 14: Dependent Variables

\begin{tabular}{|l|l|}
\hline \multicolumn{1}{|c|}{ Name } & \multicolumn{1}{c|}{ Description } \\
\hline Information Generation (IG) & Number of blog posts \\
\hline Information Depth (ID) & Average word count of blog posts \\
\hline \multirow{3}{*}{ Variety of Information (VI) } & $\begin{array}{l}\text { Media Variety (M-VI): Number of unique blog sources } \\
\text { polarity of blog posts }\end{array}$ \\
\hline
\end{tabular}

\section{c.2 Dataset Description}

All merger-related information has been retrieved form Thomson Reuters SDC Platinum database (SDC). My sampling objective was to build a sample of publicly traded firms where a merger is announced that is later either cancelled or completed. In July 2012, I identified 28,933 (U.S. only) M\&A transactions on the SDC database that have been announced in the time period between 1/1/2008 - 12/31/2011. From the previous results 5,022 observations have been classified as mergers by the SDC. To ensure that the transaction would be of interest to private investors, I only took those mergers into my sample, where according to the database the acquirer and the target are public companies, leaving me with 640 observations. In addition, the deal value had to be greater or equal $\$ 100$ million, in order to ensure blog coverage of merger events, leaving me with 323 observations. The deal status of the merger has been restricted to be either 'completed' or 'withdrawn', because I want to focus only on those transactions where the outcome was already known, finally leaving me with 318 observations. Table 15 provides a descriptive statistic of the merger data sampling process. 
Table 15: Merger Data

\begin{tabular}{|l|l|}
\hline No. of Observations after Query & \multicolumn{1}{c|}{ Query Description } \\
\hline 28,933 & $\begin{array}{l}\text { SDC M\&A (US only) announced between 1/1/2008 } \\
\text { and } 12 / 31 / 2011\end{array}$ \\
\hline 5,022 & Merger transactions only \\
\hline 640 & Public companies only \\
\hline 323 & Deal value is $\$ 100$ million or higher \\
\hline 318 & Deal status is either 'completed' or 'withdrawn' \\
\hline
\end{tabular}

Lexis-Nexis, a database of legal and journalistic documents, was used for gathering the required blog data. This database provides access to blog postings via the blog content aggregator Newstex. Newstex's service 'Newstex Blogs On Demand' provides full-text blog content from a large amount of blogs covering a wide variety of topics, including, among others, economic and finance topics. Lexis-Nexis enables the use of search strings. To maximize the accuracy of search results for blog content that is related to a specific merger, I used the following Boolean search expression for each of the 318 identified mergers: 'name of the acquirer' AND 'name of the target company' AND 'merger'. The date range was set according to the merger's date of announcement and the date of either its completion or cancelation, which have been retrieved from the SDC database. The blog results provided me with the following information for each discovered blog post: source of the blog post, publication date of the blog post, and the full text of the content of the blog post (including the title). From the 318 previously identified mergers, 254 were covered by at least one blog during the above mentioned time period. Table 16 provides a descriptive statistic of the blog data sample. 
Table 16: Blog Data

\begin{tabular}{|l|l|}
\hline \multicolumn{1}{|c|}{ Blog Database } & \multicolumn{1}{c|}{ Newstex } \\
\hline Identification of blog posts & $\begin{array}{l}\text { Boolean search string: 'name of the acquiring } \\
\text { company' AND 'name of the target company' } \\
\text { AND 'merger' }\end{array}$ \\
\hline Time period & $\begin{array}{l}\text { From the announcement date to the date of } \\
\text { merger completion/ cancelation }\end{array}$ \\
\hline Search results & $\begin{array}{l}\text { Source of the blog, date of the blog post , and } \\
\text { the full text of the blog content }\end{array}$ \\
\hline Number of mergers covered by blogs & 254 \\
\hline Average number of blog posts per merger & 17.94 \\
\hline Average number of words per blog post & 811.22 \\
\hline Average number of unique blog sources & 7.64 \\
\hline
\end{tabular}

\section{c.3 Analysis Method}

For the following tests I compare independent samples of blog data representing different levels of uncertainty. As stated in a previous section, in the case of a merger event different factors do exist that can serve as an indicator for the likelihood of a merger being either completed or canceled. According to the previously presented measures of uncertainty I can deduce the uncertainty about the completion likelihood of a merger attempt being either 'high' or 'low' in the case of the variables TA and NMA, or 'high', 'medium', and 'low', in the case of the variable MP. In so doing, I test if different levels of uncertainty lead to different levels in the previously stated dependent variables. In the following $* * *$ indicates $1 \%$ level of significance.

The sampling distributions of the different data samples are not normally distributed (Kolmogorov-Smirnov test and Shapiro-Wilk test have been applied) and the sample sizes are not big enough in several cases in order to assume the sampling distributions to be approximately normal distributed. Therefore, I applied several nonparametric tests to test the previously stated hypotheses. In the case of nonparametric tests no assumptions about the shape of a population have to be made (Weiers 2005).

Firstly, in order to compare two independent samples, with respect to the dependent variables TA and NMA, I applied the Mann-Whitney $U$-Test. Secondly, in order to compare more than 
two independent samples, with respect to the dependent variable MP, I applied the KruskalWallis $H$-Test. The results of these tests are stated and discussed in the following section.

\section{d. Results}

Table 17 states the results of the Mann-Whitney $U$-Test that compares merger deals where no ('No') termination agreement exists with those where at least one of the two involved parties agreed to a termination fee agreement ('Yes'). The Mann-Whitney $U$-Test in this case states that there is no significant difference between the ranks of the two types of merger deals. This means that deals with or without a termination agreement do not differ with respect to the different dependent variables, showing no support for the previously stated hypotheses.

Table 17: Termination Agreement

\begin{tabular}{|c|c|c|c|c|c|c|}
\hline \multicolumn{2}{|c|}{ Termination Agreement (TA) } & $\mathbf{N}$ & Mean Rank & Mann-Whitney-U & $\mathbf{Z}$ & $\mathbf{p}$ \\
\hline \multirow{2}{*}{ Information Generation (IG) } & No & 39 & 134.86 & \multirow{2}{*}{3905.5} & \multirow{2}{*}{-0.682} & \multirow{2}{*}{0.495} \\
\hline & Yes & 215 & 126.17 & & & \\
\hline \multirow{2}{*}{ Information Depth (ID) } & No & 39 & 131.37 & \multirow{2}{*}{4041.5} & \multirow{2}{*}{-0.358} & \multirow{2}{*}{0.721} \\
\hline & Yes & 215 & 126.8 & & & \\
\hline \multirow{2}{*}{ Media Variety $(M-V I)$} & No & 39 & 130.62 & \multirow{2}{*}{4071} & \multirow{2}{*}{-0.29} & \multirow{2}{*}{0.7} \\
\hline & Yes & 215 & 126.93 & & & \\
\hline \multirow{2}{*}{ Disagreement (D-VI) } & No & 33 & 103.56 & \multirow{2}{*}{2856.5} & \multirow{2}{*}{-0.3} & \multirow{2}{*}{0.7} \\
\hline & Yes & 179 & 107.04 & & & \\
\hline
\end{tabular}

Furthermore, Table 18 states the results of the Mann-Whitney $U$-Test that compares merger deals that are mutual agreed by the two involved parties ('No') with those that are not mutual agreed ('Yes'). The Mann-Whitney U-Test in this case states, with respect to the different dependent variables (except in the case of 'Disagreement'), that there is a significant difference (on the 5\% level of significance) between the ranks of the two types of merger deals. This means that deals that are mutual agreed or are not mutual agreed do differ significantly with respect to the different dependent variables. Furthermore, in the case of IG, ID, and M-VI the mean rank of the merger deals that represent a 'low' uncertainty concerning the likelihood of a merger being completed is lower than for mergers that are more uncertain concerning their completion. This shows strong support for the three previously stated hypotheses. Whether a merger is mutual agreed or not seems as a convincing and obvious measure to judge if a merger attempt is more likely to be completed or not, because if the 
management of the target company does not agree with the merger plans of the acquirer, the target company will most likely take actions against the merger attempt. In summary, higher uncertainty related to a merger attempt is related to more comprehensive information that is generated by a variety of blogs.

Table 18: Not Mutual Agreed

\begin{tabular}{|c|c|c|c|c|c|c|}
\hline \multicolumn{2}{|c|}{ Not Mutual Agreed (NMA) } & \multirow{2}{*}{$\begin{array}{r}\mathbf{N} \\
236\end{array}$} & \multirow{2}{*}{$\begin{array}{l}\text { Mean Rank } \\
124.12\end{array}$} & \multirow{3}{*}{\begin{tabular}{l}
\multicolumn{1}{c}{$\begin{array}{c}\text { Mann- } \\
\text { Whitney-U }\end{array}$} \\
1326.5
\end{tabular}} & \multirow{3}{*}{$\begin{array}{c}\mathbf{Z} \\
-2.664\end{array}$} & \multirow{3}{*}{$\begin{array}{c}\mathbf{p} \\
0.08^{* *}\end{array}$} \\
\hline \multirow{2}{*}{ Information Generation (IG) } & No & & & & & \\
\hline & Yes & 18 & 171.81 & & & \\
\hline \multirow{2}{*}{ Information Depth (ID) } & No & 236 & 124.49 & \multirow{2}{*}{1414} & \multirow{2}{*}{-2.363} & \multirow{2}{*}{$0.018 * *$} \\
\hline & Yes & 18 & 166.94 & & & \\
\hline \multirow{2}{*}{ Media Variety $(M-V I)$} & No & 236 & 124.91 & \multirow{2}{*}{1513.5} & \multirow{2}{*}{-2.048} & \multirow{2}{*}{$0.041 * *$} \\
\hline & Yes & 18 & 161.42 & & & \\
\hline \multirow{2}{*}{ Disagreement (D-VI) } & No & 195 & 107.71 & \multirow{2}{*}{1421} & \multirow{2}{*}{-0.975} & \multirow{2}{*}{0.33} \\
\hline & Yes & 17 & 92.59 & & & \\
\hline
\end{tabular}

At last, Table 19 states the results of the Kruskal-Wallis $H$-Test that compares three types of merger deals according to the method of payment ('Cash', 'Hybrid', and 'Stock') with respect to the different dependent variables. In contrast to previous results, the Kruskal-Wallis $H$-Test in this case states, with respect to the dependent variables IG, ID, and M-VI, that there is no significant difference between the ranks of the three types of merger deals. Hence, I find no support for the three previously stated hypotheses. Nevertheless, in the case of 'Disagreement' the Null-Hypothesis can be rejected, but only at a $10 \%$ level of significance. Accordingly, I applied a post-hoc test to analyze if the different method of payments are significant different from one another in this case (Table 20). 
Table 19: Method of Payment

\begin{tabular}{|c|c|c|c|c|c|c|}
\hline \multicolumn{2}{|c|}{ Method of Payment (PA) } & $\mathbf{N}$ & Mean Rank & Chi-Square (H) & df & $\mathbf{p}$ \\
\hline \multirow{3}{*}{ Information Generation (IG) } & Cash & 115 & 117.35 & \multirow{3}{*}{3.178} & \multirow{3}{*}{2} & \multirow{3}{*}{0.204} \\
\hline & Hybrid & 84 & 135.49 & & & \\
\hline & Stock & 49 & 122.45 & & & \\
\hline \multirow{3}{*}{ Information Depth (ID) } & Cash & 115 & 134.61 & \multirow{3}{*}{4.295} & \multirow{3}{*}{2} & \multirow{3}{*}{0.117} \\
\hline & Hybrid & 84 & 116.63 & & & \\
\hline & Stock & 49 & 114.27 & & & \\
\hline \multirow{3}{*}{ Media Variety $(M-V I)$} & Cash & 115 & 117.05 & \multirow{3}{*}{3.421} & \multirow{3}{*}{2} & \multirow{3}{*}{0.181} \\
\hline & Hybrid & 84 & 135.82 & & & \\
\hline & Stock & 49 & 122.57 & & & \\
\hline \multirow{3}{*}{ Disagreement (D-VI) } & Cash & 94 & 93.11 & \multirow{3}{*}{5.941} & \multirow{3}{*}{2} & \multirow{3}{*}{$0.051^{*}$} \\
\hline & Hybrid & 74 & 115.11 & & & \\
\hline & Stock & 39 & 109.17 & & & \\
\hline
\end{tabular}

Table 20 shows that only deals with the payment method 'Cash' and 'Hybrid' are significantly different from one another (on the $5 \%$ level of significance). Deals with 'Cash' (low uncertainty) as the method of payment show a lower standard deviation of blog sentiment, which is in favor of the third hypotheses. Nevertheless, 'Cash' and 'Stock deals are not significantly different from one another. Therefore, I cannot fully conclude that 'Method of Payment' is related to 'Disagreement'.

Table 20: Post Hoc-Disagreement (D-VI)

\begin{tabular}{|l|l|l|l|}
\hline \multicolumn{2}{|c|}{ Method of Payment (PA) } & \multicolumn{1}{c|}{ Mean Rank } & \multicolumn{1}{|c|}{ p } \\
\hline \multirow{2}{*}{ Cash \& Hybrid } & Cash & 76.59 & \\
\cline { 2 - 3 } & Hybrid & 94.55 & \multirow{2}{*}{0.638} \\
\hline \multirow{2}{*}{ Hybrid \& Stock } & Hybrid & 58.05 & \\
\cline { 2 - 3 } & Stock & 55 & \multirow{2}{*}{0.167} \\
\hline Cash \& Stock & Cash & 64.03 & \\
\cline { 2 - 3 } & Stock & 74.17 & \\
\hline
\end{tabular}




\section{e. Summary and Conclusion}

In this paper I have explored information processing activities on blogs related to mergerrelated uncertainty. My analysis covers merger events and the respective blog posts that occurred between the date of announcement and final date of completion/cancelation of a respective merger transaction. From an information processing and sense-making perspective I generally hypothesized that higher levels of merger-related uncertainty relates to higher levels of information processing in social media. I investigated this with respect to the uncertainty concerning the completion likelihood of a merger and the corresponding blog posts. I hypothesized that the higher the uncertainty the more information is generated, and the higher the depth and the variety of generated information. This was strongly supported in the case of 'Not Mutual Agreed' as an uncertainty measure concerning the completion likelihood of a merger.

In a financial context, research on social media was mainly concerned with the impact of online communication and information exchange in order to make predictions about the market reaction (Antweiler \& Frank 2004). Herrmann (2007) already stated the relevance of the sense-making process of individuals in the financial context. My analysis provides first hints concerning information processing and sense-making in social media with respect to the financial domain in general, and in particular, with respect to merger events. Furthermore, my study provides additional insights on information processing in social media, because the results show that financial event-related uncertainty can be related to information processing activities in social media.

\section{f. Limitations and Further Research}

While my results provide empirical insights into information processing in social media, my research provides motivation for future research directions in this field. My research is based on basic measures that I aim to refine in future research in order to capture and explore more deeply information processing in social media. Because it is of highest practical relevance to examine information processing in social media in order to better understand how and why different types of social media are selected and used, a phenomenon that has increased exponentially over the last decade, I aim to combine different types of social media in one analysis. 


\section{Paper 3}

Table 21: Fact Sheet of Paper 3a (Zülch 2013a)

\begin{tabular}{|l|l|}
\hline Title & An Empirical Analysis of Merger-Related Blog Posts \\
\hline Authors & Mirko Jan Zülch, mirko.zuelch @ wiwi.uni-goettingen.de* \\
*University of Göttingen
\end{tabular}

\section{a. Introduction}

Blogs are a type of social media. At the end of 2011, it was estimated that 173 million blogs exist, with an estimated rate of growth of about 175,000 new blogs per day (Statista 2013). Amongst others, financial topics and financial events, such as mergers, are frequently discussed on the internet in blogs. On financial blogs, individual investors provide financial relevant information, ranging from personal opinions and investment recommendations to specific analyses. In general, investors make use of social media in order to gather reliable information. In particular, blogs can play a critical role as an information source during the decision making process of investors.

Previous studies that investigate the role of social media in the financial domain primarily have been concerned with the predictive power of online information exchange with respect to the market reaction (Das \& Chen 2007; Antweiler \& Frank 2004; Wysocki 1998; Fotak 2007). Nevertheless, none of these studies has investigated if the textual information provided 
by blogs and other types of social media can be used as an indicator for other financial phenomena besides capital market reactions. This study aims to fill this gap by exploring blog posts in the event of a merger attempt and is, to the best of my knowledge, the first of its kind.

A merger is the combination of two separate organizations that merge into a single legal entity (SEC 2013) and is primarily driven by strategic, managerial, and financial motives (Napier 1989). Due to the severe price reaction subsequent to the announcement of a merger, a merger represents an event of great relevance for investors that have invested or are going to invest in either one of the involved parties (Dodd 1980). Consequently, investors have to reassess their investment decisions and have to evaluate the synergistic gains of the merger attempt (Louis \& Sun 2010). Nevertheless, an important fact remains: a lot of mergers attempts are unsuccessful (Chakravorty 2012). Therefore, my research question is as follows:

Do blog posts reflect the merger-related uncertainty concerning the completion of a merger attempt?

The remainder of the paper is structured as follows. In the next section, I provide a review of the relevant literature, including the general hypothesis. Then, I present the study setup which comprises a description of the dataset and my research approach. In the following section, I formulate the research hypotheses and present the empirical results. I finally conclude with a summary of my findings, the limitations of my research and potential future research directions.

\section{b. Literature Review and Hypotheses Development}

\section{b.1 Blogs}

Blogs are "frequently updated websites where content (text, pictures, sound files, etc.) is posted on a regular basis and displayed in reverse chronological order" (Schmidt 2007, p. 1409). Furthermore, blogs are a specific type of social media. Social media can be defined as "a group of Internet-based applications that build on the ideological and technological foundations of Web 2.0, and that allow the creation and exchange of User Generated Content" (Kaplan \& Haenlein 2010, p. 61). Many motives do exist for people to maintain a blog. Nardi et al. (2004) identified five motives for people to blog: documenting one's life, providing commentary and opinions, expressing deeply felt emotions, articulating ideas through writing, 
and forming and maintaing community forums. Many classification schemes have been proposed in the literature, an overview of blog typologies is provided by Silva et al. (2008).

In general, blogs are considered as a reliable source of information that is less biased by conflicting interests (The Nielson Company 2007). In particular, in the financial domain, blogs are commonly used as a source of financial related information and as a means for information exchange. Financial blogs do not only cover most recent events in the financial domain, but also provide analysis and investment recommendations. They are not primarily maintained by individual investors who want to share their personal opinions on financial topics. In some cases, financial blogs are also maintained by professional financial websites, a famous example is "Yahoo! Finance Blogs". In the financial context, Fotak (2007) investigated the relation between stock recommendations on financial blogs and market reactions. He found that financial blogs are mostly concerned with high liquid stocks. Furthermore, he found that financial blogs seem to influence trading volumes and stock prices with respect to the recommended stocks. Therefore, blog recommendations have predictive power with regard to their accuracy of their recommendations. In addition, Zülch (2013) analyzed information processing activities on blogs with regards to merger attempts. He used characteristics and structure of a merger transaction as proxies for the uncertainty concerning the completion likelihood of a merger. In so doing, he showed that the merger-related uncertainty can be related to information processing activities on blogs. In this sense, my study aims to extend his findings by analyzing if the textual information provided by blogs reflects the merger-related uncertainty. Overall the literature on blogs in the financial context illustrates that blogs, as a type of social media, play an influential role in the financial domain.

\section{b.2 Merger and Uncertainty}

In this study I aim to explore if the content of blog posts reflects the uncertainty concerning the final result of a merger attempt during the time period between the date of announcement of a merger and the date of completion/withdrawal. Galbraith (1973) generally defines uncertainty as the difference between the amount of information possessed and the amount of information required. Furthermore, uncertainty "is the inability to predict future outcomes or states of the world" (Galbraith 1977, p. 36). Uncertainty is also based on imperfect knowledge with respect to environmental and situational factors (Duncan 1972). Generally, information asymmetries do exist between investors and the management of organizations (insiders) 
(Healy \& Palepu 2001). Hence, investors experience informational uncertainties compared to insiders in any case. In addition, the outcome of an announced merger attempt is uncertain; therefore investors and authors of financial blogs experience also additional uncertainty concerning the completion of a merger.

Mergers and acquisition (M\&A) activities of organizations are based on several motives that range from strategic and managerial to sheer financial ones (Napier 1989). The term M\&A includes several types of transactions, ranging from the acquisition of a minority stake in a target company by another company to the merging of two previously separate companies. In particular, mergers are "business combination transactions involving the combination of two or more companies into a single entity" (SEC 2013). They represent a growth opportunity, especially for external growth, and can increase or enable synergies, for example via economies of scale and scope (Chakravorty 2012; Halpern 1983), whereby the terms 'merger' and 'acquisition' are often used interchangeably (Chakravorty 2012). A merger may also involve acquiring all shares of a target company and is in that case officially declared as a merger, but is in fact an acquisition in economic terms (Faulkner et al. 2012).

A merger passes through several phases from the initial offer by one organization to another organization to the legal unification of both organizations before the completion of the merger is announced. At first, after both involved parties have negotiated on the terms of the merger, an official announcement of the merger proposal is made. In the U.S., the SEC further specifies that mergers have to "be approved by at least a majority of a company's shareholders if the merger will have a significant impact on either the acquiring or target company" (SEC 2013). In addition, governmental and regulatory authorities usually also have to give their approval to the merger. Governmental and regulatory authorities will examine if the merger violates any antitrust laws.

The described high-level merger process shows that during several stages of a merger attempt, an abandonment of the merger is possible. Either the management of one of the involved parties does abandon the merger attempt, or the merger is not approved by shareholders, or governmental and regulatory authorities. Therefore, investors, who are invested and/or are considering to invest in at least of one of the involved parties, face uncertainty concerning the final outcome of a merger attempt during the whole merger process from the date of the public announcement of a merger to the date of the final outcome of the merger attempt. In 
the remainder of the paper, I refer to the uncertainty concerning the outcome of a merger attempt.

A merger announcement represents a very relevant event for investors, because of its direct and significant impact on share prices. Many studies analyzed the relationship between the announcement of a merger and the corresponding market reaction (Dodd 1980; Asquith 1983; Kau et al. 2008). In particular, some studies investigated the relationship between the market reaction subsequent to a merger announcement and the probability of a merger being completed (Kau et al. 2008; Luo 2005). They find that the management of public companies does listen to the market, meaning that the management extracts information from the market reaction, and is consequently likely to cancel a merger when the market reacts adversely after the public announcement of the merger. Asquith (1983) examined abnormal stock returns throughout the merger process, from the public announcement of a merger up to the final outcome of a merger attempt (completion/withdrawal of the merger attempt). Furthermore, the market reaction throughout a merger process for the target firm reflects the probability of a merger. Newly available information during a merger process is reflected by share prices, and thus, representing the current amount of uncertainty (Asquith 1983).

Other studies have been concerned with the characteristics of a merger and the structure of the deal in relation to the probability of merger completion (Muehlfeld et al. 2007; Walkling 1985; Bates \& Lemmon 2003). They find that the probability that a merger attempt is successful is affected by the chosen method of payment and the deal attitude (i.e. hostile or friendly offer). In a hostile merger attempt the target company's management does not approve the merger and may employ several defensive tactics to counteract a takeover attempt (e.g. white knight; poison pills, or macaroni defense).

Other factors, like for example the existence of a termination fee agreement, can decrease the uncertainty concerning the outcome of a merger attempt. In a merger agreement, a termination fee clause "entail a contingent payment by one party to a counter party and are triggered when the former dissolves the agreement" (Bates \& Lemmon 2003, p. 470). Hence, acquiring company and target company provisions for termination fees in the event that the merger agreement is terminated signals more commitment to the agreed merger attempt. Bates \& Lemmon (2003) showed that the existence of a termination fee can have a significant positive effect on the likelihood of deal completion. 
To summarize, many reasons do exist why investors and authors of merger-related blogs experience uncertainty or have second thoughts concerning the outcome of an announced merger attempt. Since financial events such as a merger is being heavily discussed by financial oriented blogs (Fotak 2007), the general hypotheses that this study aims to explore is therefore:

Blog posts related to a failed merger attempt reflect more uncertainty compared to blog posts related to a successful merger attempt.

\section{c. Study Setup}

\section{c.1 Dataset Description}

In the following I used of two kinds of data sources. First, I collected a sample of merger transactions of publicly-traded U.S. companies (Thomson Reuters SDC Platinum database). Second, I used a blog content aggregator (Newstex) in order to collect merger-related blog post data.

Merger Data. Thomson Reuters SDC Platinum (SDC) database was used in order to collect merger-related data. In this study, I focus on merger transactions that have been announced between 1.1.2008 - 31.12.2011. The sample selection took several things into account. First, I made sure that the merger transaction would be of interest to investors. Second, I ensured that these merger transactions have a high potential to get attention from blogs. Therefore, I only considered mergers with a transaction value equal or greater \$100 million. In addition, I only considered mergers where the acquiring company and the target company are publicly traded U.S. companies. Finally, in this study only mergers are taken into account where the deal status is either 'completed' (successful merger attempt) or 'withdrawn' (unsuccessful merger attempt). Table 22 provides a description of the sampling selection process concerning merger transactions. 
Table 22: Sample Description of Merger Data

\begin{tabular}{|l|l|}
\hline \multicolumn{2}{|c|}{ Merger Data - Sample Selection } \\
\hline Number of observations after query & \multicolumn{1}{c|}{ Query description } \\
\hline 28,933 & $\begin{array}{l}\text { M\&A transactions announced between 1.1.2008 and } \\
31.12 .2011\end{array}$ \\
\hline 5,022 & Only merger transactions \\
\hline 640 & Only publicly traded U.S. companies \\
\hline 323 & Transaction value is equal or greater \$100 million \\
\hline 318 & Merger status is completed/withdrawn \\
\hline
\end{tabular}

Blog Data. "Newstex Blogs on Demand" (Newstex) was used in order to gather blog posts that are related to mergers from the previously described sample of merger transactions. "Newstex Blogs on Demand" is a blog content aggregator and provides full-text blog content. I was able to access Newstex blog data via Lexis-Nexis, a database of legal and journalistic documents. For each of the identified mergers, the name of the acquiring company, the name of the target company, and the date range from the date of the announcement of the merger to the date of completion/withdrawal of the merger (retrieved via SDC) was used in order to identify blog posts that are related to a specific merger attempt. For each identified merger, the following Boolean search expression was used in order to ensure maximum accuracy in identifying merger-related blog posts: "company1" AND "company2" AND "merger". The following information was retrieved from each discovered blog post: the full content of the blog post, publication date of the blog post, and the source of the blog post. Not all previously identified mergers were covered by blogs. 254 of the 318 identified mergers have been addressed by blog posts within the respective date range. Table 23 provides a description of the sampling selection process concerning merger-related blog posts. 
Table 23: Sample Description of Blog Data

\begin{tabular}{|l|l|}
\hline \multicolumn{2}{|c|}{ Blog Data - Sample Selection } \\
\hline Database & Newstex Blogs on Demand \\
\hline Identification of merger-related blog posts & $\begin{array}{l}\text { Boolean search string: "company1" AND } \\
\text { "company2" AND "merger" }\end{array}$ \\
\hline Date range of merger-related blog posts & $\begin{array}{l}\text { From the announcement date to the date of } \\
\text { merger completion/withdrawal }\end{array}$ \\
\hline Search results & $\begin{array}{l}\text { Source of blog posts, publication date of } \\
\text { blog post, and the full content of blog posts } \\
\text { (including the title) }\end{array}$ \\
\hline Number of mergers that are covered by blogs & 254 \\
\hline Average number of blog posts per merger & 17.94 \\
\hline
\end{tabular}

\section{c.2 Research Approach}

In order to assess if merger-related blog posts show hypothesized characteristics, I used a computer-assisted approach for content analyses of textual data, the General Inquirer (Stone et al. 1966). The General Inquirer maps written natural language with counts on dictionarysupplied categories (182 categories in total). Several dictionaries are combined consisting of several word lists classified in categories of meaning.

Firstly, I used six word lists in order to build three pairs of word categories that are opposite in meaning. The first pair represents the concept of 'certainty' and is represented by words that either indicate a feeling of certainty and sureness (sure) or a feeling of uncertainty and doubt (if). In addition, in order to explore more deeply the descripted merger-related uncertainty concerning the final outcome of a merger attempt, I included other word categories. The additional concepts assess if merger-related blog posts show optimism ('sentiment') or the tendency towards failure ('success') of the merger attempt. Therefore, the second pair represents the concept of 'sentiment' and is represented by words that either indicate a positive (positive) outlook or a negative one (negative). Finally, the third pair represents the concept of 'success' and is represented by words that either indicate that goals have been achieved (complete) or indicate that goals have not been achieved (fail). A description of the word categories and their respective concept are described by Table 24 . 
Table 24: Description of Concepts

\begin{tabular}{|l|l|}
\hline Concept & \multicolumn{1}{|c|}{ Description of Word Categories } \\
\hline \multirow{3}{*}{ Certainty } & sure $=$ words indicating a feeling of certainty and sureness \\
\cline { 2 - 2 } & if = words indicating a feeling of uncertainty and doubt \\
\hline \multirow{2}{*}{ Sentiment } & positive $=$ words indicating a positive outlook \\
\cline { 2 - 2 } & negative = words indicating a negative outlook \\
\hline \multirow{2}{*}{ Success } & complete = words indicating that goals have been achieved \\
\cline { 2 - 2 } & fail = words indicating that goals have not been achieved \\
\hline
\end{tabular}

Secondly, for each word pair I calculated the 'polarity' of each blog post in order to measure the tendency of blog posts with respect to the previously described concepts (Zhang \& Skiena 2010). In general, in this study the 'polarity' of a blog post with respect to a specific concept is measured as the difference between the number of words of the blog post belonging to one category and the number of words of the blog post belonging to another category, divided by the sum of the number of words of the blog post belonging to those two categories. For 'certainty' I calculate the 'polarity' as:

$$
\text { certainty }=(\text { sure }- \text { if }) /(\text { sure }+ \text { if })
$$

For 'sentiment' I calculate the 'polarity' as:

$$
\text { sentiment }=(\text { positive }- \text { negative }) /(\text { positive }+ \text { negative })
$$

For 'success' I calculate the 'polarity' as:

$$
\text { success }=(\text { complete }- \text { fail }) /(\text { complete }+ \text { fail })
$$

\section{d. Research Hypotheses and Empirical Results}

As previously stated, in my research I explore if blog posts reflect the uncertainty concerning the success of a merger attempt during the time period between the date of announcement and the date of completion/withdrawal. Given the previously described reasons for the uncertainty of investors during a merger process, my first hypothesis (H1) that is tested is therefore:

Hypothesis 1: Blog posts related to a failed merger attempt reflect more uncertainty compared to blog posts related to a successful merger attempt.

For the hypotheses tests, I applied the unequal variances t-test for comparing the means of two independent samples (Weiers 2005). I did not apply an equal variances $t$-test for 
comparing the means of two independent samples, because the corresponding $F$-tests on the equality of the two sample variances have been rejected in each case. In the following, with respect to the different 'polarity' measures (certainty, success and sentiment), for each hypothesis test, $N$ represents the total number of blog posts related to mergers that are completed or withdrawn in the end of a merger attempt.

Statistically, H1 is explored by the following null hypotheses, which I aim to reject in the following:

$\mathrm{H} 1_{0} \mu($ certainty; completed $) \leq \mu($ certainty; withdrawn $)$ vs.

$\mathrm{H} 1_{\mathrm{a}} \mu($ certainty; completed $)>\mu($ certainty; withdrawn $)$

Table 25: Certainty - Comparison of successful and failed Merger Attempts

\begin{tabular}{lllc}
\hline & \multicolumn{3}{c}{ Certainty } \\
\cline { 2 - 4 } Merger Status & Mean & Std. dev. & $N$ \\
\hline Completed & -0.139 & 0.507 & 3546 \\
Withdrawn & -0.187 & 0.439 & 818 \\
\hline$t$-Value $(F$-Value) & & $-2.732 * * *$ & $(23.829 * * *)$ \\
\hline$* * *$ indicates1\% level of significance & &
\end{tabular}

On average, blog posts that are concerned with a merger that is later being withdrawn show a greater uncertainty $($ mean $=-0.187 ;$ Std. dev. $=0.439)$ than blog posts that are concerned with merger that is completed $($ mean $=-0.139$; Std. dev. $=0.507)$ in the end of the merger process. This difference was significant $(t=-2.732)$ at the $1 \%$ level of significance. This shows strong support for my previously stated hypothesis (H1). Furthermore, on average, all merger-related blog posts show some kind of uncertainty, which confirms that mergers are in general highly complex transactions, where many information asymmetries exist between investors and the management of the involved organizations (Louis \& Sun 2010).

After exploring the reflected uncertainty in blog posts, I explore if the merger-related blog posts reflect the notion of 'success' with respect to the final result of the merger attempt. Therefore, I formulate the corresponding hypothesis $(\mathrm{H} 2)$ which I again aim to reject in the following:

Hypothesis 2: Blog posts related to a successful merger attempt reflect more success compared to blog posts related to a failed merger attempt. 
Statistically, H2 is explored by the following null hypotheses, which I again aim to reject in the following:

$\mathrm{H} 2_{0} \mu$ (success; completed $) \leq \mu$ (success; withdrawn) vs.

$\mathrm{H} 2_{\mathrm{a}} \mu($ success; completed $)>\mu($ success; withdrawn $)$

Table 26: Success - Comparison of successful and failed Merger Attempts

\begin{tabular}{lllc}
\hline & \multicolumn{3}{c}{ Success } \\
\cline { 2 - 4 } Merger Status & Mean & Std. dev. & $\mathrm{N}$ \\
\hline Completed & 0.521 & 0.622 & 2969 \\
Withdrawn & 0.467 & 0.682 & 666 \\
\hline$t$-Value $(F$-Value) & & $-1.866^{*}$ & $\left(13.798^{* * *}\right)$ \\
\hline
\end{tabular}

*** indicates $1 \%$ level of significance

On average, blog posts that are concerned with a merger that is later being canceled indicate less success $($ mean $=0.467$; Std. dev. $=0.682)$ than blog posts that are concerned with merger that is completed $($ mean $=0.521$; Std. dev. $=0.622)$ in the end of the merger process. This difference was significant $(t=-1.866)$ at the $10 \%$ level of significance, showing only slight support for my previously stated second hypothesis (H2). Nevertheless, on average, all merger-related blog posts are associated with achieving a certain goal, which indicates that blogs do not necessarily talk about the theme of failure concerning a merger attempt before the decision to cancel the deal is made.

Finally, I aim to explore if blog posts related to a successful merger attempt show more optimism before the final result of the merger is certain. Hence, I formulate the corresponding hypothesis (H3):

Hypothesis 3: Blog posts related to a successful merger attempt show a more positive sentiment compared to blog posts related to a failed merger attempt.

Statistically, H3 is explored by the following null hypotheses, which I again aim to reject in the following:

$\mathrm{H} 3_{0} \mu($ sentiment; completed $) \leq \mu($ sentiment; withdrawn $)$ vs.

$\mathrm{H} 3_{\mathrm{a}} \mu($ sentiment; completed $)>\mu($ sentiment; withdrawn $)$ 
Table 27: Sentiment - Comparison of successful and failed Merger Attempts

\begin{tabular}{lllc}
\hline & \multicolumn{3}{c}{ Sentiment } \\
\cline { 2 - 4 } Merger Status & Mean & Std. dev. & $\mathrm{N}$ \\
\hline Completed & 0.368 & 0.331 & 3706 \\
Withdrawn & 0.342 & 0.303 & 839 \\
\hline$t$-Value $(F$-Value $)$ & & $-2.206^{* *}$ & $(10.694 * * *)$ \\
\hline
\end{tabular}

*** indicates $1 \%$ level of significance

On average, blog posts that are concerned with a merger that is later being canceled show a more negative sentiment $($ mean $=0.342 ;$ Std. dev. $=0.303)$ than blog posts that are concerned with merger that is completed (mean $=0.368$; Std. dev. $=0.331$ ) in the end of the merger process. This difference was significant $(t=-1.866)$ at the $5 \%$ level of significance, this shows support for my previously stated third hypothesis (H3). In addition, on average, all mergerrelated blog posts show a positive sentiment. This could be interpreted as an overall optimism with regard to merger attempts, which can be explained due to the fact that mergers are generally associated with growth opportunities, the possibility for realizing synergistic gains, and the increase of market power (Chakravorty 2012).

\section{e. Summary and Conclusion}

In this paper I have explored if blog posts reflect the uncertainty concerning the final result of a merger attempt during the time period between the date of announcement and the date of completion/withdrawal of a merger attempt. My analysis covers mergers that have been announced between January 2008 and December 2011. The analysis is based on blog posts that occurred between the date of announcement and the date of the final result of a merger attempt.

I generally hypothesized that blog posts related to a failed merger attempt reflect more uncertainty compared to blog posts related to a successful merger attempt. With a computerassisted approach for content analyses of textual data I created several word count measures in order to assess the notion reflected in blog posts ('certainty', 'sentiment', and 'success'). According to my measures, I explored if blog posts related to failed merger attempts reflect more uncertainty, pessimism, and the notion of failure. My results indicate that blog posts, related to a merger attempt that is withdrawn in the end, reflect more uncertainty and less optimism, and indicate a higher notion of failure compared to blog posts related to successful merger attempts. This shows that information exchange in social media can serve as an 
indicator for other financial phenomena besides capital market reactions, i.e. in my case the outcome of a merger attempt. Hence, my empirical analysis fills the previously described gap in the literature and is therefore particularly suitable for triggering further empirical social media research in a financial context.

\section{f. Limitations and Further Research}

While my results provide empirical insights into merger-related blog posts, my research provides motivation for future research directions in this field. My empirical analysis is based on word count measures that I aim to refine in future research. A possible approach is to improve my described word count measures by applying additional word lists that reflect more accurately the notion of texts in a financial context (Loughran \& McDonald 2011). Furthermore, since a merger passes through several phases, it would be interesting to explore the changes of reflected uncertainty in blog posts over time. 


\section{Paper 4}

Table 28: Fact Sheet of Paper 4a (Zülch et al. 2014a)

\begin{tabular}{|l|l|}
\hline Title & Drivers of Information Quantity: The Case of Merger-Acquisition Events \\
\hline Authors & $\begin{array}{l}\text { Mirko Jan Zülch, mirko.zuelch @ wiwi.uni-goettingen.de* } \\
\text { Balaji Rajagopalan, bur14@ @su.edu** } \\
\text { Jan Muntermann, muntermann@ wiwi.uni-goettingen.de* }\end{array}$ \\
*University of Göttingen \\
**Pennsylvania State University
\end{tabular}

\section{a. Introduction}

From Twitter to Facebook, social media activity (i.e. the creation and exchange of usergenerated content) is a key driver of business models' success (Luo et al. 2013). It is hence no surprise that social media platforms direct significant efforts to keep the user engaged and create content. Research on what drives information exchange in social media is critical to understanding why some social media businesses succeed while others fail. While prior studies in business-related disciplines (e.g. IS, finance, and marketing) have focused on a range of issues relating to social media, most of it is primarily concerned with the influence and predictive power of user-generated content (UGC) (Antweiler \& Frank 2004; Godes \& 
Mayzlin 2004; Luo et al. 2013). Moreover, studies build upon social cognitive theory and the social capital theory in order to investigate and explain information exchange in virtual communities (Lu \& Yang 2011; Chiu et al. 2006).

Little attention, however, has been directed to studying drivers of information exchange relating to major business events such as corporate actions. As businesses aim at leveraging the power of social media, an understanding of what drives online chatter relating to the firm can be critical for crafting social media strategies. As a critical first step, in this exploratory study, we examined how factors relating to two categories - Firm Visibility and Information Needs influence the generation of postings in social media. We study this in the context of a very common and important financial business event - mergers and acquisitions. Using merger events as the context of our study, our research aims to answer the following research question: What are the influencing factors that drive information exchange in social media subsequent to the announcement of major business events?

With an extensive dataset that spans multiple social media platforms, our study is among the first to provide insights into drivers of information quantity for business events across both synchronous (e.g. Twitter) and asynchronous (e.g. message boards or blogs) social media platforms.

The remainder of this paper is organized as follows. In the next section, we review related prior work and develop our hypotheses. In section G.IV.c, we describe our datasets. Next, we outline the empirical approach, present analyses and discuss the findings. The final section presents concluding remarks and addresses the limitations of our work and potential future research directions.

\section{b. Literature Review and Hypotheses Development b.1 Social Media and User-Generated Content}

According to Kaplan \& Haenlein (2010) social media in general can be defined as: "a group of Internet-based applications that build on the ideological and technological foundations of Web 2.0, and that allow the creation and exchange of User-Generated Content" (p. 61). Types of social media discussed by the authors include: blogs, social networking sites, collaborative projects, content communities, virtual social worlds, and virtual gaming world. Other types of 
social media generally discussed in practice and research include microblogging services and online message boards.

Taken cumulatively, various types of social media platforms enable individuals/firms to communicate, express opinions and feelings, share information, provide feedback, and to facilitate the building of interpersonal/business-customer relationships on an unprecedented scale. At the center of social media platforms is the engaged user who is responsible for both generating and disseminating of content. According to the OECD (2007), user-generated content can be defined as "i) content made publicly available over the Internet, ii) which reflects a certain amount of creative effort, and iii) which is created outside of professional routines and practices" (p. 4). UGC can be considered as an output through the use of social media by individuals (Kaplan \& Haenlein 2010). There is little doubt that the advent of social media fundamentally changes the way in which people generate and exchange information where the density of digital interconnectedness is driven by users themselves. Indeed, social media enables individuals to spread and share UGC on an unmatched scale and pace (Luo et al. 2013).

The value resulting from this unique ability of social media to reach hundreds of millions of users almost instantaneously is now well recognized by individuals, firms and researchers. Today, due to the vast amount of information exchange by individuals that is facilitated by social media, researchers have the opportunity to directly observe human behavior (Golder \& Macy 2012). Enabled through social media, online business communities are emerging with increasing frequency. In virtual communities, communication is facilitated by the use of different types of social media, discussing all kinds of business-related subjects ranging from topics related to products to global market events. In the context of merger-acquisition events, Zülch et al. (2014b) showed that the consecutive choices of social media types determine the communication process following a merger announcement. More so today than in the early days of digital technologies, social media is used and perceived to be a reliable source of information. For example in the financial domain, social media types like blogs are commonly used for providing investment advice and further insights on market events (Fotak 2007). Previous empirical research used social media-based metrics like volume (i.e. quantity), dispersion, and the valence of UGC in order to investigate the influence of UGC (Godes \& Mayzlin 2004; Liu 2006; Luo et al. 2013). IS, finance, and marketing literature 
likewise made use of these metrics and investigated the predictive power of UGC with regards to different types of social media. In doing so, studies applied these metrics to different research objectives and contexts, like product sales, capital market performance and major business events.

Information systems and marketing literature has focused on areas like the influence of UGC (in this context also known as electronic word-of-mouth (eWoM)) on product sales. Several studies analyzed the impact of UGC in the context of box office revenues and TV show/movie ratings. Godes \& Mayzlin (2004) identified a significant relationship between the dispersion of UGC provided by online message boards (Usenet newsgroups) and future ratings of TV shows. Others investigated the role of UGC with respect to box office sales. Using data from message boards (e.g. Yahoo! Movies) and review sites, these studies show that, in contrast to ratings, the volume of UGC has predictive power with regard to box office revenues (Liu 2006; Dellarocas et al. 2007; Duan et al. 2008). In addition, Duan et al. (2008) could show that the volume of UGC is also strongly influenced by sales providing first insights concerning what influences the volume of UGC. Chevalier \& Mayzlin (2006) analyzed the influence of UGC (i.e. online reviews) on relative book sales at two online retailers. They found that the volume of UGC on the site of one online retailer also has an impact on book sales of the other retailer, whereby negative reviews have a greater influence compared to positive ones.

Furthermore, IS, finance, and marketing literature likewise are concerned with the predictive power of UGC in the financial domain. As one of the first studies, Wysocki (1998) investigated if the quantity of UGC (Yahoo! stock message board postings) is influenced by underlying firm characteristics and stock market activity. Accordingly, the quantity of UGC postings was highest for companies with high market capitalization, low institutional holdings, high number of analyst following, high market-to-book and price-earnings ratios, high trading volume and volatility, and extreme past returns. In addition, overnight posted UGC can predict changes in subsequent returns and trading volumes. Antweiler \& Frank (2004) also showed that the quantity of UGC (Yahoo! stock message board postings and raging bull message board postings) and the valence of UGC help to predict subsequent trading volumes, stock returns and stock volatility. Tirunillai \& Tellis (2012) used several metrics of UGC and investigated the relationship between UGC and stock market 
performance. UGC was correlated with abnormal returns, risk, and trading volumes. Interestingly, the quantity of UGC had the strongest relationship with abnormal returns and trading volume. In addition, negative UGC had the strongest effect (shorter wear-in time) on abnormal returns and trading volume. Other studies have focused on the extraction of the sentiment of UGC and investigated how this relates to stock market performance. Das \& Chen (2007) extracted investor sentiment from stock message boards and showed that the sentiment of UGC can be related to stock index levels, trading volumes, and volatility. Furthermore, Bollen et al. (2011) extracted the sentiment of daily UGC posted on Twitter (representing the public mood) and were able to find a correlation between the public mood and subsequent changes in the Dow Jones Industrial Average index values. Luo et al. (2013) analyzed the predictive relationships between social media and firm equity value. Their study is among the first to show that social media-based metrics like the valence and quantity of UGC postings on blogs and consumer ratings have more predictive power with regard to firm equity value compared to online behavioral metrics like the amount of web searches and web traffic. In addition, one of the most recent studies showed that blog coverage has an impact at the screening stage in a venture financing context (Aggarwal \& Singh 2013).

Overall, existing studies provide evidence that companies need to recognize the benefits of social media investments with regard to firm performance, strategic advantages and shareholder value creation.

\section{b.2 Information Exchange in Social Media - Hypotheses Development}

The previous section emphasizes the economic value of social media. In addition, in business contexts the literature on social media is mainly concerned with the influence of UGC, especially the predictive power of the quantity of UGC is recognized in the literature. Nevertheless, the growing body of literature on social media does not investigate what influences the generation of UGC related to major business events such as corporate actions (e.g. mergers). Individuals use social media for the creation and exchange of user-generated content. Information exchange in social media refers to the quality of content and the quantity of information exchanged (Lu \& Yang 2011). Information quantity represents the total amount of information exchanged, typically represented by the number of messages (postings) sent or exchanged (Lu \& Yang 2011). As a first step, in this paper we focus on the quantity of UGC. Therefore, our objective is to analyze what influences the quantity of UGC 
creation in a business context. As a first attempt in order to explore business-related factors that influence the quantity of UGC, we distinguish between firm characteristics, representing more general factors related to the firm, and event characteristics, representing event-related factors, meaning factors that are tied to and determined by the specific characteristics of a major business event itself. In doing so, we want to explore which of these factors drive information quantity exchanged in social media in the context of a major business event.

We chose the event of a merger attempt (i.e. a corporate action) in order to explore businessrelated factors that may influence information exchange in social media. In general, a merger is defined as the combination of two firms that form a single legal entity and is driven by financial, strategic, and managerial motives aiming to realize growth opportunities and synergistic gains (Napier 1989; SEC 2013). A merger attempt represents an adequate opportunity to investigate business-related factors that influence information exchange in social media since it represents an event of great interest and informational uncertainties for individuals (i.e. investors or potential investors). In our study, a merger attempt encompasses the time period from the merger announcement till the final outcome of a merger attempt is known (i.e. completion or withdrawal of the merger).

For investors and potential investors of involved companies, a merger attempt bears informational uncertainties on many levels. Depending on the structure of the deal (eventrelated factors), investors have to reevaluate their investment decisions (Louis \& Sun 2010). In order to make informed decisions with regard to the merger, information needs based on merger-related factors may incentivize decision-makers to engage in information exchange via social media during the merger process (Herrmann 2007). A lot of mergers fail with regards to their post-acquisition performance (Chakravorty 2012). Hence, investors have to assess if proclaimed synergies can be realized and if growth can be achieved. Moreover, the relatedness based on the field of business and industries of the two merging companies provide indication about the strategic fit of the combination of the two involved companies, meaning a higher probability for realizing synergistic gains achieved by the merger. A lack of strategic fit will result in a poor post-acquisition performance (Healy et al. 1992; Chakravorty 2012). In addition, the chosen method of payment for the transaction has a signaling effect to investors (Yook 2003). Overvalued acquirers tend to prefer financing the merger with equity (i.e. stocks) and undervalued acquirers tend to prefer financing the transaction with cash 
(Myers \& Majluf 1984). Cash financed deals signal the acquirer's confidence in realizing synergistic gains, meaning less uncertainty about the post-acquisition performance, whereby stock financed deals may require additional information and evaluation of the offer (Goergen $\&$ Renneboog 2004). Finally, the deal size and moreover the magnitude of the difference of the firm size of the involved parties are indicators of the financial risk of the acquirer, giving investors reason to talk about the merger in order to assess the situation at hand (Louis \& Sun 2010).

To conclude, information asymmetries do exist between merging companies and investors (Healy \& Palepu 2001). Individuals may engage in information exchange via social media, leading to the generation of UGC postings in order to reduce informational uncertainties with regard to the merger attempt. Information Needs are caused by the previously described distinct deal characteristics of a merger attempt (event-related factors) that incentivize investors to engage in online information exchange in order to satisfy their information needs (Wysocki 1998). Hence, we posit:

Hypothesis 1 (H1): Event characteristics related to event-specific information needs have a significant predictive relationship with the information quantity exchanged in social media.

Besides event-related factors that trigger Information Needs, other more general and eventunrelated factors representing firm characteristics of each of the involved companies may influence information exchange in social media. To some extent, users may talk about an announced merger because they are familiar with one or both of the involved companies. The level of awareness about a firm is determined by a firm's visibility (Chang et al. 2012; Pfarrer et al. 2010). Firm Visibility can influence the awareness about a firm and can draw the attention of an investor or an individual to an event like a merger and accordingly will be more likely to talk about the merger.

Several factors determine the visibility of a firm. Higher media coverage by traditional news media creates more awareness among users of social media about a firm and thus it is more visible (Aggarwal et al. 2012; Chang et al. 2012, Pfarrer et al. 2010). In addition, the greater the size of a firm, the more it receives media coverage and analyst following which positively influences the visibility of a firm (Bushee \& Miller 2012; Pfarrer et al. 2010; Wysocki 1998). Furthermore, the proportion of shares of a firm that are held by ordinary investors and not held by institutional investors as a strategic investment, is also an indicator that the ownership 
of a company is more dispersed among a higher amount of investors leading to a higher visibility in the capital market (Chang et al. 2012; Pfarrer et al. 2010; Wysocki 1998). Finally, from a consumer perspective, if a firm is more focused on selling goods and services to consumers, it creates awareness and visibility among consumers who then engage in online discussions concerning these products and their producers (Capriotti 2009; Godes \& Mayzlin 2004). We posit that a firm's visibility is associated with the information quantity exchanged in social media:

Hypothesis 2 (H2): Firm characteristics related to a firm's visibility have a significant predictive relationship with the information quantity exchanged in social media.

To conclude, in the context of a major business event such as a merger announcement, we are investigating if the quantity of UGC postings is influenced by Firm Visibility of involved firms and/or by Information Needs triggered by the merger attempt.

\section{c. Data}

We used several databases for the data collection process. For all financial data, we used Thomson Reuters SDC Platinum database (SDC) and Thomson Reuters Datastream (Datastream), which are very commonly used in empirical financial studies (Bates \& Lemmon 2003; Faccio \& Masulis 2005). In addition, we used LexisNexis in order to access published news articles (Antweiler \& Frank 2004). Finally, we used Social Intelligence Solutions' SM2 database (SDL-SM2) to obtain UGC posted via various social media types and platforms.

\section{c.1 Sample Selection - Event Data}

First, we identified 5,022 US Merger transactions that were announced between 1.1.2008 and 31.12.2011 (SDC). In order to ensure the attention by individuals (e.g. private investors) concerning these transactions, only mergers of listed companies were included where the deal value was equal or greater $\$ 100$ million (Kau et al. 2008), leaving us with 323 observations. In addition, only merger attempts were included for which the outcome of the merger process (i.e. 'completed' or 'withdrawn') was already known, leaving us with 318 merger attempts (Bates \& Lemmon 2003). Furthermore, in order to ensure coverage by social media, we focused on mergers attempts that were announced between 1.1.2010 and 31.12.2011. Finally, based on the availability of data from other data sources (which will be described in the 
following section), we were left with 143 observations in our sample. Table 29 provides an overview of the sample selection with respect to the merger data and overall data availability.

Table 29: Sample Selection

\begin{tabular}{|l|l|}
\hline \multicolumn{2}{|c|}{ Merger -Data } \\
\hline No. of Observations after Query & \multicolumn{1}{c|}{ Query Description } \\
\hline 5,022 & $\begin{array}{l}\text { US merger transactions announced between 1.1.2008 } \\
\text { and 31.12.2011 }\end{array}$ \\
\hline 640 & Only public companies \\
\hline 323 & Deal value at least \$100 million \\
\hline 159 & $\begin{array}{l}\text { Deal status is either 'completed' or 'withdrawn' as of } \\
\text { July 2012 }\end{array}$ \\
\hline 143 & Merger announced between 1.1.2010 and 31.12.2011 \\
\hline
\end{tabular}

\section{c.2 Data Collection}

SDC provides merger- and company-related data (e.g. names of merging companies and the date of announcement). We made use of Datastream in order to gather financial and companyrelated information that was not provided by SDC. As mentioned above, we used LexisNexis in order to obtain news articles citing a respective company of our sample. We used the company search feature of LexisNexis in order to maximize the accuracy of our queries. In addition, LexisNexis provides the opportunity to restrict the search to specific sources.

SDL-SM2 is a database for historical social media content which gave us the opportunity to not only focus on one specific social media platform representing one specific social media type, but to analyze UGC postings across the whole variety of social media types. In the social media literature, a lot of studies focus their inquiries on one specific social media type and platform (Das \& Chen 2007; Aggarwal et al. 2012; Bollen et al. 2011). In contrast, our study is concerned with the overall information exchange, including various social media types represented by all kinds of social media service providers and platforms. We made use of SDL-SM2 in order to identify merger-related UGC. SDL-SM2 captures data from all kinds of social media platforms as well as provides extensive historical data including in-depth information for each identified search result. SDL-SM2 also provides the possibility to use 
specific search strings, apply a filter for languages, and set a date range for which results are retrieved. Table 30 provides a description of the available data that is provided for each search result (original denotation of SDL-SM2).

Table 30: SDL-SM2 - Data Fields

\begin{tabular}{|l|l|}
\hline \multicolumn{1}{|c|}{ Data Field } & \multicolumn{1}{c|}{ Description } \\
\hline Media Type & $\begin{array}{l}\text { "Message Board/Forum", "Microblog", "Blog", "Social Network", } \\
\text { "Video/Photo Sharing", "Wiki", or "Media Types - Other" }\end{array}$ \\
\hline Platform & Identified social media platform (e.g. Facebook or Twitter) \\
\hline Author Name & Name or nickname of the author of UGC \\
\hline Full Content & Textual content of UGC \\
\hline Blog URL & URL of the social media platform \\
\hline Time Published & Date and time of publication \\
\hline
\end{tabular}

SDL-SM2 classifies each result to one out of six social media types, which is in line with the classification of social media types of previous literature (Kaplan \& Haenlein 2010). A list of these media types and a well-known example found in our sample for each of these is as follows: "Message Board/Forum" - finance.yahoo.com/mb/, "Microblog" - twitter.com, "Blog" - blogger.com, "Social Network" - facebook.com, "Video/Photo Sharing" youtube.com, "wiki" - wikipedia.org. Results that that cannot be assigned to one of the six mentioned social media types are classified as "Media Types - Other" representing content provided by professional news sites that cannot be considered as UGC (OECD 2007).

\section{d. Empirical Approach}

\section{d.1 Variables}

In the following we describe the operationalization of the previously described constructs according to our formulated hypotheses (see section G.IV.b.2).

\section{d.1.1 Information Quantity - Dependent Variable}

Quantity of UGC (QUGC): Following Lu \& Yang (2011), we operationalize information quantity that is exchanged in social media as the number of UGC postings. We collected postings across all social media types (content classified as "Wiki" and "Media Types Other" are excluded) per merger attempt that have been posted between the date of announcement of a merger attempt and the date when the final outcome of the merger attempt 
is known (SDL-SM2). For each merger attempt, we applied the following Boolean search expression in order to maximize accuracy in identifying merger-related UGC: "name of acquiring company" AND "name of the target company" and filtered for content written in English language. Finally, we were left with a total of 104,337 social media postings for our sample $(\mathrm{N}=143)$.

\section{d.1.2 Information Needs - Independent Variables}

Relatedness (R): We measure the degree of relatedness between a potential acquirer's industry and the target's industry by comparing the two-digit SIC code (Standard Industrial Classification) of both companies (SDC). The value of one indicates that both companies' business is related and zero otherwise (binary variable) (Louis \& Sun 2010).

Method of Payment (MOP): SDC provides information about the method of payment of the transaction for all merger attempts in our sample. The transaction can be carried out by either a transaction of cash, stock, a mixture of both, or other forms of payment. The value of one indicates that a transaction in our sample would have been carried out by cash and zero otherwise (binary variable) (Yook 2003).

Deal Value (DV): Magnitude of a merger attempt is measured as the total amount of consideration paid by the acquirer (excluding fees and expenses) (SDC) (Luo 2005).

Ratio of Target-to-Bidder Size (T-MV/A-MV): The relative size of companies involved in a merger attempt is measured as the ratio of the target's market value to the market value of the acquirer (Rosen 2006). The market value of a company is measured as the share price multiplied by the number of ordinary shares in issue four weeks prior to the announcement of a merger attempt (SDC) (Schwert 2000).

\section{d.1.3 Firm Visibility - Independent Variables}

Media Attention (A-MA or T-MA): In our sample we differentiate between companies that receive a lot of media coverage and those who do not. Hence, Media Attention is measured as the total number of articles citing the name of a company published in The Wall Street Journal and The New York Times (LexisNexis) (Power 2004; Antweiler \& Frank 2004). For each company involved in a merger attempt, we only took articles into account that were published during the year prior to the announcement of the merger attempt. The value of one 
indicates that a company is in the top quartile of number of citations across companies in our sample and zero otherwise (binary variable) (Pfarrer et al. 2010).

$B 2 B$ vs. $B 2 C$ (A-B2B or T-B2B): The business model of each company in our sample has been classified with regard to their four-digit SIC code as either being business-to-business (B2B) oriented or being business-to-consumer (B2C) oriented.

Firm Size (A-FS or T-FS): The enterprise value of each company is used in order to measure Firm Size of each company in our sample (Agrawal \& Nasser 2012; Mantecon 2008). The enterprise value is commonly calculated by "adding together a company's market capitalization, its debt such as bonds and bank loans, other liabilities such as a pension fund deficit and subtracting liquid assets like cash and investments" (Thomson Reuters Financial Glossary 2013). For each company the enterprise value is determined as of the date of the end of the prior fiscal year before the announcement of a merger attempt (Datastream).

Free Float (A-FF or T-FF): For each company Free Float was measured as the percentage of total shares in issue that are available to ordinary investors (strategic holdings are excluded) as of the date of the end of the prior fiscal year before the announcement of a merger attempt (Datastream) (Chang et al. 2012).

Table 31 provides an overview of all the described variables above as well as the respective data source. 
Table 31: Description of Variables

\begin{tabular}{|l|l|l|l|}
\hline \multicolumn{1}{|c|}{ Construct } & \multicolumn{1}{|c|}{ Name of Variable } & \multicolumn{1}{|c|}{ Abbreviation } & Data Source \\
\hline Information Quantity & Quantity of UGC & QUGC & SDL-SM2 \\
\hline \multirow{5}{*}{ Information Needs } & Relatedness & R & SDC \\
\cline { 2 - 4 } & Method of Payment & MOP & SDC \\
\cline { 2 - 4 } & Deal Value & DV & SDC \\
\cline { 2 - 4 } & Ratio of Target-to-Bidder Size & T-MV/A-MV & SDC \\
\hline \multirow{3}{*}{ Firm Visibility } & $\begin{array}{l}\text { Media Attention (of acquirer or } \\
\text { target company) }\end{array}$ & A-MA or T-MA & LexisNexis \\
\cline { 2 - 4 } & $\begin{array}{l}\text { B2B vs. B2C (of acquirer or } \\
\text { target company) }\end{array}$ & A-B2B or T-B2B & SDC \\
\cline { 2 - 4 } & $\begin{array}{l}\text { Firm Size (of acquirer or target } \\
\text { company) }\end{array}$ & A-FS or T-FS & Datastream \\
\cline { 2 - 4 } & $\begin{array}{l}\text { Free Float (of acquirer or target } \\
\text { company) }\end{array}$ & A-FF or T-FF & Datastream \\
\hline
\end{tabular}

\section{d.2 Analysis and Discussion}

To test the proposed hypotheses, we use a multiple linear regression model (in SPSS) for which all previously described variables (see Table 31) are used as predictors for the Quantity of UGC (QUGC). In addition, specific continuous variables (DV; T-MV/A-MV; A-FS; T-FS; QUGC) have been log transformed in order to reduce skewness and improve data normality. We also applied an arcsine transformation to variables measured as percentages (A-FF; T-FF) in order to reduce skewness and improve data normality (McDonald 2009).

Analysis of variance inflation factors (VIFs) indicates no evidence of multicollinearity between predictors. Furthermore, residual analyses verified the assumptions of normally distributed errors and homoscedasticity. In addition, no serial correlations between errors have been detected (Durbin-Watson test).

The descriptive statistics of continuous and binary variables are provided by Table 32 . 
Table 32: Descriptive Statistics

\begin{tabular}{|c|c|c|c|c|c|c|}
\hline Variable & Mean & Std. Deviation & & $\mathbf{N}$ & Min. & Max. \\
\hline log_DV & 2.976 & 0.594 & \multicolumn{2}{|c|}{143} & 2.000 & 4.468 \\
\hline log_T-MV/A-MV & -0.934 & 0.736 & \multicolumn{2}{|c|}{143} & -3.315 & 0.552 \\
\hline log_A-FS & 3.958 & 0.652 & \multicolumn{2}{|c|}{143} & 0.000 & 5.353 \\
\hline log_T-FS & 2.912 & 0.700 & \multicolumn{2}{|c|}{143} & 0.000 & 4.467 \\
\hline arc_A-FF & 1.204 & 0.229 & \multicolumn{2}{|c|}{143} & 0.451 & 1.571 \\
\hline arc_T-FF & 1.082 & 0.244 & \multicolumn{2}{|c|}{143} & 0.383 & 1.571 \\
\hline log_QUGC & 2.437 & 0.609 & \multicolumn{2}{|c|}{143} & 0.903 & 4.235 \\
\hline \multirow{2}{*}{$\mathrm{R}$} & \multirow{2}{*}{0.720} & \multirow{2}{*}{0.450} & 0 & 40 & \multirow{2}{*}{0.000} & \multirow{2}{*}{1.000} \\
\hline & & & 1 & 103 & & \\
\hline \multirow{2}{*}{ MOP } & \multirow{2}{*}{0.450} & \multirow{2}{*}{0.500} & 0 & 78 & \multirow{2}{*}{0.000} & \multirow{2}{*}{1.000} \\
\hline & & & 1 & 65 & & \\
\hline \multirow{2}{*}{ A-MA } & \multirow{2}{*}{0.240} & \multirow{2}{*}{0.427} & 0 & 109 & \multirow{2}{*}{0.000} & \multirow{2}{*}{1.000} \\
\hline & & & 1 & 34 & & \\
\hline \multirow{2}{*}{ T-MA } & \multirow{2}{*}{0.200} & \multirow{2}{*}{0.398} & 0 & 115 & \multirow{2}{*}{0.000} & \multirow{2}{*}{1.000} \\
\hline & & & 1 & 28 & & \\
\hline \multirow{2}{*}{ A-B2B } & \multirow{2}{*}{0.620} & \multirow{2}{*}{0.488} & 0 & 55 & \multirow{2}{*}{0.000} & \multirow{2}{*}{1.000} \\
\hline & & & 1 & 88 & & \\
\hline \multirow{2}{*}{ T-B2B } & \multirow{2}{*}{0.590} & \multirow{2}{*}{0.494} & 0 & 59 & \multirow{2}{*}{0.000} & 1000 \\
\hline & & & 1 & 84 & & 1.000 \\
\hline
\end{tabular}

The model is specified as follows:

$\log _{-} Q U G C_{i}=b_{0}+b_{1} R_{i}+b_{2} M O P_{i}+b_{3} \log _{-} D V_{i}+b_{4} \log _{-} T-M V / A-M V_{i}+b_{5} A-M A_{i}+b_{6} T-$

$M A_{i}+b_{7} A-B 2 B_{i}+b_{8} T-B 2 B_{i}+b_{9} l o g_{-} A-F S_{i}+b_{10} l o g_{-} T-F S_{i}+b_{11} a r c \_A-F F_{i}+b_{12} a r c_{-} T-F F_{i}$

$+\varepsilon_{i}$

Let $\mathrm{i}=1, \ldots, \mathrm{N}$ index the merger attempts.

The results of the linear regression are presented in Table 33. The regression model overall predicts the Quantity of $U G C$ (log_QUGC) significantly well (F is 11.042). The overall model is significant, explaining 50.5\% (45.9\% - adjusted R Squared) of the variance in the Quantity of UGC. While there is evidence that two key variables - Deal Value and Media Attention of 
our two constructs - Firm Visibility and Information Needs are driving online chatter (i.e. Quantity of $U G C)$. Both variables make a significant contribution $(\mathrm{p}<0.01)$ to predict the Information Quantity in social media.

The coefficient of Deal Value (log_DV) is positive (0.708) and statistically significant. This means that a $1 \%$ increase of the Deal Value leads to an increase of the total Quantity of UGC (log_QUGC) by $0.708 \%$. Furthermore, the coefficient of Acquirer's Media Attention (A-MA) is also positive (0.364) and significant. The predicted Quantity of UGC (log_QUGC) is approximately $36.4 \%$ higher for companies belonging to the group that receives high media coverage. Overall, results show support for hypotheses 1 and 2.

Table 33: Regression Output

\begin{tabular}{|l|l|l|l|l|}
\hline \multicolumn{5}{|c|}{ Dependent Variable $=$ log_QUGC } \\
\hline \multicolumn{1}{|c|}{ Variable } & \multicolumn{1}{c|}{ Coefficient } & \multicolumn{1}{c|}{ Standard Error } & t-value & Sig. \\
\hline (Constant) & 0.533 & 0.361 & 1.476 & 0.14 \\
\hline R & 0.018 & 0.090 & 0.198 & 0.84 \\
\hline MOP & 0.077 & 0.090 & 0.858 & 0.39 \\
\hline log_DV & $0.708^{* * * *}$ & 0.140 & 5.038 & 0.00 \\
\hline log_T-MV/A-MV & -0.040 & 0.092 & -0.431 & 0.67 \\
\hline A-MA & $0.364^{* * * *}$ & 0.119 & 3.065 & 0.00 \\
\hline T-MA & 0.042 & 0.105 & 0.399 & 0.69 \\
\hline A-B2B & -0.001 & 0.116 & -0.013 & 0.99 \\
\hline T-B2B & 0.099 & 0.117 & 0.850 & 0.40 \\
\hline log_A-FS & 0.055 & 0.096 & 0.573 & 0.57 \\
\hline log_T-FS & -0.139 & 0.103 & -1.349 & 0.18 \\
\hline arc_A-FF & -0.263 & 0.193 & -1.363 & 0.18 \\
\hline arc_T-FF & 0.059 & 0.168 & 0.349 & 0.73 \\
\hline
\end{tabular}

$R$ Squared $=50.5 \%($ Adjusted $R$ Squared $=45.9 \%) ; F=11,042 * * *$

*** indicates $1 \%$ level of significance

The significant influence of Deal Value on Quantity of UGC (H1) suggests that online discussions are driven by the significance of the transaction. Higher value deals attract the attention of users and the sheer magnitude of the merger event serves to generate higher online chatter activity. Interestingly, the other variables (R; MOP; T-MV/A-MV) in the 
Information Needs category appear to have little influence on chatter activity in terms of the amount of information exchanged. Specifically, the information quantity in social media is not influenced by the evaluation uncertainties indicated by the method of payment. One possible explanation for this result could be that most merger-acquisition deals involve high levels of informational uncertainties and the method of payment does little to reduce it, at least in the initial stages. Initial results on Relatedness suggest that there is no impact on the Quantity of UGC. In our analysis, merging companies of different fields of business do not drive online chatter activity. This requires further investigation. It is possible that this relationship is more nuanced and the binary coding based on the two-digit SIC code doesn't help us uncover the dynamics. In addition, the Ratio of Target-to-Bidder Size (T-MV/A-MV) does not drive online chatter. This also supports the notion that the pure size of the merger attempt is driving online chatter and that the relative size of both companies does not attract the attention of social media users.

With respect to Firm Visibility, the significant impact of the Acquirer's Media Attention on the Quantity of $U G C(\mathrm{H} 2)$ suggests that online chatter is also driven by media exposure of the acquiring company. It is particularly important to underline that media exposure was measured prior to the merger attempt and thus firms have little leverage over the information exchange in social media relating to a particular event. Consequently, firms' persistent efforts over a long period of time to be covered in the press do pay off when such events occur. Conclusively, firms are well advised to design strategies for creating visibility of their company over the long run to reap benefits of significant social media activity relating to specific events and corporate actions (Aggarwal \& Singh 2013).

The lack of association of other measures related to Firm Visibility (T-MA; A-B2B; T-B2B; A-FS; T-FS; A-FF; T-FF) requires further inquiry. Surprisingly, the size of a firm (A-FS; TFS) does not drive the Quantity of UGC, whereat Acquirer's Media Attention does (H2). It is reasonable to expect that larger firms would experience more news coverage than smaller firms and thus, the size of a firm should also influence online chatter activity. More surprisingly, occurring online chatter in the event of a merger attempt depends not on a company's field of business being associated with the everyday life of social media users. Our analysis does not support that consumer-oriented companies attract more amounts of UGC being generated. Furthermore, the Quantity of $U G C$ is not influenced by the dispersion of 
ownership among institutional and ordinary investors. Since social media is heavily used by private investors to discuss stock and trading related topics (Antweiler \& Frank 2004), this slightly indicates that there is no connection between the Information Quantity in social media and the structure of ownership of companies.

In general, the results indicate that our suggested constructs account significantly for the Information Quantity in social media related to companies that are involved in a merger attempt. Although, both constructs Firm Visibility and Information Needs explain a significant percentage of the variation in the total quantity of user-generated content, further research is needed to understand the dominant nature of these influencers.

\section{e. Conclusions}

Business and research likewise acknowledge the potential and economic value of social media. In this paper we explored how factors influence online chatter activity (UGC) in terms of information quantity in the context of economic events. In the context of merger attempts, we explored factors that are either related to the event or factors that are determined by certain characteristics of the involved companies. We made use of a rich data set that is not limited to specific social media types and platforms but also includes financial market data. We were able to show that the magnitude of transaction (i.e. Deal Value) and the media coverage of the acquiring company (i.e. Media Attention) explain a significant percentage of the variation in the total quantity of information (i.e. Quantity of $U G C$ ) shared via social media platforms in the event of a merger attempt.

In doing so, we contribute to the growing body of literature on information exchange in social media by proposing two categories of influencers - Firm Visibility and Information Needs on information exchange in social media. Our exploratory analysis suggests that there is evidence of strong positive influence of both these categories. Building on this study which explored the UGC postings across various social media types and platforms, it is important to construct a theory of information exchange in social media that helps uncover deep interconnections between the characteristics of social media platforms, user activity, and the business context. In the social media literature the predictive power of both quantity and quality of UGC has been investigated (Antweiler \& Frank 2004; Luo et al. 2013). Therefore, our study is a first exploratory attempt to understand influencing factors on the quantity of information exchange via social media in the case of merger-acquisition events. 
Finally, our findings bear important practical implications. Our analysis revealed that eventrelated factors are not only responsible for event-related information exchange in social media. Instead, firm-related factors are also responsible for higher amounts of information exchange in social media. This means that businesses, which want to leverage the power of social media, cannot rely only on short-term corporate social media strategies. To attract attention in social media, i.e. to achieve desired amounts of online chatter with respect to corporate actions and business events, firms have to design strategies for creating higher levels of firm visibility, which can only be achieved in the long term. For example, a generally higher level of media coverage cannot easily be achieved by short-term measures.

\section{f. Limitations and Further Research}

While our results provide empirical insights into drivers of online chatter (UGC) related to major business events, our research provides motivation for future research directions in the field of information exchange via social media. Our research is based on some basic measures (e.g. Relatedness) that we aim to refine on future research in order to capture and explore more deeply what drives information exchange via social media. Moreover, since we explored influencing factors on the quantity of postings that were generated on social media platforms, from a scientific and practical perspective it is also important to explore influencing factors on the nature of the content itself, i.e. the quality of the shared content. Furthermore, in order to unravel drivers of information exchange in social media even further, a comprehensive analysis is needed that reveals the dynamics between social media types and their distinctive characteristics with regard to the creation of user-generated content. 


\section{Paper 5}

Table 34: Fact Sheet of Paper 5 a (Zülch et al. 2014)

\begin{tabular}{|c|c|}
\hline Title & Drivers of Information Quality on Blogs: The Case of Business Events \\
\hline Authors & $\begin{array}{l}\text { Mirko Jan Zülch, mirko.zuelch@ wiwi.uni-goettingen.de* } \\
\text { Jan Muntermann, muntermann@ @iwi.uni-goettingen.de* } \\
\text { Balaji Rajagopalan, bur14@psu.edu** } \\
\text { *University of Göttingen } \\
\text { **Pennsylvania State University }\end{array}$ \\
\hline Outlet & $\begin{array}{l}\text { Proceedings of the 20th Americas Conference on Information Systems (AMCIS } \\
\text { 2014) }\end{array}$ \\
\hline Abstract & $\begin{array}{l}\text { With the exponential growth of online content in general and social media in } \\
\text { particular, quality of content has important business implications. Hence, the } \\
\text { often heard phrase - "content is king". While the importance of information } \\
\text { quality is well established, the question of what factors drive content quality } \\
\text { has received limited attention. In this exploratory study, we seek to understand } \\
\text { the drivers of information quality on blogs in the context of business events. } \\
\text { We posit that event characteristics (information needs) and firm characteristics } \\
\text { (firm visibility) jointly influence blog information quality. Our empirical } \\
\text { analysis shows that quality of information is high where information needs are } \\
\text { high and mixed results regarding the relationship between information quality } \\
\text { of blog content and firm visibility. }\end{array}$ \\
\hline Keywords & $\begin{array}{l}\text { Information Quality, Blog, Social Media, Social Media Analytics, Mergers and } \\
\text { Acquisitions }\end{array}$ \\
\hline
\end{tabular}

\section{a. Introduction}

In reference to the merger of Google Inc and Motorola Mobility, on April 11th 2012 an anonymous blogger wrote: "You'd think that by now, google's $\$ 12.5$ billion purchase of motorola mobility (its largest acquisition ever) would be shaping into some sort of brilliant strategy. But you'd be wrong. We've heard little about google's plans since it announced the acquisition in august, other than vague commentary on how the purchase will strengthen google's patent portfolio."

From the brief excerpt above, it is clear that the blogger is establishing a link between lack of strategy and the expected success of the Motorola Mobility acquisition. Such an exposition can be valuable to investors. However, not all posts are likely to be relevant and useful. Hence, information quality of user-generated content (UGC) has been an important topic of 
study (Lu \& Yang 2011). Information quality "refers to the quality of content of information exchanged" (Lu \& Yang 2011, p. 530). Blog posts that provide quality content provide better information and reduce information-processing costs of readers (Gu et al. 2007). Some studies have investigated the influence of social capital in virtual communities on information quality (Lu \& Yang 2011). Few to our knowledge, however, have studied drivers of information quality of blogs in a business context. Our research is an attempt to provide insights that explain the drivers of information quality on blogs that have implications for both theory and practice. Aggarwal et al. (2012) suggest studying blog posts in different business settings amongst others in the context of merger and acquisition events. Our study builds on this idea and choses the event of a merger announcement to explore factors that influence the information quality of blog posts.

Using the business context of a merger-acquisition event, we study the following question: What are the influencing factors that drive information quality of blog posts?

In the next section, we provide a review of the relevant literature, followed by our hypotheses development. Then, we present the study setup, including the description of datasets, methodology and analysis. We conclude with a discussion of our findings, present limitations and describe potential future research directions.

\section{b. Blogs and User-Generated Content}

Prior research highlights the business value of social media and in particular that of blogs (Luo et al. 2013). Blogs offer a platform for generating UGC "where content (text, pictures, sound files, etc.) is posted on a regular basis and displayed in reverse chronological order" (Schmidt 2007, p. 1409). User-generated content represents “i) content made publicly available over the Internet, ii) which reflects a certain amount of creative effort, and iii) which is created outside of professional routines and practices" (OECD 2007, p. 4). The growth of the internet, the increased availability of blog hosting sites and blog software has propelled the exponential growth of blogs in recent years (Aggarwal \& Singh 2013). Similar to other types of social media, blogs contribute to quick generation of content and diffusion of information on the web (Luo et al. 2013).

Information shared on blogs can range from personal diaries to relevant insights into specific topic areas. Silva et al. (2008) provide a comprehensive overview about blog typologies in the literature. Blogs may be used to document one's life, provide commentary and opinions, 
express deeply felt emotions, articulate ideas through writing, and form and maintain community forums (Nardi et al. 2004).

While they have a lot in common with other platforms of UGC, blogs are different in some respects - there is typically a certain type of expertise expected from the blogger, it is an interactive communication platform with both 1-many (blogger-reader) and many-many (reader-commenter) interactions. In addition, Bloggers may interact with one another, via subscriptions or by joining a blogring, and form a blogger community (i.e. a virtual community or blogosphere) (Chau \& Xu 2012). A blogger community facilitates the exchange and spreading of information among bloggers. Bloggers that are well connected gain popularity and influence in the community (Aggarwal et al. 2012).

Blog content is considered by some as unbiased and informative (Johnson \& Kaye 2004). Consequently, blogs are viewed as having more credibility than traditional media because of their independent status and because they shed light on topics that may not be adequately covered by the traditional media (Johnson \& Kaye 2004). In addition, blogs often provide high information quality in terms of depth and the richness of insights they provide (Johnson \& Kaye 2004). An empirical investigation of blogs and traditional media in the context of the U.S. presidential election of 2008 showed that blog coverage has significant influence on the campaign process and the election outcome (Wattal et al. 2010).

In business contexts, blogs are frequently used as an alternative information source (Aggarwal et al. 2012). Several research streams highlight the benefits of blogs for business intelligence purposes (Chau \& Xu 2012). In a marketing context, blogs enable companies to acquire information about what people think about their and competitors' products, brands, services, and help firms manage customer relationships (Kozinets et al. 2010).

Studies show that UGC provided by blogs is particularly valuable in the finance domain. For example, blogs serve as a useful source of information for investors. Social media metrics (e.g. volume, valence and dispersion) can serve as an indicator to predict firm equity value compared to traditional online metrics (e.g. web traffic and web search metrics) (Luo et al. 2013). In addition, based on social media metrics blog posts reflect informational uncertainties due to financial market events (Zülch 2013). Furthermore, stock recommendations provided by blogs influence the market reactions (Fotak 2007). However, in general bloggers mainly provide information about stocks of large companies. 
Some prior work focused on the influence of UGC provided by blogs in the context of venture financing decisions (Aggarwal et al. 2012; Aggarwal \& Singh 2013). Word of mouth from blogs (eWoM) is known to influence venture financing decisions though the mechanism of signaling. In particular, negative eWoM from popular bloggers showed a greater influence on venture financing decisions compared to positive eWoM (Aggarwal \& Singh 2013). Nevertheless, eWoM from popular bloggers can support ventures to get higher funding. In addition, after controlling for eWoM, traditional media had no influence on venture financing (Aggarwal \& Singh 2013).

\section{c. Hypotheses Development}

The previous section highlights the influence and business value of blogs but drivers of information quality of blogs in business contexts are not explored in previous research. As stated before, blogs are a frequently used information source in business contexts. Accordingly, we chose merger events in order to investigate drivers of information quality of blogs because they represent events of informational uncertainties and trigger information needs for investors.

The U.S. Securities and Exchange Commission (SEC) defines mergers as "business combination transactions involving the combination of two or more companies into a single entity" (SEC 2013). Amongst other motives, mergers are expected to provide economies of scale and scope, to achieve strategic diversification and synergies, and to gain market power (Chakravorty 2012). Mergers, as an event of high stakes for all stakeholders, possess certain characteristics that trigger information needs for investors, potential investors, and businessminded individuals. From the time of announcement of a merger it may take months or even years depending on the circumstances until the final and official completion of the merger is announced. During this time period a merger has to be approved "by at least a majority of a company's shareholders if the merger will have a significant impact on either the acquiring or target company" (SEC 2013) and by regulatory authorities. In addition, the management of either one of the merging companies may withdraw from the transaction.

Financial information and information about the motives of a merger disseminated to market participants is very complex (Loughran \& McDonald 2014). This information, when processed by the market, results in price reactions following the announcement (Asquith 1983). A merger represents a situation with information asymmetry and informational 
uncertainty for investors (Healy \& Palepu 2001). Hence, investors or potential investors are incentivized to gather additional information with regards to the effect of such an event on the firms involved in the merger. Investors seek to close the gap of information asymmetry by using a variety of sources of information including blogs to meet their information needs as part of their sense-making process (Herrmann 2007). Here, blogs are a useful information source for investors in order to satisfy information needs and to make sense of the situation at hand. We posit that a greater information need in the market is associated with better information quality of blogs to meet this need:

Hypothesis 1 (H1): Event characteristics related to event-specific information needs are positively related to information quality of blog content.

Certain firm characteristics of the companies involved in a merger may influence not only coverage by blogs but also drive the information quality. Market awareness of a firm is influenced by certain factors which determine a firm's visibility (Capriotti 2009). We argue that the status of high visibility has resulted in creating high awareness of the firm and this higher level of awareness of the context will drive higher quality content. Hence, we posit:

Hypothesis 2 (H2): Firm characteristics related to a firm's visibility are positively related to information quality of blog content.

By testing the two hypotheses our study aims to explore how event characteristics related to event-specific information needs and firm characteristics related to a firm's visibility influence the information quality of blog posts.

\section{d. Empirical Analysis}

\section{d.1 Data}

\section{d.1.1 Sample}

To create a sample of merger events we made use of the Reuters SDC Platinum database. In our study we focus on the US market and identified 5,022 merger attempts that took place between 2008 and 2011. In order to ensure data availability of merger transactions and the respective blog coverage, we focused on merger attempts of public companies with a deal value of at least $\$ 100$ million (Kau et al. 2008). Our study is focused on the information quality of blog posts following a merger announcement where the final outcome is known (Bates \& Lemmon 2003). As an exploratory study, we further restricted the sample to merger 
attempts that were announced between 2010 and 2011, leaving us with a sample of 150 merger attempts. An overview of the sample collection is given by Table 35 .

Table 35: Sample Selection

\begin{tabular}{|l|l|}
\hline \multicolumn{1}{|c|}{ Query Description } & No. of Observations \\
\hline US merger transactions (between 2008 and 2011) & 5,022 \\
\hline Public companies only & 640 \\
\hline Deal value is equal or higher \$100 million & 323 \\
\hline Deal status is either completed or withdrawn (as of July 2012) & 318 \\
\hline Merger announced between 2010 and 2011 & 159 \\
\hline Data availability & 150 \\
\hline
\end{tabular}

\section{d.1.2 Data Collection}

In our data collection process we made use of several databases. We used Thomson Reuters Datastream and the Thomson Reuters SDC Platinum database (SDC) in order to collect merger-specific and company-specific data. LexisNexis was used to collect news articles related to companies in our sample. Our blog data was collected from SDL's SM2 platform providing access to historical social media data. SDL is continuously monitoring and crawling social media content that is stored in their SM2 database, which is then typically licensed to corporate users or market analysts.

SDL-SM2 provides several search options and gave us the opportunity to collect blog posts that are related to mergers in our sample. From a research perspective, using a publicly available data source that can be licensed by others has the advantage that our data collection is reproducible. We applied the following Boolean search expression for each merger in order to find relevant blog posts: "name of acquirer" AND "name of the target company", at which the publication date of identified blog posts had to be between the date of announcement of the merger attempt and the date of the final outcome of the merger attempt. We filtered for content written in English and deleted duplicates and results with missing content. In total, we were left with 27,047 blog posts. Table 36 provides a list of the relevant data fields that are provided by SDL-SM2. 
Table 36: SDL-SM2 - Data Fields

\begin{tabular}{|l|l|}
\hline \multicolumn{1}{|c|}{ Data Field } & \multicolumn{1}{c|}{ Description } \\
\hline Author Name & Name of the author \\
\hline Title & Title of the blog post \\
\hline Full Content & Content of blog post \\
\hline Blog URL & URL of the blog \\
\hline Time Published & Date and time of publication \\
\hline
\end{tabular}

\section{d.2 Variables}

\section{d.2.1 Dependent Variables (Information Quality)}

The information science and information systems literature provides several frameworks in order to assess information quality (Knight \& Burn 2005; Wang \& Strong 1996). Other social media studies adopted several dimensions from these frameworks in order to assess information quality of UGC (Lu \& Yang 2011). We adopt this idea in order to create measures that measure certain dimensions of information quality. Table 37 provides a description of adopted dimensions of information quality that we quantitatively measure for each blog post.

Table 37: Dimensions of Information Quality based on Wang \& Strong (1996)

\begin{tabular}{|l|l|}
\hline \multicolumn{1}{|c|}{ Dimension } & \multicolumn{1}{c|}{ Definition } \\
\hline Understandability & extent to which information is easily comprehended \\
\hline Amount of Information & the quantity of available information \\
\hline Objectivity & extent to which information is unbiased \\
\hline Timeliness & $\begin{array}{l}\text { extent to which the information is sufficiently up-to-date for the } \\
\text { task at hand }\end{array}$ \\
\hline Relevance & extent to which information is relevant for the task at hand \\
\hline
\end{tabular}

In general, every dependent variable is measured for blog posts related to a specific merger attempt. For each merger attempt blog posts published between the date of announcement and the date of the final outcome of the merger (completion or abandonment of the merger) are taken into account.

Readability of UGC: In prior research several metrics have been used in order to assess the readability of textual documents (DuBay 2004). In our study we used the Gunning-Fog Index 
to measure readability of blog posts, which has been applied frequently in related studies (Ghose \& Ipeirotis 2011; Loughran \& McDonald 2014). The higher the Gunning-Fog Index of a blog post, the less readable is the blog content. Meaning the Gunning-Fog Index (i.e. readability of UGC) is negatively related to Understandability and thus to information quality. For each merger attempt we measure the average readability of blog posts as follows (with complex words being the number of words of three or more syllables):

readability $=0.4\left[\left(\frac{\text { words }}{\text { sentences }}\right)+100\left(\frac{\text { complex } \text { words }}{\text { words }}\right)\right]$

Number of Words of UGC: For each merger attempt we measure the amount of information provided by blogs as the average number of words of blog posts (Mudambi \& Schuff 2010).

Objectivity of UGC: Prior UGC studies have assessed the subjectivity of UGC (Ghose \& Ipeirotis 2011; Zhang et al. 2012). We use the approach of Zhang \& Skiena (2010) in order to build an objectivity measure of blog posts as follows:

objectivity $=1-\left(\frac{\text { number of negative words }+ \text { number of positive word }}{\text { total number of words }}\right)$

We used the General Inquirer (a computer-assisted approach for analyses of textual data that is widely used in content analysis research) in order to obtain the frequency of positive and negative words for each blog post (Stone et al. 1966). For each merger attempt we measure the average objectivity of blog posts.

Timing of UGC: To assess the extent to which the information provided by blog posts is sufficiently up-to-date, we measure the time lapse between the event and the time of publication of blog posts. For each merger attempt we measure the average time lapse between the merger announcement and the occurrence of related blog posts. Higher values of the timing of UGC indicate that blog content is less up-to-date. Meaning timing of UGC is negatively related to Timeliness and thus to information quality.

Relevance of UGC: Due to our previously described data collection process we already ensured that the collected blog posts are related to both companies being involved in the merger attempt. Therefore, in order to further assess the extent to which context-specific information (i.e. financial insights related to a merger) is provided by a post we count the 
frequency of words that match with the Thomson Reuters Financial Glossary (Thomson Reuters Financial Glossary 2013). This glossary contains key terms and definitions used in the financial industry. For each merger attempt we measure the average matches of blog posts with the glossary.

It is important to note that readability of UGC and timing of UGC are expected to be negatively related to information quality while the number of words of UGC, objectivity of UGC and relevance of UGC are expected to be positively related to information quality.

\section{d.2.2 Independent Variables (Event and Firm Characteristics)}

In the context of a merger event, several characteristics of the event trigger information needs for investors. Investors have to access whether the merger can meet the announced strategic and synergistic gains (Chakravorty 2012). Evidence concerning the strategic fit of merging firms is the relatedness of their field of business (Goergen \& Renneboog 2004). Mergers of unrelated firms have a higher uncertainty concerning the post-merger performance. The transaction value of a merger bears a financial risk for the acquiring company, giving investors reasons to talk about the justification of the value of the transaction (Louis \& Sun 2010). The chosen mode of transaction is also a signal for investors (Yook 2003). For example, cash as a chosen method of payment implies confidence with regards to the postmerger performance implying less information needs for investors. On the other hand, stock as a method of payment is preferred by overvalued acquirers implying evaluation uncertainties for investors (Goergen \& Renneboog 2004). In the following we present a list of variables by which we measure typical characteristics related to merger events:

Relatedness: We follow the approach of Louis \& Sun (2010) and use "a binary variable taking the value of one if the two merging partners are in the same two-digit SIC code and zero otherwise".

Transaction Value: The transaction value (the total amount of consideration paid by the acquirer) of the announced merger attempt is measured in million USD (Luo 2005).

Method of Payment: In general, in the event of a merger several types of consideration can be offered by the acquirer. Cash, stock, a mixture of both, or other forms of payment may be offered as consideration. We use a binary variable that indicates that the consideration offered 
in the merger is cash (value of one) or any other form of payment (value of zero) (Yook 2003).

Furthermore, firms that are larger in size attract more attention by market participants and bloggers. In addition, firms that receive higher levels of media coverage are also more likely to attract attention to their business activity (Capriotti 2009). Firms that are related to consumer products, where the visibility of a firm is also increased by advertisements, are more likely to get attention by blogs, especially from blogs that may not be directly focused on the business domain (Capriotti 2009). In the following we present a list of variables (firm characteristics) measured for the acquirer (A) and the target company (T):

Firm Size: As a proxy for the firm size of either the acquirer or the target company we used the enterprise value as of the date of the end of the prior fiscal year before the announcement of the merger attempt (Mantecon 2008). According the Reuters Financial Glossary the enterprise value is obtained by "adding together a company's market capitalization, its debt such as bonds and bank loans, other liabilities such as a pension fund deficit and subtracting liquid assets like cash and investments".

Media Coverage: For each company involved in a merger attempt in our sample we obtained the number news articles published in The Wall Street Journal and The New York Times citing the name of the respective company. We only took articles into account that were published within one year before the announcement of a respective merger attempt. We created a binary variable taking the value of one if a company is in the top quartile of the number of total citations across companies of our sample and zero otherwise (Pfarrer et al. 2010).

Focus of Business: We used the four-digit SIC code of a company in our sample in order to classify the business model (binary variable) as being either business-to-consumer (value of one) or business-to-business (value of zero) focused.

Table 38 provides an overview of constructs and variables with their respective data source. 
Table 38: Overview of Constructs and Variables

\begin{tabular}{|c|c|c|c|c|}
\hline \multicolumn{2}{|c|}{ Construct } & Variable & Abbreviation & Data Source \\
\hline \multirow{5}{*}{ Information Quality } & Understandability & $\begin{array}{l}\text { Readability of } \\
\text { UGC }\end{array}$ & REA & SDL-SM2 \\
\hline & $\begin{array}{l}\text { Amount of } \\
\text { Information }\end{array}$ & $\begin{array}{l}\text { Number of } \\
\text { Words of UGC }\end{array}$ & \#Words & SDL-SM2 \\
\hline & Objectivity & $\begin{array}{l}\text { Objectivity of } \\
\text { UGC }\end{array}$ & OBJ & SDL-SM2 \\
\hline & Timeliness & Timing of UGC & $\mathrm{T}$ & SDL-SM2 \\
\hline & Relevance & $\begin{array}{l}\text { Relevance of } \\
\text { UGC }\end{array}$ & RVC & SDL-SM2 \\
\hline \multirow{3}{*}{$\begin{array}{l}\text { Event } \\
\text { Characteristics }\end{array}$} & \multirow{3}{*}{$\begin{array}{l}\text { Information } \\
\text { Needs }\end{array}$} & Relatedness & REL & SDC \\
\hline & & $\begin{array}{l}\text { Method of } \\
\text { Payment }\end{array}$ & MOP & SDC \\
\hline & & $\begin{array}{l}\text { Transaction } \\
\text { Value }\end{array}$ & TV & SDC \\
\hline \multirow{3}{*}{ Firm Characteristics } & \multirow{3}{*}{ Firm Visibility } & Media Coverage & A-MC/T-MC & LexisNexis \\
\hline & & $\begin{array}{l}\text { Focus of } \\
\text { Business }\end{array}$ & $\mathrm{A}-\mathrm{B} 2 \mathrm{C} / \mathrm{T}-\mathrm{B} 2 \mathrm{C}$ & SDC \\
\hline & & Firm Size & A-FS/T-FS & Datastream \\
\hline
\end{tabular}

\section{d.3 Analysis}

To analyze the relationship between each dimension of information quality and the independent variables we use an OLS regression. We use a set of five multiple linear regression models to test our proposed hypotheses. All previously described independent variables are used as predictors for each of the five factors that represent information quality of blog posts. We applied log transformation in order to reduce skewness of continuous variables. Consequently, a residual analysis confirmed the assumptions of normally distributed errors and homoscedasticity for each regression analysis. Furthermore, for each regression analysis, we did not detect any serial correlations between errors (Durbin-Watson test) and an analysis of variance inflation factors provides no evidence of multicollinearity between predictors. 
Table 39 provides the descriptive statistics of continuous and binary variables that are included in our analyses.

Table 39: Descriptive Statistics

\begin{tabular}{|c|c|c|c|c|c|c|}
\hline Variable & Mean & Std. Deviation & & $\mathbf{N}$ & Min. & Max. \\
\hline log_REA & 1.104 & 0.152 & \multicolumn{2}{|c|}{150} & 0.716 & 2.184 \\
\hline log_T & 1.415 & 0.533 & \multicolumn{2}{|c|}{150} & -0.381 & 2.617 \\
\hline log_\#Words & 3.042 & 0.232 & \multicolumn{2}{|c|}{150} & 2.394 & 3.6 \\
\hline $\log _{-} \mathrm{OBJ}$ & -0.032 & 0.007 & \multicolumn{2}{|c|}{150} & -0.052 & -0.014 \\
\hline log_RVC & -1.295 & 0.178 & \multicolumn{2}{|c|}{150} & -1.919 & -0.902 \\
\hline log_TV & 2.981 & 0.591 & \multicolumn{2}{|c|}{150} & 2 & 4.468 \\
\hline $\log _{-} \mathrm{A}-\mathrm{FS}$ & 3.957 & 0.65 & \multicolumn{2}{|c|}{150} & 0 & 5.353 \\
\hline log_T-FS & 2.932 & 0.702 & \multicolumn{2}{|c|}{150} & 0 & 4.467 \\
\hline \multirow{2}{*}{ REL } & \multirow{2}{*}{0.700} & \multirow{2}{*}{0.460} & 0 & 45 & & \\
\hline & & & 1 & 105 & & \\
\hline \multirow{2}{*}{ MOP } & \multirow{2}{*}{0.467} & \multirow{2}{*}{0.501} & 0 & 80 & & \\
\hline & & & 1 & 70 & & \\
\hline \multirow{2}{*}{ A-MC } & \multirow{2}{*}{0.247} & \multirow{2}{*}{0.433} & 0 & 113 & & \\
\hline & & & 1 & 37 & & \\
\hline \multirow{2}{*}{ T-MC } & \multirow{2}{*}{0.220} & \multirow{2}{*}{0.416} & 0 & 117 & & \\
\hline & & & 1 & 33 & & \\
\hline \multirow{2}{*}{ A-B2C } & \multirow{2}{*}{0.367} & \multirow{2}{*}{0.484} & 0 & 95 & & \\
\hline & & & 1 & 55 & & \\
\hline \multirow{2}{*}{ T-B2C } & \multirow{2}{*}{0.400} & \multirow{2}{*}{0.492} & 0 & 90 & & \\
\hline & & & 1 & 60 & & \\
\hline
\end{tabular}

\section{d.4 Results}

Table 40 shows the results of our linear regressions. Overall, all models are significant and explain a significant variation in the dependent variable.

The method of payment (MOP) has a significant influence on all dimensions of information quality. Except in the case of readability (log_Rea), MOP has a negative influence on measures of information quality. Readability of UGC is also negatively influenced by the size 
of the acquirer (log_A-FS) and positively influenced by the media coverage of the acquirer (A-MC). The transaction value (log_TV) only has a significant positive influence on the objectivity of blog posts (log_OBJ).

The media coverage of target companies (T-MC) has a negative influence on the relevance ( $\log \_$RVC) and the amount of information (log_\#Words) provided by blog content. The amount of information is also influenced by the focus of business of both the acquirer (AB2C) and the target company (T-B2C). Interestingly, the coefficient of A-B2C is positive whereat the coefficient of T-B2C is negative. However, A-B2C $(p<0.1)$ has a lower significance than T-B2C $(p<0.05)$.

Table 40: Estimation Results

\begin{tabular}{|c|c|c|c|c|c|}
\hline Variable & log_REA & $\log \mathrm{T}$ & $\log _{-} \#$ Words & log_OBJ & log_RVC \\
\hline (Constant) & $1.475(0.088)$ & $0.609(0.322)$ & $2.787(0.154)$ & $-0.035(0.004)$ & $-1.33(0.115)$ \\
\hline REL & $-0.024(0.024)$ & $0.064(0.088)$ & $0.006(0.042)$ & $0.001(0.001)$ & $0.031(0.032)$ \\
\hline MOP & $0.101(0.023) * * *$ & $-0.373(0.085)^{* * * *}$ & $-0.079(0.041)^{*}$ & $-0.003(0.001)^{* * * *}$ & $-0.061(0.03) * *$ \\
\hline $\log \_\mathrm{TV}$ & $-0.016(0.036)$ & $0.209(0.13)$ & $0.058(0.062)$ & $0.003(0.002)^{*}$ & $0.03(0.046)$ \\
\hline A-MC & $0.118(0.03)^{* * *}$ & $0.074(0.11)$ & $0.055(0.052)$ & $0.001(0.002)$ & $-0.038(0.039)$ \\
\hline T-MC & $0.033(0.028)$ & $-0.034(0.101)$ & $-0.081(0.048)^{*}$ & $-0.002(0.001)$ & $-0.06(0.036)^{*}$ \\
\hline A-B2C & $0.003(0.033)$ & $0.07(0.12)$ & $0.103(0.057)^{*}$ & $0.001(0.002)$ & $0.034(0.043)$ \\
\hline T-B2C & $0.028(0.033)$ & $-0.184(0.119)$ & $-0.128(0.057)^{* *}$ & $-0.002(0.002)$ & $-0.05(0.042)$ \\
\hline log_A-FS & $-0.116(0.022) * * *$ & $0.054(0.08)$ & $0.021(0.038)$ & $-0.001(0.001)$ & $-0.029(0.029)$ \\
\hline $\log _{-} \mathrm{T}-\mathrm{FS}$ & $0.019(0.027)$ & $0.045(0.099)$ & $0.016(0.047)$ & $-0.001(0.001)$ & $0.033(0.035)$ \\
\hline $\mathrm{R}^{2}$ & $33.00 \%$ & $27.00 \%$ & $12.65 \%$ & $14.06 \%$ & $16.26 \%$ \\
\hline F Test & $7.554 * * *$ & $5.754 * * *$ & $2.252 * *$ & $2.545 * * *$ & $3.021 * * *$ \\
\hline
\end{tabular}

***/**/* means significance at 0.01, 0.05, and 0.10 level, respectively. Standard errors are in parentheses.

\section{e. Discussion and Conclusions}

On the basis of our analysis, we can show that at higher levels of information needs represented by the method of payment increases Understandability, the Amount of Information, the Objectivity, and the Relevance of blog posts, showing support for H1. Surprisingly, Timeliness decreases (i.e. timing of UGC increases), which may be explained by the fact that at higher levels of information needs it takes longer to assess the complex situation of merger attempts. In addition, information needs represented by the financial magnitude of the merger (i.e. the transaction value) have a marginal positive influence on the 
Objectivity of blog posts. Overall this provides evidence that information needs based on the event - merger characteristics - drive the information quality on blogs.

Our analysis also provides evidence that a firm's visibility drives several factors of information quality on blogs. However $\mathrm{H} 2$ is not supported, because no relationship between firm visibility and either Timeliness or Objectivity was detected. In addition, blog posts related to firms that receive higher levels of media coverage offer a lower Understandability, Amount of Information and Relevance. This indicates that bloggers may focus less on situations where there is adequate coverage in the traditional press outlets. Thus, higher levels of media coverage reduce the amount of information needed and the relevance provided by blog content. This implies that the specialized business/financial media already meet the information needs of investors.

Another interesting finding is that if the acquirer is a consumer-oriented company or when the target is not a consumer-oriented company, a positive impact on the Amount of Information provided by blog posts can be observed. Further content analysis is needed to better understand this finding.

Except in the case of Timeliness and Objectivity, factors representing both of our introduced constructs (information needs and firm visibility) are driving information quality of blog posts. This bears an important practical implication. For businesses, the information quality of blogs provides indications about market participants' information needs concerning their corporate actions.

\section{f. Limitations and Further Research}

Limitations of our study are, that we did not include other measures to operationalize firm visibility such as the number of analysts following the merging companies and that we did not qualitatively assess the content of merger-related blog posts. Future research can apply our presented approach to quantitatively measure information quality of UGC to other social media types. Furthermore, it is important to investigate the influence of event- and firmcharacteristics in the context of other corporate actions. 


\section{Paper 6}

Table 41: Fact Sheet of Paper 6a (Zülch et al. 2014b)

\begin{tabular}{|l|l|}
\hline Title & $\begin{array}{l}\text { Social Media Choice: An Explorative Study on Information Transmission via } \\
\text { Social Media }\end{array}$ \\
\hline Authors & $\begin{array}{l}\text { Mirko Jan Zülch, mirko.zuelch @ wiwi.uni-goettingen.de* } \\
\text { Jan Muntermann, muntermann@ wiwi.uni-goettingen.de* }\end{array}$ \\
\hline Outlet & $\begin{array}{l}\text { *University of Göttingen } \\
\text { **Goethe University Frankfurt }\end{array}$ \\
\hline Proceedings of the 27th Bled eConference (BLED 2014)
\end{tabular}

\section{a. Introduction}

Social media in general can be defined as: "a group of internet-based applications that build on the ideological and technological foundations of Web 2.0, and that allow the creation and exchange of user-generated content" (Kaplan \& Haenlein 2010, p. 61). According to a survey of the Pew Research Center (2013), 42\% of adults that are using social media, use multiple social media types and platforms. This raises two questions: Why do people use multiple social media types and platforms, and when do they favor one over the other?

Questions of media choice have always been an important topic in the IS literature. A large variety of empirical studies investigated media choice with respect to traditional media (e.g. 
fax, email or video/telephone conferences) (Daft \& Lengel 1986). Yet, to the best of our knowledge, no empirical study sheds light into the topic of social media choice.

According to the provided definition of social media, the generation of user-generated content (UGC) is a result of the use of social media by individuals on the internet. UGC can be defined as "i) content made publicly available over the internet, ii) which reflects a certain amount of creative effort, and iii) which is created outside of professional routines and practices" (OECD 2007, p. 4). Therefore, the occurrence of UGC across different social media types related to a certain task can provide insights into the phenomenon of social media choice. In our empirical analysis we aim to explore social media choice by analyzing the communication process following merger announcements, where social media users are incentivized to transmit and process information in order to reduce merger-related uncertainties.

In the next section, we provide a review of the relevant literature and formulation of our research question followed by a description of used datasets and variables. Then we present our methodology and analysis results, followed by a discussion of our findings. We conclude with a summary of our findings, present limitations and describe potential future research directions.

\section{b. Background and Research Question}

Social media continue to pervade the life of internet users and are the primary choice of online social interaction and communication (Goh et al. 2013). Social media enables users to share information, to express feelings and opinions, and to build interpersonal relationships among users (Chiu et al. 2006). Burnett (2000) developed a typology of information exchange and classified information behavior of social media users. In addition, with respect to various topic areas (e.g. politics, business and products), social media are considered a reliable information source that supports users in their decision making process (e.g. consumer decisions or investment decisions) (Aggarwal \& Singh 2013; Weiss et al. 2008). Especially in the presence of informational uncertainties, individuals approach social media in order to satisfy their information needs and reduce uncertainties (Lu \& Yang 2011; Weiss et al. 2008). This explains why social media is responsible for the increased frequency of online information exchange and the creation of UGC. 
Various types of social media have been identified by the literature. These social media types differ in their nature and functionalities. Social media types are e.g., blogs, microblogs, social network sites, message boards, collaborative projects, virtual social worlds and virtual game worlds. Kaplan \& Haenlein (2010) propose a classification of social media types based upon media richness and social presence theory. These social media types are represented by existing social media platforms (e.g. Facebook, Twitter, YouTube or Second Life). Kietzmann et al. (2011) identified functionalities by which social media platforms can be classified: identity, conversations, sharing, presence, relationships, reputation, and groups. In our study we focus on social media types that are responsible for the generation of text-based UGC: blogs, microblogs, social network sites, and message boards (Boyd \& Ellison 2007; Schmidt 2007; Stieglitz \& Dang-Xuan 2013; Im \& Chee 2006).

While earlier media theory on media richness (Daft \& Lengel 1986) had a focus on medium's information richness, i.e. its capability to reproduce information, later theory also focuses on other, more functional, media capabilities. Media synchronicity theory (Dennis et al. 2008) presents different media capabilities, which describe how a medium supports individuals that want to transmit and process information to accomplish a certain task, e.g. to acquire useful information in situations of uncertainty. These media capabilities are transmission velocity, parallelism, symbol sets, rehearsability, and reprocessability. Given these diverse media capabilities, media synchronicity theory suggests that "the 'best medium' for a given situation may be a combination of media" (Dennis et al. 2008, p. 588). Thus, there are repeated choices to use media at certain points in time during task-related communication processes. Each individual media choice and usage will then be affected by the fit of media capabilities and the task-related information needs at a particular time.

In this paper, we aim to explore individuals' combined usage of social media to transmit and process information in the context of situations of uncertainty. We therefore explore the communication process following a major business event (merger announcement) and the subsequent choice and usage of diverse social media types during this process. While existent research has explored the different capabilities and usage of more traditional media during communication processes (e.g. Mohan et al. 2009), to the best of our knowledge, there is no empirical study that explores the combined choice of social media (e.g. microblogs or social network sites) in the context of task-related communication processes. 
Given the central hypothesis of media synchronicity theory that "communication performance will be enhanced when different media are used at different times" (Dennis et al. 2008, p. 576), we aim to empirically explore the usage of different social media types during the business-related communication processes following the announcements of major business events. On this basis, using the business context of a merger event we state the following research question:

How do individuals make use of different social media types at different times during the communication process subsequent to the announcement of major business events?

The event of a merger announcement (i.e. a major business event) represents an adequate context to investigate usage of social media in the presence of uncertainties. In the context of merger-acquisition events, Zülch et al. (2014a) showed that information quantity in social media is driven by certain event and firm characteristics. In general, a merger announcement represents a situation of information asymmetries for investors and is followed by severe price reactions (Healy \& Palepu 2001; Asquith 1983). Furthermore, information concerning a merger disseminated into the market is very complex (Loughran \& McDonald 2014). Investors and potential investors have to assess if a combination of two companies will achieve future strategic or synergistic gains (Chakravorty 2012). Given the descripted circumstances, investors are incentivized to engage in information exchange via social media in order to reduce informational uncertainties (Herrmann 2007). Several merger-related factors (i.e. event-related factors) represent reasons to exchange information concerning a merger. These factors concern the strategic fit of the two merging companies (Goergen \& Renneboog 2004), the financial risk of the transaction (Louis \& Sun 2010), or the chosen method of payment (where cash-acquisitions signal confidence in a positive post-merger performance) (Yook 2003; Goergen \& Renneboog 2004).

In addition, it is reasonable to assume that the extent of information exchange in social media concerning merger events is also affected by the characteristics of merging companies. Some events are more likely to be talked about than others based on the fact that people are more aware about some companies compared to others. Companies that are bigger in size, or receive more media coverage, or sell goods and services to consumers are more visible to social media users (Capriotti 2009). These firm-related factors create visibility among people 
which may influence the extent of information exchange in social media that needs to be controlled for.

\section{c. Data}

\section{c.1 Sample}

Thomson Reuters SDC Platinum database (SDC) was used in our sample selection process. Our sample selection had several objectives. First, we focused on merger attempts of publicly listed companies with a deal value equal or higher $\$ 100$ million in order to ensure that these transactions quicken interest for individual investors (Kau et al. 2008). Second, we focused on US mergers in order to ensure communication in English language. Third, in order to ensure increased social media coverage we restricted our sample to merger attempts in recent years that have been announced between 2010 and 2011. At last, our study is focused on the online communication in the time period between the announcement of a merger attempt and the announcement of its final outcome. Therefore, we restricted our sample to merger attempts where the final outcome was known (Bates \& Lemmon 2003). These objectives lead us to a sample of 159 merger transactions.

\section{c.2 Data Collection}

We used a variety of databases for collecting data. Our data collection of social media data had several objectives. First, our study aims to investigate communication patterns across a large variety of social media types. In contrast to other social media studies, we do not restrict our empirical analysis to a specific social media type (Aggarwal et al. 2012; Bollen et al. 2011; Das \& Chen 2007). Second, we want to ensure that the social media data is publicly available for reproducibility purposes. Therefore, we collected social media data by using Social Intelligence Solutions' SM2 database (SDL-SM2). SDL-SM2 provides several advantages for collecting historical social media data. SDL-SM2's assignment of UGC to a specific social media type is consistent with classification schemes of social media types from the literature (Kaplan \& Haenlein 2010) and all relevant social media types that enable text based information exchange for social media users are identified by SDL-SM2. In addition, SDL-SM2 provides a large variety of query functions. We were able to use specific search terms, limit our search to UGC written in English, and to specify a date range for which UGC was obtained. An overview on the relevant information available for each identified UGC obtained from SDL-SM2 is provided by Table 42. 
Table 42: Data Description - SDL-SM2

\begin{tabular}{|l|l|}
\hline \multicolumn{1}{|c|}{ Data Field } & \multicolumn{1}{c|}{ Description } \\
\hline Author Name & Name of the author of UGC \\
\hline Title & Title of the UGC \\
\hline Full Content & Content of UGC \\
\hline URL & URL of UGC \\
\hline Time Published & Time and date of publication of UGC \\
\hline $\begin{array}{l}\text { Social Media } \\
\text { Type }\end{array}$ & $\begin{array}{l}\text { Identified social media types: Message Boards, Microblogs, Blogs, } \\
\text { Social Network Sites }\end{array}$ \\
\hline $\begin{array}{l}\text { Social Media } \\
\text { Platform }\end{array}$ & Identified social media platform (e.g. Twitter or Facebook) \\
\hline
\end{tabular}

For collecting merger-related data and data related to companies in our sample we made use of databases that are commonly used in financial studies. Thomson Reuters SDC Platinum database (SDC) was used for collecting merger-related data (Bates \& Lemmon 2003). Thomson Reuters Datastream (Datastream) was used for collecting company-related data (Faccio \& Masulis 2005). Finally, we used LexisNexis to collect press articles related to companies in our sample (Wattal et al. 2010).

\section{d. Variables}

\section{d.1 Dependent Variable}

In order to explore the choice of diverse social media types subsequent to a merger announcement, we measure the occurrence of postings across different social media types by using the following dependent variable:

- Posting Lag of UGC (PL): For each merger attempt in our sample, we identified merger-related postings across previously mentioned social media types (see section G.VI.b) by applying the following Boolean search string: "name of the acquiring company" AND "name of the target company". For each query, we restricted the date range to the date of announcement of a merger attempt and the date when the final outcome of the merger attempt was known. SDL-SM2 identified a total of 137,668 social media postings that are related to merger attempts in our sample. For each posting that was related to a specific merger attempt, we calculated the difference 
between the time of announcement of that merger attempt and the related posting time of UGC (time difference was measured in hours).

\section{d.2 Independent Variables}

In the following we present a list of variables by which we differentiate social media postings according to their identified social media type:

- Microblog (MICB): A dummy variable where the value of one indicates that identified UGC was posted on a microblog.

- Blog (BG): A dummy variable where the value of one indicates that identified UGC was posted on a blog.

- Social Network Site (SNS): A dummy variable where the value of one indicates that identified UGC was posted on a social network site.

- Message Board (MB): A dummy variable where the value of one indicates that identified UGC was posted on an online message board.

\section{d.3 Control Variables}

In the following we present a list of variables by which we control for event-related (i.e merger-related) factors that also may influence information exchange in social media:

- Duration of Merger (D): Number of days between date of announcement of a merger attempt and the date when the final outcome of the merger attempt is known.

- Relatedness (R): We measure merging firm's industry relatedness by using a dummy variable that takes "the value of one if the two merging partners are in the same twodigit SIC code and zero otherwise" (Louis \& Sun 2010, p. 1784).

- Method of Payment (MP): A dummy variable where the value of one indicates that cash was chosen as a method of payment for a merger and the value of zero indicates other forms of payment (e.g. stock) (Yook, 2003).

- Transaction Value (TV): The transaction value represents the announced amount of consideration that is paid (in million USD) by the acquiring company (Luo 2005).

In addition, we also control for firm-related factors (determined for the acquiring company (A) and the target company (T)) that may influence information exchange in social media: 
- News Coverage (A-NC, T-NC): We collected the total number of news articles citing a company's name involved in a merger published in The New York Times and The Wall Street Journal within one year prior to the respective merger attempt (Antweiler \& Frank 2004). A dummy variable was created to further distinguish between companies with a high and a low news presence. We defined companies with a high news presence as companies that are in the top quartile of total number of news citations in our sample (Pfarrer et al. 2010).

- Business Focus (A-BF, T-BF): A dummy variable where the value of one indicates that a company in our sample is focused on selling goods and services to consumers and zero otherwise. The classification is based on a company's four-digit SIC code.

- Firm size (A-E, T-E): The enterprise value of a company involved in a merger attempt is determined as of the end of the fiscal year prior to a respective merger announcement (Agrawal \& Nasser 2012).

Table 43 provides a list of all variables and their respective data source.

Table 43: List of Variables

\begin{tabular}{|c|c|c|c|c|}
\hline Type of Variable & Factor Category & Variable & Abbreviation & Data Source \\
\hline \multicolumn{2}{|l|}{ Dependent Variable } & Posting Lag of UGC & $\mathrm{PL}$ & SDL-SM2 \\
\hline \multirow{4}{*}{$\begin{array}{l}\text { Independent } \\
\text { Variables }\end{array}$} & \multirow{4}{*}{$\begin{array}{l}\text { Social Media } \\
\text { Types }\end{array}$} & Microblog & MICB & SDL-SM2 \\
\hline & & Blog & BG & SDL-SM2 \\
\hline & & Social Network Site & SNS & SDL-SM2 \\
\hline & & Message Board & $\mathrm{MB}$ & SDL-SM2 \\
\hline \multirow{7}{*}{ Control Variables } & \multirow{4}{*}{$\begin{array}{l}\text { Event-related } \\
\text { Factors }\end{array}$} & Duration of Merger & $\mathrm{D}$ & SDC \\
\hline & & Relatedness & $\mathrm{R}$ & SDC \\
\hline & & Method of Payment & MP & SDC \\
\hline & & Transaction Value & TV & SDC \\
\hline & \multirow{3}{*}{$\begin{array}{l}\text { Firm-related } \\
\text { Factors }\end{array}$} & News Coverage & A-NC, T-NC & LexisNexis \\
\hline & & Business Focus & A-BF, T-BF & SDC \\
\hline & & Firm Size & A-E, T-E & Datastream \\
\hline
\end{tabular}




\section{e. Empirical Analysis \\ e.1 Methodology}

Our analysis will investigate how individuals make use of different social media types at different times during the communication process subsequent to the announcement of a merger attempt. As we observe information processing by individuals in terms of total posting lags of UGC, we select a hazard function model regression (Greene 1997). This supports the non-linear behavior of posting lags as well as the strict positive characteristics of the model variables and avoids broken assumptions compared to a linear regression (Greene 1997). Designed to estimate how long an entity will stay in a certain state, these models have been applied to divorce rates, length of studies and pensions, and mortality expectations in social science (Greene 1997).

The hazard rate $\lambda$ is the likelihood at which an event observer (author of UGC) does not change the state to post UGC about an event within a given period. The model estimates the likelihood with given influencing factors and allows to estimate the likelihood of influencing the posting lag. Thus, if the model estimates a positive coefficient then the likelihood of longer posting lags increases in the percentage value of the coefficient and vis-à-vis. We expect that the posting lag is dependent to their influencing factors:

$$
\begin{gathered}
\text { PostingLagOfUGC }_{i}(t)=\text { PostingLagOfUGC }_{0}(t) \exp \left(\beta_{1} \text { SocialMediaTypes }_{i 1}+\right. \\
\left.\beta_{2} \text { EventRelatedFactors }_{i 2}+\beta_{3} \text { FirmRelatedFactors }_{i 3}\right)
\end{gathered}
$$

As the incentive to publish UGC decreases over time (longer posting lags are much less likely than shorter ones) we expect a Weibull distribution of posting lags (positive random variables and not normal-distributed) that is also often used in previous research and validate this assumption with the descriptive statistics in the next section (Fréchet 1927). The significance of all dummy variables is tested by a Chi-squared test for each factor category as well as for the overall model.

\section{e.2 Descriptive Statistics and Results}

Our resulting cross-sectional dataset consists of 136,935 valid UGC postings addressing a specific merger including the posting lag, the variables for 4 social media types, 3 event related factors and 6 firm-related factors. 5,962 observations are discarded due to missing values, so that the final dataset consists of 130,973 complete UGC postings. Posting lags are 
measured in hours with an average length of 1,479 hours (61 days). The median is 251.35 hours (10.45 days). Half of the UGC is posted within 245 hours, but it needs 3,064 hours (4.2 month) that more than $80 \%$ of the postings appeared. It takes 6,711 hours after which $95 \%$ of postings can be observed. On the one hand, there exist postings that appeared within the first hour, while on the other hand, the longest posting lag is 12,981 hours (580 days). The total posting lag has a standard deviation of 2,375.7 hours. The difference between average and median indicates a right-skewed distribution.

The histogram depicted in Figure 8 indicates a Weibull distribution that approximates the distribution of posting lags best compared to other distributions used in survival analysis.

Figure 8: Frequency Distribution of the Dependent Variable - Posting Lag of UGC (measured in Hours)

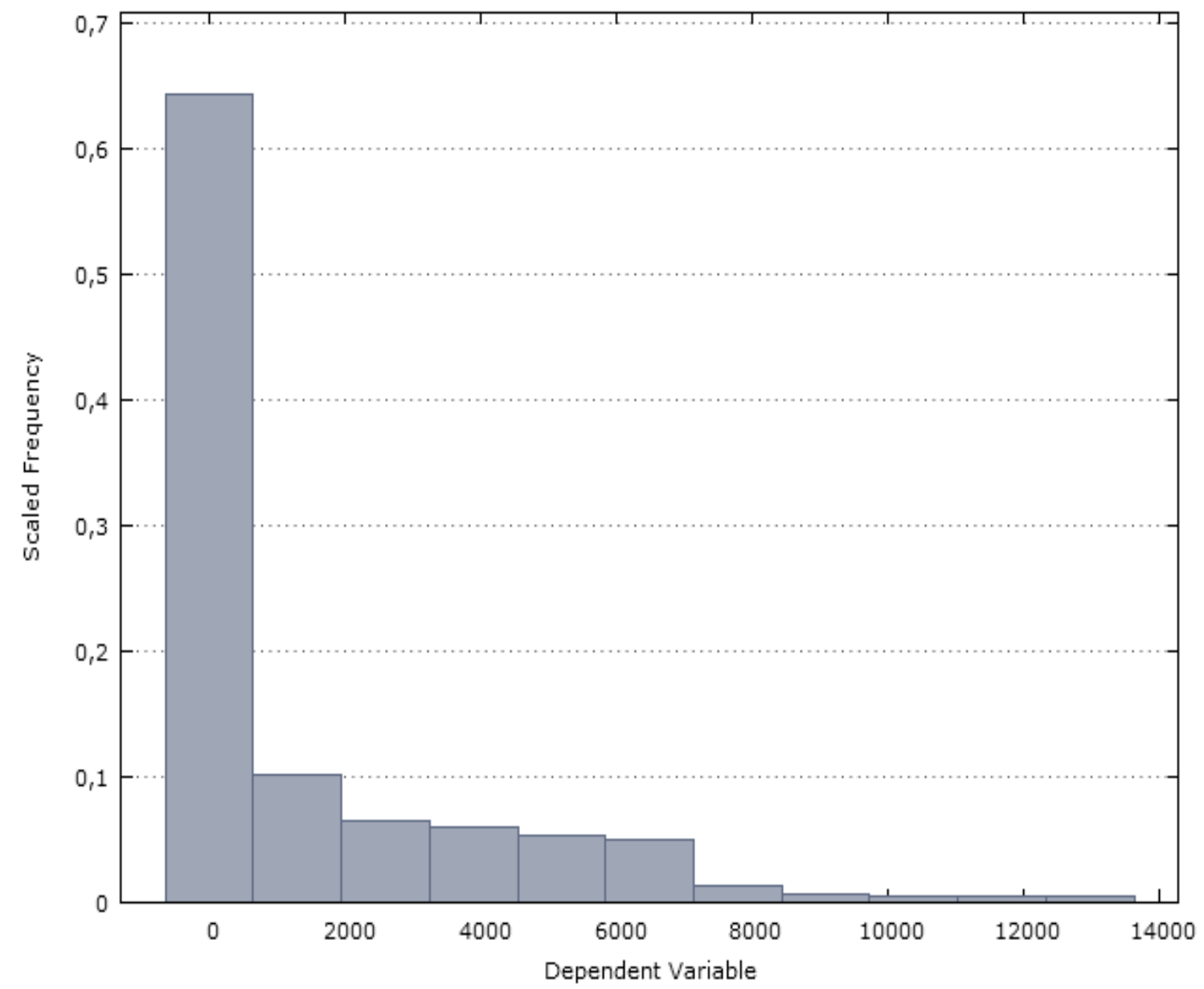

In addition, Figure 8 illustrates that the distribution of observations shows declining posting lags and that this time measure is positively, randomly ordinary and not normal-distributed. Consequently, we treat all 130,973 UGC posting lags as a cross-sectional dataset and 
investigate the influences using a Weibull-distributed hazard function model. In our final regression we dropped the variable T-E as it shows expectable collinearity with the transaction value. In addition, the microblog variable MICB is removed from the data set due to perfect collinearity with other variables from the social media type category. As a result the remaining coefficients of the social media type category show the likelihood of each social media type having longer posting lags compared to microblogs in percentage. Results of the regression analysis (Table 44) explain the influence of each individual entity within the four factor categories to the posting lag.

Table 44: Extract of Regression Results for Posting Lag of UGC

\begin{tabular}{|l|l|l|l|}
\hline & \multicolumn{1}{|c|}{ Coefficient } & \multicolumn{1}{|c|}{ Std. Error } & \multicolumn{1}{c|}{ z-Value } \\
\hline Const. & $4.658590 * * *$ & 0.022 & 212.437 \\
\hline BG & $0.591258 * * *$ & 0.011 & 52.916 \\
MB & $0.551301 * * *$ & 0.011 & 51.948 \\
SNS & $0.499597 * * *$ & 0.026 & 19.517 \\
\hline D & $0.007829 * * *$ & $<0.001$ & 147.615 \\
TV & $0.000011 * * *$ & $<0.001$ & 12.232 \\
MP & $0.148425 * * *$ & 0.015 & 10.043 \\
R & $-0.159902 * * *$ & 0.014 & -11.673 \\
\hline T-NC & $0.211914 * * *$ & 0.013 & 16.387 \\
A-NC & $0.415368 * * *$ & 0.014 & 30.733 \\
A-E & $-0.000007 * * *$ & $<0.001$ & -58.702 \\
T-BF & $0.481590 * * *$ & 0.015 & 31.823 \\
A-BF & $-0.241236 * * *$ & 0.015 & -16.114 \\
\hline sigma & $1.73579 * * *$ & 0.003 & 501.076 \\
\hline Chi-square (12) & $43,414.92 * * *$ & & \\
\hline
\end{tabular}

*** indicates $1 \%$ level of significance

\section{e.3 Discussion and Conclusions}

A Chi-squared test indicates the overall model validity. Interestingly, all variables are highly significant at the $1 \%$ level $(\mathrm{p}<0.01)$, providing evidence that all factor categories (i.e. social media types, event-related factors, and firm-related factors) influence the posting lag of UGC (PL). 
To recall, coefficients of the social media category show the likelihood of each social media type not having published UGC compared to microblogs in percentage. Social network sites have a $49.96 \%$, message boards a $55.13 \%$, and blogs a $59.13 \%$ higher likelihood to be slower in posting UGC than microblogs. This provides several indications with regard to choice and usage of social media types subsequent to a major business event. Our results correlate with the expected length of UGC. While microblogs and SNS are more likely to publish shorter postings, $\mathrm{MB}$ and blogs are typical channels to publish longer postings that need a longer time to be written. In addition, our results provide evidence concerning the successive usage of social media types. Microblogs are faster in providing UGC and are responsible for early buzz with regard to a new announced merger event. Microblogs are followed by SNS and the discussion is then carried on to $\mathrm{MB}$ and blogs, where a more in-depth information exchange concerning a merger event can be established. Overall, our results provide evidence that different social media types are used at different times during the business-related communication process following the announcement of a merger.

The variable duration of a merger process (D) indicates an increase of posting lag of UGC. The transaction value (TV) has a minor positive influence and relatedness (R) has a negative influence on the likelihood of not having published merger-related UGC. Higher information needs and thus increased information processing activity by social media users due to the magnitude and the financial risk of the transaction, as well as a lack of strategic fit of merging companies (i.e. no industry relatedness between companies), are responsible for longer posting lags. The signaling effect of transactions not carried out by cash $(\mathrm{MP}=0)$ negatively influences posting lags of UGC, which indicates that uncertainties due to the chosen method of payment are responsible for faster information processing in social media.

Both news coverage variables (A-NC and T-NC) positively influence the likelihood of not having published UGC. It is reasonable to assume that companies that in general receive high media coverage also receive higher levels of media coverage during a merger event. Therefore, information processing activity of social media users is increased by higher levels of news coverage. The processing time of UGC is fast for mergers where acquirers are larger in size (A-E) and that are focused on selling goods and service to consumers (A-BF). This indicates that a higher awareness of a company among users results in a faster information processing in social media. Surprisingly T-BF has a stronger positive influence on the 
likelihood of having lagged publishing merger-related UGC compared to A-BF. An interpretation of this finding is subject to further inquiries.

Overall, our analysis provides strong evidence that the choice of social media types determines the task-related communication process (i.e. information exchange in order to evaluate a major business event) when controlling for other task-related influencing factors. The observed difference in the usage of social media types may be explained by their specific media capabilities. It is subject to future research to investigate which distinct characteristics of each social media type are responsible for this effect.

Our findings bear important practical implications. Companies that are interested in leveraging the power of monitoring social media activity have to take into account that different social media types are used at different times during the communication process with respect to company-related events and actions.

\section{f. Limitations and Further Research}

While our results provide empirical insights into social media choice during a task-related communication process, our research provides motivation for future research directions. The relationship between posting lags of UGC and our binary control variables may be more nuanced and the binary coding may not uncover all the dynamics. In addition, a merger passes through several phases (e.g. shareholder voting or regulatory approval) which we did not account for in this study, except for controlling for the duration of the merger attempt.

Future research should further investigate social media choice by taking into account the distinct capabilities of different social media types and platforms. 


\section{References}

Adjei, M.T., Noble, S.M., and Noble, C.H. (2010) The influence of C2C communications in online brand communities on customer purchase behavior. Journal of the Academy of Marketing Science, 38(5), 634-653.

Aggarwal, R., and Singh, H. (2013) Differential influence of blogs across different stages of decision making: the case of venture capitalists. MIS Quarterly, 37(4), 1093-1112.

Aggarwal, R., Gopal, R., Gupta, A., and Singh, H. (2012) Putting Money Where the Mouths Are: The Relation Between Venture Financing and Electronic Word-of-Mouth. Information Systems Research, 23(3-part-2), 976-992.

Aggarwal, R., Gopal, R., Sankaranarayanan, R., and Singh, P.V. (2012a) Blog, blogger, and the firm: Can negative employee posts lead to positive outcomes?. Information Systems Research, 23(2), 306-322.

Agrawal, A. and J. Jaffe, J.F. (2000) The post merger performance puzzle. In: Cooper, C., and Gregory, A., Advances in Mergers and Acquisitions, Vol. 1., Elsevier, Amsterdam: Elsevier., 7-41.

Agrawal, A., and Nasser, T. (2012) Insider trading in takeover targets. Journal of Corporate Finance, 18(3), 598-625.

Akerlof, G.A. (1970) The Market for "Lemons": Quality Uncertainty and the Market Mechanism. The Quarterly Journal of Economics, 84(3), 488-500.

Antweiler, W., and Frank, M.Z. (2004) Is All That Talk Just Noise? The Information Content of Internet Stock Message Boards. The Journal of Finance, 59(3), 1259-1294.

Asquith, P.(1983) Merger bids, uncertainty, and stockholder returns. Journal of Financial Economics, 11(1-4), 51-83.

Baker, H.K., Powell, G.E., and Weaver, D.G. (1999) Does NYSE listing affect firm visibility?. Financial Management, 28(2), 46-54.

Bandura, A. (1986) Social Foundations of Thought and Action: A Social Cognitive Theory. New York: Prentice-Hall. 
Barnard, C.I. (1938) The functions of the executive. Cambridge: Harvard university press.

Bates, T.W., and Lemmon, M.L. (2003) Breaking up is hard to do? An analysis of termination fee provisions and merger outcomes. Journal of Financial Economics, 69(3), 469-504.

Belkin, N.J. (1980) Anomalous states of knowledge as a basis for information-retrieval. Canadian Journal of Information Science, 5, 133-143.

Bickart, B., and Schindler, R.M. (2001) Internet forums as influential sources of consumer information. Journal of interactive marketing, 15(3), 31-40.

Blau, P.M. (1964) Exchange and power in social life. New York: John Wiley.

Bollen, J., Mao, H., and Zeng, X. (2011) Twitter mood predicts the stock market. Journal of Computational Science, 2(1), 1-8.

Boyd, D.M., and Ellison, N.B. (2007) Social network sites: Definition, history, and scholarship. Journal of Computer-Mediated Communication, 13(1), 210-230.

Bradley, M., Desai, A., and Kim, E. H. (1988) Synergistic gains from corporate acquisitions and their division between the stockholders of target and acquiring firms. Journal of financial Economics, 21(1), 3-40.

Brown, J., Broderick, A.J., and Lee, N. (2007) Word of mouth communication within online communities: Conceptualizing the online social network. Journal of interactive marketing, 21(3), 2-20.

Burnett, G. (2000) Information exchange in virtual communities: a typology. Information Research, 5(4), 1-25.

Busch, A. (2002) Divergence or Convergence? State Regulation of the Banking System in Western Europe and the United States. In: Workshop on Theories of Regulation, Oxford: Nuffield College.

Bushee, B.J., and Miller, G.S. (2012) Investor Relations, Firm Visibility, and Investor Following. The Accounting Review, 87(3), 867-897.

Butler, B.S. (2001) Membership size, communication activity, and sustainability: A resourcebased model of online social structures. Information systems research, 12(4), 346-362. 
Capriotti, P. (2009) Economic and Social Roles of Companies in the Mass Media: The Impact Media Visibility Has on Businesses’ Being Recognized as Economic and Social Actors. Business \& Society, 48 (2), 225-242.

Carlson, P.J., and Davis, G.B. (1998) An Investigation of Media Selection among Directors and Managers: From "Self" to "Other" Orientation. MIS Quarterly, 22(3), 335-362.

Carter, M.E., and Soo, B.S. (1999) The Relevance of Form 8-K Reports. Journal of Accounting Research, 37(1), 119-132.

Chai, S., Das, S., and Rao, H.R. (2011) Factors affecting bloggers' knowledge sharing: An investigation across gender. Journal of Management Information Systems, 28(3), 309342.

Chakravorty, J.N. (2012) Why do Mergers and Acquisitions quite often Fail?. Advances In Management, 5(5), 21-28.

Chang, O., Kedia, S., Wei, J. and Xing, Z. (2012) Firm Visibility and Corporate Bond Liquidity. http://www.centerforpbbefr.rutgers.edu/2012PBFEAM/papers/059Visibity\%20and\%20Bond\%20Liquidity_Mar\%2026,\%202012.docx, Accessed: 15.02.2013.

Chau, M., and Xu, J. (2012) Business intelligence in blogs: Understanding consumer interactions and communities. MIS quarterly, 36(4), 1189-1216.

Chen, Y., and Xie, J. (2008) Online consumer review: Word-of-mouth as a new element of marketing communication mix. Management science, 54(3), 477-491.

Chen, Y., Wang, Q., and Xie, J. (2011) Online social interactions: A natural experiment on word of mouth versus observational learning. Journal of marketing research, 48(2), 238254.

Cheung, C.M.K., and Lee, M.K.O. (2012) What drives consumers to spread electronic word of mouth in online consumer-opinion platforms. Decision support systems, 53(1), 218225.

Chevalier, J.A., and Mayzlin, D. (2006) The Effect of Word of Mouth on Sales: Online Book Reviews. Journal of Marketing Research, 43(3), 345-354. 
Chintagunta, P.K., Gopinath, S., and Venkataraman, S. (2010) The effects of online user reviews on movie box office performance: Accounting for sequential rollout and aggregation across local markets. Marketing Science, 29(5), 944-957.

Chiu, C.-M., Hsu, M.-H., and Wang, E.T.G. (2006) Understanding knowledge sharing in virtual communities: An integration of social capital and social cognitive theories. Decision Support Systems, 42(3), 1872-1888.

Cios, K.J., Pedrycz, W., Swiniarski, R.W., and Kurgan, L. (2007) Data Mining: A Knowledge Discovery Approach. New York: Springer.

Coleman, J.S. (1988) Social Capital in the Creation of Human Capital. The American Journal of Sociology, 94, 95-120.

Copeland, T.E., Weston, J.F., and Shastri, K. (1988) Financial theory and corporate policy. Reading: Addison-Wesley.

Cotei, C., and Joseph Farhat, J. (2013) Informational externalities of initial public offerings: Does venture capital backing matter?. Journal of Economics and Finance, 37(1), 80-99.

Daft, R.L., and Lengel, R.H. (1984) Information Richness: A New Approach to Managerial Behavior and Organization Design. Research in Organizational Behavior, 6, B. M. Staw and L. L. Cummings (eds.), Greenwich: JAI Press, 191-233.

Daft, R.L., and Lengel, R.H. (1986) Organizational information requirements, media richness and structural design. Management Science, 32(5), 554-571.

Daft, R.L., and Macintosh, N.B. (1981) A Tentative Exploration into the Amount and Equivocality of Information Processing in Organizational Work Units. Administrative Science Quarterly, 26(2), 207-224.

Daft, R.L., Lengel, R.H., and Trevino, L.K. (1987) Message Equivocality, Media Selection, and Manager Performance: Implications for Information Systems. MIS Quarterly, 11(3), $355-366$

Danbolt, J., Siganos, A., and Vagenas-Nanos, E. (2015) Investor sentiment and bidder announcement abnormal returns. Journal of Corporate Finance, 33, 164-179.

Das, S., Martínez-Jerez, A., and Tufano, P. (2005) eInformation: A Clinical Study of Investor Discussion and Sentiment. Financial Management, 34(3), 103-137. 
Das, S.R., and Chen, M.Y. (2007) Yahoo! for Amazon: Sentiment Extraction from Small Talk on the Web. Management Science, 53(9), 1375-1388.

De Long, J.B., Shleifer, A., Summers, L.H., and Waldmann, R.J. (1990) Noise trader risk in financial markets. Journal of political Economy, 98(4), 703-738.

De Valck, K., Van Bruggen, G.H., and Wierenga, B. (2009) Virtual communities: A marketing perspective. Decision Support Systems, 47(3), 185-203.

Dellarocas, C. (2003) The digitization of word of mouth: Promise and challenges of online feedback mechanisms. Management science, 49(10), 1407-1424.

Dellarocas, C., Zhang, X.M., and Awad, N.F. (2007) Exploring the value of online product reviews in forecasting sales: The case of motion pictures. Journal of Interactive Marketing, 21(4), 23-45.

Dennis, A.R., Fuller, R.M., and Valacich, J.S. (2008) Media, tasks, and communication processes: A theory of media synchronicity. MIS Quarterly, 32(3), 575-600.

Dervin, B. (1983) An overview of sense-making research: Concepts, methods and results. Paper presented at the annual meeting of the International Communication Association, Dallas.

Dervin, B. (1998) Sense-making theory and practice: an overview of user interests in knowledge seeking and use. Journal of Knowledge Management, 2(2), 36-46.

Dervin, B. (1999) On studying information seeking methodologically: the implications of connecting metatheory to method. Information Processing \& Management, 35(6), 727750 .

Dewan, S., and Ramaprasad, J. (2014) Social media, traditional media, and music sales. Mis Quarterly, 38(1), 101-121.

Dewenter, K., Novaes, W., and Pettway, R.H. (2001) Visibility versus Complexity in Business Groups: Evidence from Japanese Keiretsu. The Journal of Business, 74(1), 79100.

Diamond, D.W., and Verrecchia, R.E. (1991) Disclosure, liquidity, and the cost of capital. The Journal of Finance, 46(4), 1325-1359. 
Dodd, P. (1980) Merger proposals, management discretion and stockholder wealth. Journal of Financial Economics, 8(2), 105-137.

Downey, H.K., and Slocum, J.W. (1975) Uncertainty: Measures, Research, and Sources of Variation. The Academy of Management Journal, 18(3), 562-578.

Duan, W., Gu, B., and Whinston, A.B. (2008) Do online reviews matter? - An empirical investigation of panel data. Decision Support Systems, 45(4), 1007-1016.

DuBay, W.H. (2004) The Principles of Readability. http://files.eric.ed.gov/fulltext/ED490073.pdf, Accessed: 15.02.2013.

Duncan, R.B. (1972) Characteristics of Organizational Environments and Perceived Environmental Uncertainty. Administrative Science Quarterly, 17(3), 313-327.

EU Directive (2003) EU directive 2003/6/EC. http://eur-lex.europa.eu/legalcontent/EN/TXT/HTML/?uri=CELEX:32003L0006\&from=EN, Accessed: 28.6.2016.

Faccio, M., and Masulis, R.W. (2005) The choice of payment method in European mergers and acquisitions. The Journal of Finance, 60(3), 1345-1388.

Fama, E.F. (1965) The behavior of stock-market prices. The journal of Business, 38(1), 34105.

Fama, E.F. (1970) Efficient Capital Markets: A Review of Theory and Empirical Work . The Journal of Finance, 25(2), 383-417.

Fama, E.F., Fisher, L., Jensen, M.C., and Roll, R. (1969) The adjustment of stock prices to new information. International economic review, 10(1), 1-21.

Faulkner, D., Teerikangas, S., and Joseph, R.J. (2012) The handbook of mergers and acquisitions. Oxford: Oxford University Press.

Ferguson, C., and Seow, P.-S. (2011) Accounting information systems research over the past decade: Past and future trends. Accounting \& Finance, 51(1), 235-251.

Financial Services Authority (2011) FSA Handbook. http://fsahandbook.info/FSA/html/handbook/Glossary/I, Accessed: 28.02.2011. 
Forman, C., Ghose, A., and Wiesenfeld, B. (2008) Examining the relationship between reviews and sales: The role of reviewer identity disclosure in electronic markets. Information Systems Research, 19(3), 291-313.

Fotak, V. (2007) The Impact of Blog Recommendations on Security Prices and Trading Volumes. http://papers.ssrn.com/sol3/papers.cfm?abstract_id=1089868, Accessed: 15.02.2013.

Fréchet, M. (1927) Sur la loi de probabilité de l'écart maximum. In: Annales de la Société Polonaise de Mathématique, 6, 93-116.

Galbraith, J.R. (1973) Designing Complex Organizations. Boston: Addison-Wesley Longman.

Galbraith, J.R. (1977) Organization Design. Reading: Addison-Wesley.

Gelinas, U.J., and Dull, R.B. (2008) Accounting Information Systems. Mason: Thomson South-Western.

George, J.F., Carlson, J.R., and Valacich, J.S. (2013) Media Selection as a Strategic Component of Communication. MIS Quarterly, 37(4), 1233-1251.

Ghose, A., and Ipeirotis, P.G. (2011) Estimating the helpfulness and economic impact of product reviews: Mining text and reviewer characteristics. IEEE Transactions on Knowledge and Data Engineering, 23(10), 1498-1512.

Godes, D., and Mayzlin, D. (2004) Using online conversations to study word-of-mouth communication. Marketing science, 23(4), 545-560.

Godfrey, P.C., Merrill, C.B., and Hansen, J.M. (2009) The relationship between corporate social responsibility and shareholder value: an empirical test of the risk management hypothesis. Strategic Management Journal, 30(4), 425-445.

Goergen, M., and Renneboog, L. (2004) Shareholder Wealth Effects of European Domestic and Cross-border Takeover Bids. European Financial Management, 10(1), 9-45.

Goh, K.-Y., Heng, C.-S., and Lin, Z. (2013) Social media brand community and consumer behavior: Quantifying the relative impact of user-and marketer-generated content. Information Systems Research, 24(1), 88-107. 
Golder, S., and Macy, M. (2012) Social Science with Social Media. ASA Footnotes, 40(1), 7.

Gosnell, T.F., Keown, A.J., and Pinkerton, J.M. (1996) The intraday speed of stock price adjustment to major dividend changes: Bid-ask bounce and order flow imbalances. Journal of Banking \& Finance, 20(2), 247-266.

Greene, W.H. (1997) Econometric Analysis (3rd ed.). London: Prentice-Hall.

Greenwald, B.C., and Stiglitz, J.E. (1986) Externalities in Economies with Imperfect Information and Incomplete Markets. The Quarterly Journal of Economics, 101(2), 229264.

Gregor, S. (2006) The Nature of Theory in Information Systems. MIS Quarterly, 30(3), 611642.

Grullon, G., Kanatas, G., and Weston, J.P. (2004) Advertising, Breadth of Ownership, and Liquidity. The Review of Financial Studies, 17(2), 439-461.

Gu, B., Konana, P., Rajagopalan, B., and Chen, H.-W.M. (2007) Competition Among Virtual Communities and User Valuation: The Case of Investing-Related Communities. Information Systems Research, 18(1), 68-85.

Gunning, R. (1952) The Technique of Clear Writing. New York: McGraw-Hill.

Halpern, P. (1983) Corporate Acquisitions: A Theory of Special Cases? A Review of Event Studies Applied to Acquisitions. The Journal of Finance, 38(2), 297-317.

Healy, P.M., and Palepu, K.G. (2001) Information asymmetry, corporate disclosure, and the capital markets: A review of the empirical disclosure literature. Journal of Accounting and Economics, 31(1-3), 405-440.

Healy, P.M., Palepu, K.G., and Ruback, R.S. (1992) Does corporate performance improve after mergers? Journal of Financial Economics, 31(2), 135-175.

Hennig-Thurau, T., Gwinner, K.P., Walsh, G., and Gremler, D.D. (2004) Electronic word-ofmouth via consumer-opinion platforms: What motivates consumers to articulate themselves on the Internet?. Journal of interactive marketing, 18(1), 38-52.

Herrmann, A.F. (2007) Stockholders in cyberspace: Weick's sensemaking online. Journal of Business Communication, 44(1), 13-35. 
Hersberger, J.A., Murray, A.L., and Rioux, K. S. (2007) Examining information exchange and virtual communities: an emergent framework. Online Information Review, 31(2), 135-147.

Hirshleifer, D. (2001) Investor psychology and asset pricing. The Journal of Finance, 56(4), $1533-1597$.

Hirshleifer, D., and Teoh, S.H. (2003) Herd behaviour and cascading in capital markets: A review and synthesis. European Financial Management, 9(1), 25-66.

Holsti, O.R. (1969) Content analysis for the social sciences and humanities. Reading: Addison-Wesley.

Houston, J.F., and Ryngaert, M.D. (1997) Equity issuance and adverse selection: A direct test using conditional stock offers. The Journal of Finance, 52(1), 197-219.

Hsu, M.H., Ju, T.L., Yen, C.H., and Chang, C.M. (2007) Knowledge sharing behavior in virtual communities: The relationship between trust, self-efficacy, and outcome expectations. International journal of human-computer studies, 65(2), 153-169.

Hu, M., and Schlagwein, D. (2013) Why firms use social media: an absorptive capacity perspective. In: Proceedings of the 21st European Conference on Information Systems Given, Paper 108.

Huberman, G. (2001) Familiarity Breeds Investment. The Review of Financial Studies, 14(3), 659-680.

Im, E.-O., and Chee, W. (2006) An online forum as a qualitative research method: practical issues. Nursing Research, 55(4), 267-273.

Java, A., Song, X., Finin, T., and Tseng, B. (2007) Why We Twitter: Understanding Microblogging Usage and Communities. In: Proceedings of the Joint 9th WEBKDD and 1st SNA-KDD Workshop '07, 56-65.

Jensen, M.C. (1986) Agency Cost Of Free Cash Flow, Corporate Finance, and Takeovers. American Economic Review, 76(2), 323-329.

Jensen, M.C., and Meckling, W.H. (1976) Theory of the firm: Managerial behavior, agency costs and ownership structure. Journal of Financial Economics, 3(4), 305-360. 
Jiang, S., Chen, H., Nunamaker, J.F., and Zimbra, D. (2014) Analyzing firm-specific social media and market: A stakeholder-based event analysis framework. Decision Support Systems, 67, 30-39.

Johnson, T.J., and Kaye, B.K. (2004) Wag the blog: How reliance on traditional media and the Internet influence credibility perceptions of weblogs among blog users. Journalism \& Mass Communication Quarterly, 81(3), 622-642.

Kahai, S.S. , and Cooper, R.B. (2003) Exploring the Core Concepts of Media Richness Theory: The Impact of Cue Multiplicity and Feedback Immediacy on Decision Quality. Journal of Management Information Systems, 20(1), 263-299.

Kane, G.C., Alavi, M., Labianca, G.J., and Borgatti, S.P. (2014) What's different about social media networks? A framework and research agenda. MIS Quarterly, 38(1), 274-304.

Kaplan, A.M., and Haenlein, M. (2010) Users of the world, unite! The challenges and opportunities of Social Media. Business Horizons, 53(1), 59-68.

Kaplan, A.M., and Haenlein, M. (2011) The early bird catches the news: Nine things you should know about micro-blogging. Business Horizons, 54(2), 105-113.

Kau, J.B., Linck, J.S., and Rubin, P.H. (2008) Do managers listen to the market?. Journal of Corporate Finance, 14(4), 347-362.

Kietzmann, J.H., Hermkens, K., McCarthy, I.P., and Silvestre, B.S. (2011) Social media? Get serious! Understanding the functional building blocks of social media. Business Horizons, 54(3), 241-251.

Klare, G.R. (1963) The Measurement of Readability. Ames: Iowa State University Press.

Knight, S.-A., and Burn, J.M. (2005) Developing a framework for assessing information quality on the World Wide Web. Informing Science: International Journal of an Emerging Transdiscipline, 8, 159-172.

Kothari, S.P. (2001) Capital markets research in accounting. Journal of Accounting and Economics, 31(1-3), 3-31.

Kozinets, R.V., De Valck, K., Wojnicki, A.C., and Wilner, S.J.S. (2010) Networked narratives: Understanding word-of-mouth marketing in online communities. Journal of Marketing, 74(2), 71-89. 
Kuhlthau, C.C. (1993) A principle of uncertainty for information seeking. Journal of Documentation, 49(4), 339 - 355.

Lawrence, P.R., and Lorsch, J.W. (1967) Organization and Environment. Cambridge: Harvard university press.

Lee, A.S. (1994) Electronic mail as a medium for rich communication: An empirical investigation using hermeneutic interpretation. MIS Quarterly, 18(2), 143-157.

Leifer, R., and Mills, P.K. (1996) An Information Processing Approach for Deciding Upon Control Strategies and Reducing Control Loss in Emerging Organizations. Journal of Management, 22(1), 113-137.

Li, Q., Wang, T., Li, P., Liu, L., Gong, Q., and Chen, Y. (2014) The effect of news and public mood on stock movements. Information Sciences, 278, 826-840.

Lipshitz, R., and Strauss, O. (1997) Coping with Uncertainty: A Naturalistic Decision-Making Analysis. Organizational Behavior and Human Decision Processes, 69(2), 149-163.

Liu, Y. (2006) Word of Mouth for Movies: Its Dynamics and Impact on Box Office Revenue. Journal of Marketing, 70(3), 74-89.

Loughran, T., and McDonald, B. (2011) When Is a Liability Not a Liability? Textual Analysis, Dictionaries, and 10-Ks. The Journal of Finance, 66(1), 35-65.

Loughran, T., and McDonald, B. (2014) Measuring readability in financial disclosures. The Journal of Finance, 69(4), 1643-1671.

Louis, H., and Sun, A. (2010) Investor inattention and the market reaction to merger announcements. Management Science, 56(10), 1781-1793.

Lu, Y., and Yang, D. (2011) Information exchange in virtual communities under extreme disaster conditions. Decision Support Systems, 50(2), 529-538.

Luo, X., Zhang, J., and Duan, W. (2013) Social Media and Firm Equity Value . Information Systems Research, 24(1), 146-163.

Luo, Y. (2005) Do insiders learn from outsiders? Evidence from mergers and acquisitions. The Journal of Finance, 60(4), 1951-1982. 
MacKinlay, A.C. (1997) Event Studies in Economics and Finance. Journal of Economic Literature, 35(1), 13-99.

Madura, J., and Ngo, T. (2012) Determinants of the medium of payment used to acquire privately-held targets. Journal of Economics and Finance, 36(2), 424-442.

Mantecon, T. (2008) An analysis of the implications of uncertainty and agency problems on the wealth effects to acquirers of private firms. Journal of Banking \& Finance, 32(5), 892-905.

Markus, M.L. (1994) Electronic Mail as the Medium of Mana- gerial Choice. Organization Science, 5(4), 502-527.

Martin, K.J. (1996) The method of payment in corporate acquisitions, investment opportunities, and management ownership. The Journal of finance, 51(4), 1227-1246.

McDonald, J.H. (2009) Handbook of Biological Statistics (2nd ed.). Baltimore: Sparky House Publishing.

Miller, E.M. (1977) Risk, uncertainty, and divergence of opinion. The Journal of Finance, 32(4), 1151-1168.

Milliken, F.J. (1987) Three Types of Perceived Uncertainty about the Environment: State, Effect, and Response Uncertainty. The Academy of Management Review, 12(1), 133143.

Mohan, K., Kumar, N., and Benbunan-Fich, R. (2009) Examining communication media selection and information processing in software development traceability: An empirical investigation. Professional Communication, IEEE Transactions on, 52(1), 17-39.

Monteiro, N.B., Zaman, Q., and Leitterstorf, S. (2007) Updated Measurement of Market Cleanliness. FSA Occasional Paper No. 25, http://papers.ssrn.com/soL3/papers.cfm?abstract_id=1011212, Accessed: 28.02.2011.

Mudambi, S.M., and Schuff, D. (2010) What Makes a Helpful Review? A Study of Customer Reviews on Amazon.com. MIS Quarterly, 34(1), 185-200.

Muehlfeld, K., Sahib, P.R., and Van Witteloostuijn, A. (2007) Completion or abandonment of mergers and acquisitions: Evidence from the newspaper industry, 1981-2000. Journal of Media Economics, 20(2), 107-137. 
Muntermann, J., and Güttler, A. (2007) Intraday stock price effects of ad hoc disclosures: the German case. Journal of International Financial Markets, Institutions and Money, 17(1), $1-24$.

Murray, K.B. (1991) A test of services marketing theory: consumer information acquisition activities. The journal of marketing, 55(1), 10-25.

Myers, S.C., and Majluf, N.S. (1984) Corporate financing and investment decisions when firms have information that investors do not have. Journal of Financial Economics, 13(2), $187-221$.

Nahapiet, J., and Ghoshal, S. (1998) Social capital, intellectual capital, and the organizational advantage. Academy of management review, 23(2), 242-266.

Napier, N.K. (1989) Mergers and acquisitions, human resource issues and outcomes: A review and suggested typology. Journal of Management Studies, 26(3), 271-290.

Nardi, B.A., Schiano, D.J., Gumbrecht, M., and Swartz, L. (2004) Why we blog. Communications of the ACM, 47(12), 41-46.

Nickerson, R.C., Varshney, U. and Muntermann, J. (2012) A method for taxonomy development and its application in information systems. European Journal of Information Systems, 22(3), 336-359.

Nofsinger, J.R. (2005) Social mood and financial economics. The Journal of Behavioral Finance, 6(3), 144-160.

OECD (2007) Participative Web and User-Created Content - Web 2.0, Wikis, and Social Networking. Paris: OECD Publishing.

Pagano, M., and Röell, A. (1996) Transparency and liquidity: a comparison of auction and dealer markets with informed trading. The Journal of Finance, 51(2), 579-611.

Pang, B., and Lee, L. (2008) Opinion Mining and Sentiment Analysis. Foundations and Trends in Information Retrieval, 2(1-2), 1-135.

Pang, B., Lee, L., and Vaithyanathan, S. (2002) Thumbs up?: sentiment classification using machine learning techniques. In: EMNLP '02 Proceedings of the ACL-02 conference on Empirical methods in natural language processing - Volume 10, Association for Computational Linguistics, 79-86. 
Patell, J.M., and Wolfson, M.A. (1981) The Ex Ante and Ex Post Price Effects of Quarterly Earnings Announcements Reflected in Option and Stock Prices. Journal of Accounting Research, 19(2), 434-458.

Patell, J.M., and Wolfson, M.A. (1984) The intraday speed of adjustment of stock prices to earnings and dividend announcements. Journal of Financial Economics, 13(2), 223-252.

Pew Research Center (2013) Social Media Update 2013.

http://www.pewinternet.org/2013/12/30/social-media-update-2013/, Accessed: 16.03.2014.

Pfarrer, M.D., Pollock, T.G., and Rindova, V.P. (2010) A tale of two assets: The effects of firm reputation and celebrity on earnings surprises and investors' reactions. Academy of Management Journal, 53(5), 1131-1152.

Pfeffer, J., and Salancik, G.R. (1978) The External Control of Organizations: A Resource Dependence Perspective.New York: Harper and Row.

Poltrock, S., Grudin, J., Dumais, S., Fidel, R., Bruce, H., and Pejtersen, A.M. (2003) Information seeking and sharing in design teams. In: GROUP '03 Proceedings of the 2003 international ACM SIGGROUP conference on Supporting group work, 239-247.

Poston, R.S., and Grabski, S.V. (2000) Accounting information systems research: Is it another QWERTY?. International Journal of Accounting Information Systems, 1(1), 9-53.

Power, D.J. (2004) Specifying An Expanded Framework for Classifying and Describing Decision Support Systems. Communications of the Association for Information Systems, 13(1), 158-166.

Ren, Y., Harper, F.M., Drenner, S., Terveen, L.G., Kiesler, S.B., Riedl, J., and Kraut, R.E. (2012) Building Member Attachment in Online Communities: Applying Theories of Group Identity and Interpersonal Bonds. Mis Quarterly, 36(3), 841-864.

Rice, R.E. (1992) Task Analyzability, Use of New Media, and Effectiveness: A Multi-Site Exploration of Media Richness. Organization Science, 3(4), 475-500.

Rosen, R.J. (2006) Merger Momentum and Investor Sentiment: The Stock Market Reaction to Merger Announcements. The Journal of Business, 79(2), 987-1017. 
Rosenberg, S.D., Schnurr, P.P., and Oxman, T.E. (1990) Content analysis: A comparison of manual and computerized systems. Journal of personality assessment, 54(1-2), 298-310.

Russell, D.M., Stefik, M.J., Pirolli, P., and Card, S.K. (1993) The cost structure of sensemaking. In: CHI '93 Proceedings of the INTERACT '93 and CHI '93 Conference on Human Factors in Computing Systems, 269-276.

Sabherwal, S., Sarkar, S.K., and Zhang, Y. (2011) Do Internet Stock Message Boards Influence Trading? Evidence from Heavily Discussed Stocks with No Fundamental News. Journal of Business Finance \& Accounting, 38(9-10), 1209-1237.

Samuels, J.A., and Steinbart, P.J. (2002) The Journal of Information Systems: A Review of the First 15 Years. Journal of Information Systems, 16(2), 97-116.

Saxton, G.D., and Anker, A.E. (2013) The aggregate effects of decentralized knowledge production: Financial bloggers and information asymmetries in the stock market. Journal of Communication, 63(6), 1054-1069.

Schmidt, J. (2007) Blogging practices: An analytical framework. Journal of ComputerMediated Communication, 12(4), 1409-1427.

Schwert, G.W. (2000) Hostility in Takeovers: In the Eyes of the Beholder?. The Journal of Finance, 55(6), 2599-2640.

SEC (2013) Mergers. http://www.sec.gov/answers/mergers.htm, Accessed: 15.02.2013.

Shannon, C.E., and Weaver, W. (1949) The Mathematical Theory of Communication. Urbana: University of Illinois Press.

Sheer, V.C., and Chen, L. (2004) Improving Media Richness Theory: A Study of Interaction Goals, Message Valence, and Task Complexity in Manager-Subordinate Communication. Management Communication Quarterly, 18(1), 76-93.

Shi, Z., Rui, H., and Whinston, A.B. (2014) Content sharing in a social broadcasting environment: evidence from twitter. MIS Quarterly, 38(1), 123-142.

Shmueli, G. (2010) To Explain or to Predict. Statistical Science, 25(3), 289-310.

Shmueli, G., and Koppius, O.R. (2011) Predictive Analytics in Information Systems Research. MIS Quarterly, 35(3), 553-572. 
Siganos, A., Vagenas-Nanosa, E., and Verwijmeren, P. (2014) Facebook's daily sentiment and international stock markets. Journal of Economic Behavior \& Organization, 107(B), 730 743.

Silva, L., Goel, L., and Mousavidin, E. (2008) Exploring the dynamics of blog communities: the case of MetaFilter. Information Systems Journal, 19(1), 55-81.

Simon, H.A. (1957) Models of Man, Social and Rational. New York: John Wiley \& Sons.

Simon, H.A. (1972) Theories of bounded rationality. C.B. McGuire and R. Radner (Eds.), Decision and Organization, Amsterdam: North-Holland Publishing Company, 161-176.

Sitkin, S.B., and Pablo, A.L. (1992) Reconceptualizing the Determinants of Risk Behavior. The Academy of Management Review, 17(1), 9-38.

Slovic, P., Fischhoff, B., and Lichtenstein, S. (1977) Behavioral decision theory. Annual Review of Psychology, 28(1), 1-39.

Spence, M. (1973) Job Market Signaling. The Quarterly Journal of Economics, 87(3), 355374.

Statista (2013) http://www.statista.com/statistics/278527/number-of-blogs-worldwide/, Accessed: 24.08.2014.

Stieglitz, S., and Dang-Xuan, L. (2013) Emotions and information diffusion in social mediasentiment of microblogs and sharing behavior. Journal of Management Information Systems, 29(4), 217-248.

Stone, P.J., and Hunt, E.B. (1963) A computer approach to content analysis: studies using the General Inquirer system. In: AFIPS '63 (Spring) Proceedings of the May 21-23, spring joint computer conference, 241-256.

Stone, P.J., Dunphy, D.C., Smith, M.S., and Ogilvie, D.M. (1966) The General Inquirer: A Computer Approach to Content Analysis, Cambridge: MIT Press.

Straub, D., and Karahanna, E. (1998) Knowledge Worker Communications and Recipient Availability: Toward a Task Closure Explanation of Media Choice. Organization Science, 9(2), 160-175. 
Sundararajan, A., Provost, F., Oestreicher-Singer, G., and Aral, S. (2013) Research commentary-information in digital, economic, and social networks. Information Systems Research, 24(4), 883-905.

Sutton, S.G. (1996) Advances in Accounting Information Systems. Greenwich: Emerald Group Publishing.

Taylor, R.S. (1962) The process of asking questions. American documentation, 13(4), 391396.

Tetlock, P.C. (2010) Does Public Financial News Resolve Asymmetric Information?. Review of Financial Studies, 23(9), 3520-3557.

The Nielson Company (2007) Word-of-Mouth the Most Powerful Selling Tool: Nielsen Global Survey. http://www.nielsen.com/us/en/insights/press-room/2007/Word-ofMouth_the_Most_Powerful_Selling_Tool_Nielsen_Global_Survey.html, Accessed: 15.02.2013.

Thompson, J.D. (1967) Organizations in Action. New York: McGraw-Hill.

Thomson Reuters Financial Glossary (2013) The Financial Glossary. http://glossary.reuters.com/index.php?title=Main_Page, Accessed: 28.8.2016.

Tipton, M.M., Bharadwaj, S.G., and Robertson, D.C. (2009) Regulatory Exposure of Deceptive Marketing and Its Impact on Firm Value. Journal of Marketing, 73(6), 227243.

Tirunillai, S., and Tellis, G.J. (2012) Does chatter really matter? Dynamics of user-generated content and stock performance. Marketing Science, 31(2), 198-215.

Travlos, N.G. (1987) Corporate takeover bids, methods of payment, and bidding firms' stock returns. The Journal of Finance, 42(4), 943-963.

Trevino, L.K., Lengel, R.H., and Daft, R.L. (1987) Media Symbolism, Media Richness, and Media Choice in Organizations. Communication Research, 14(5), 553-574.

Tsai, H.T., and Bagozzi, R.P. (2014) Contribution Behavior in Virtual Communities: Cogntive, Emotional, and Social Influences. Mis Quarterly, 38(1), 143-163. 
Tumarkin, R., and Whitelaw, R.F. (2001) News or noise? Internet postings and stock prices. Financial Analysts Journal, 57(3), 41-51.

Van De Ven, A.H., Delbecq, A.L., and Koenig Jr, R. (1976) Determinants of Coordination Modes within Organizations. American Sociological Review, 41(2), 322-338.

Verrecchia, R.E. (1983) Discretionary disclosure. Journal of Accounting and Economics, $5,179-194$.

Walkling, R.A. (1985) Predicting Tender Offer Success: A Logistic Analysis. Journal of Financial and Quantitative Analysis, 20(4), 461-478.

Wang, H., and Qian, C. (2011) Corporate Philanthropy and Corporate Financial Performance: The Roles of Stakeholder Response and Political Access. Academy of Management Journal, 54(6), 1159-1181.

Wang, R.Y., and Strong, D.M. (1996) Beyond Accuracy: What Data Quality Means to Data Consumers. Journal of Management Information Systems, 12(4), 5-33.

Wasko, M.M., and Faraj, S. (2000) "It is what one does": why people participate and help others in electronic communities of practice. The Journal of Strategic Information Systems, 9(2), 155-173.

Wasko, M.M., and Faraj, S. (2005) Why Should I Share? Examining Social Capital and Knowledge Contribution in Electronic Networks of Practice. MIS Quarterly, 35-57.

Wattal, S., Schuff, D., Mandviwalla, M., and Williams, C.B. (2010) Web 2.0 and politics: the 2008 US presidential election and an e-politics research agenda. MIS Quarterly, 34(4), 669-688.

Weber, R.P. (1984) Computer-aided content analysis: A short primer. Qualitative sociology, 7(1-2), 126-147.

Webster, J., and Trevino, L.K. (1995) Rational and Social Theories as Complementary Explanations of Communication Media Choices: Two Policy-Capturing Studies. Academy of Management Journal, 38(6), 1544-1572.

Weick, K.E. (1979) The Social Psychology of Organizing (2nd ed.). Reading: AddisonWesley. 
Weick, K.E. (1995) Sensemaking in Organizations. Thousand Oaks: Sage Publications.

Weiers, R.M. (2005) Introduction to Business Statistics. Belmont: Thomson Brooks/Cole.

Weiss, A.M., Lurie, N.H., and MacInnis, D.J. (2008) Listening to strangers: whose responses are valuable, how valuable are they, and why? Journal of Marketing Research, 45(4), 425-436.

Wilson, T.D. (1981) On User Studies and Information Needs. Journal of Documentation, $37(1), 3-15$.

Wilson, T.D. (1999) Models in information behaviour research. Journal of Documentation, 55(3), 249-270.

Wilson, T.D. (2000) Human information behavior. Informing Science, 3(2), 49-55.

Wilson, T.D. (2002) Information seeking and mediated searching: Part 2. Uncertainty and its correlates. Journal of the American Society for Information Science and Technology, 53(9), 704-715.

Wirtz, B.W. (2003) Mergers \& acquisitions management: Strategie und Organisation von Unternehmenszusammenschlüssen. Wiesbaden: Gabler Verlag.

Witten, I.H., and Frank, E. (2005) Data Mining: Practical Machine Learning Tools and Techniques. San Francisco: Morgan Kaufmann Publishers.

Wysocki, P.D. (1998) Cheap Talk on the Web: The Determinants of Postings on Stock Message Boards. University of Michigan Business School Working Paper No. 98025, http://papers.ssrn.com/sol3/papers.cfm?abstract-id=160170, Accessed: 15.02.2013.

Xia, R., Zong, C., and Li, S. (2011) Ensemble of feature sets and classification algorithms for sentiment classification. Information Sciences, 181(6), 1138-1152.

Yook, K.C. (2003) Larger Return to Cash Acquisitions: Signaling Effect or Leverage Effect?. The Journal of Business, 76(3), 477-498.

Yu, Y., Duan, W., and Cao, Q. (2013) The impact of social and conventional media on firm equity value: A sentiment analysis approach. Decision Support Systems, 55(4), 919-926.

Zeng, D., Chen, H., Lusch, R., and Li, S.-H. (2010) Social Media Analytics and Intelligence. IEEE Intelligent Systems, 25(6), 13-16. 
Zhang, W., and Skiena, S. (2010) Trading Strategies to Exploit Blog and News Sentiment. In: Proceedings of the Fourth International AAAI Conference on Weblogs and Social Media, 375-378.

Zhang, Z., Li, X., and Chen, Y. (2012) Deciphering word-of-mouth in social media: Textbased metrics of consumer reviews. ACM Transactions on Management Information Systems (TMIS), 3(1), Article No. 5, 1-23.

Zülch, M.J. (2013) “Will They Merge?” - Financial Event-Related Information Processing in Social Media. In: Proceedings of the 19th Americas Conference on Information Systems.

Zülch, M.J. (2013a) An Empirical Analysis of Merger-Related Blog Posts. In: Proceedings of the 26th Bled eConference, Paper 35, 264-274.

Zülch, M.J., Alic, I., and Muntermann, J. (2011) How "good” is bad News? Exploring Sentiments of Corporate Disclosures. In: Proceedings of the 17th Americas Conference on Information Systems, Paper 257.

Zülch, M.J., Muntermann, J., and Rajagopalan, B. (2014) Drivers of Information Quality on Blogs: The Case of Business Events. In: Proceedings of the 20th Americas Conference on Information Systems.

Zülch, M.J., Rajagopalan, B., and Muntermann, J. (2014a) Drivers of Information Quantity: The Case of Merger-Acquisition Events. In: Proceedings of the 18th Pacific Asia Conference on Information Systems, Paper 83.

Zülch, M.J., Weber, M.C., and Muntermann, J. (2014b) Social Media Choice: An Explorative Study on Information Transmission via Social Media. In: Proceedings of the 27th Bled eConference, Paper 44. 